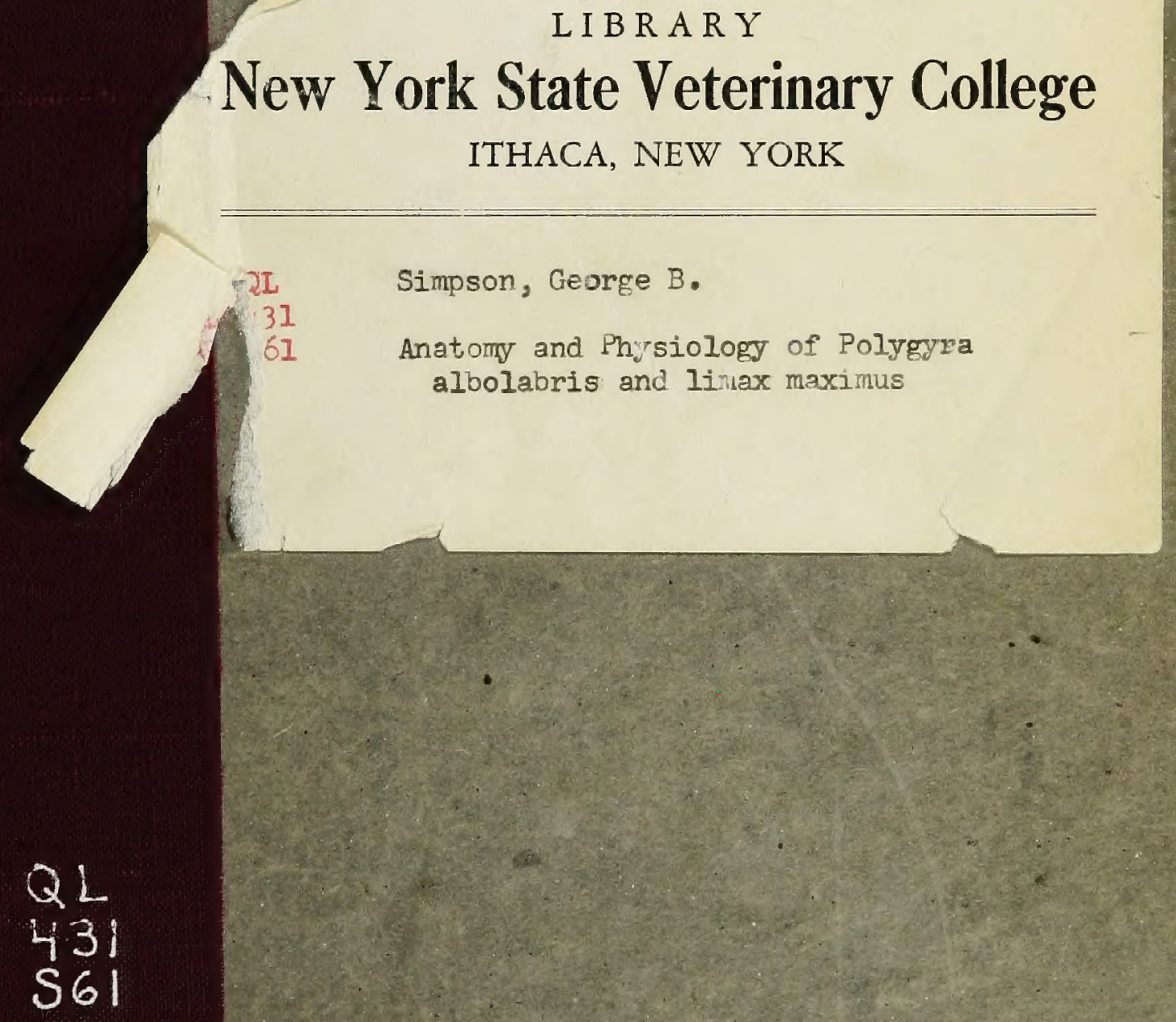




\section{QL 431.S61

Anatomy and physiology of Polygyra Albol
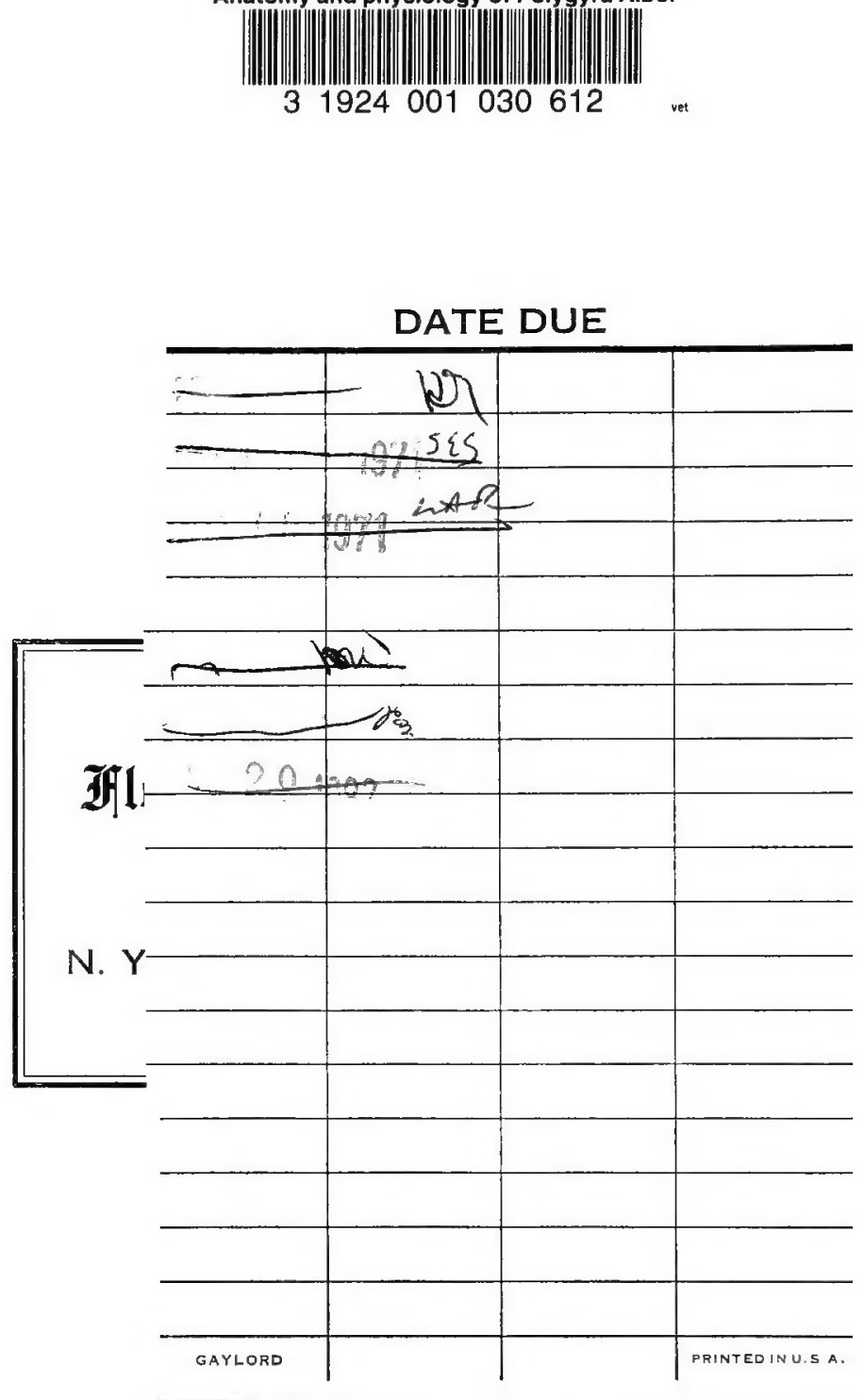


\section{B U L LET I N}

OF THE

New York State Museum

-Frederick J. H. Merrill Director

No. 40 Vol. 8

October I90I.

ANATOMY AND PHYSIOLOGY

OF

POLYGYRA ALBOLABRIS AND LIMAX MAXIMUS

1 AND

EMBRYOLOGY OF LIMAX MAXIMUS

BY

QL

431

GEORGE B. SIMPSON

Division of paleontology

561

\section{ALBANY}

UNIVERSITY OF THE STATE OF NEW YORK

I 901 


\section{University of the State of New York}

REGENTS

With years of election

1874 ANSON JUdD UPSON L.H.D. D.D. LL.D.

Chancellor, Glens Falls

I892 William Croswell Doane D.D. LL.D.

$$
\text { Vice-Chancellor, Albany }
$$

1873 Martin I. Townsend M.A. LL.D. - - - Troy

1877 Chauncey M. Depew Ll.D. _ _ - New York

I877 Charles E. Fitch LL.B. M.A. L.H.D. - - Rochester

I 877 ORRIS H. WARREN D.D. _ _ _ _ Syracuse

I878 Whitelaw Reid M.A. LL.D. - - - - New York

188I William H. WatSon M.A. M.D. - - - Utica

I88ז Henry E. Turner -

I883 St Clair McKelway M.A. L.H.D. LL.D. D.C.L. Brooklyn

I885 Daniel Beach Ph.D. LL.D. - _ _ Watkins

I888 Carroll E. Smith LL.D. _ _ _ $\quad$ - Syracuse

I8go Pliny T. Sexton LL.D. - _ _ - - Palmyra

I890 T. Guilford Smith M.A. C.E. LL.D. - - Buffalo

r893 Lewis A. Stimson B.A. LL.D. M.D. - - New York

1895 Albert Vander Veer Ph.D. M.D. - - - Albany

I895 Charles R. Skinner M.A. LL.D.

Superintendent of Public Instruction, ex officio

I897 Chester S. LoRd M.A. LL.D. - _ - - Brooklyn

I897 Tiмothy L. Woodruff M.A. Lieutenant-Governor, ex officio

I 899 John T. McDonough LL.B. LL.D. Secretary of State, ex officio

I900 Thomas A. Hendrick M.A. LL.D. - _ _ Rochester

igoi Benjamin B. Odell JR LL.D. Governor, ex officio

rgor Robert C. Pruyn M.A. - $\quad$ - $\quad$ _ $\quad$ - - Albany

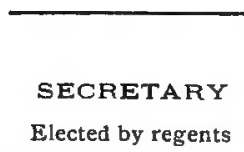

igoo James Russell Parsons JR M.A.

DIRECTORS OF DEPARTMENTS

I888 Melvil Dewey M.A. State library and Home education I89o James Russell Parsons jR M.A.

Administrative, College and High school dep'ts

i $89 \circ$ Frederick J. H. Merrill Ph.D. State museum 


\section{B U L LET I N}

OF THE

\section{New York State Museum}

Frederick J. H. Merrill Director

No. 40 Vol. 8

October I90I

\section{ANATOMY AND PHYSIOLOGY}

$\mathrm{OF}$

POLYGYRA ALBOLABRIS AND LIMAX MAXIMUS

AND

EMBRYOLOGY OF LIMAX MAXIMUS

BY

GEORGE B. SIMPSON

Division of paleontology

ALBANY

UNIVERSITY OF THE STATE OF NEW YORK 


\section{M, a \\ CON T E N TS}

Preface........................................................... 239

Introduction ................................................ $24 \mathbf{I}$

Methods and apparatus..................................... 24I

Methods of killing and manipulating .............................. 24I

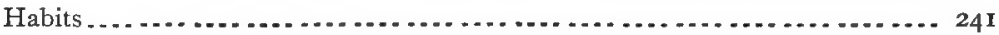

Polygyra albolabris ............................................... 244

Shell .................................................... 244

External features.............................................. 245

Movement ................................................. 247

Food-carnivorous habits.................................... 247

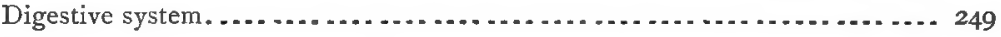

Pedal gland...................................................... 254

Generative system ........................................... 255

Description of a species of Entozoa ............................. 26 I

Circulatory system......................................... 262

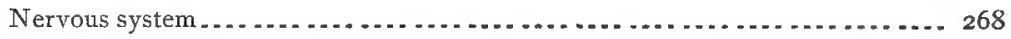

Special organs of sense...................................... 272

Limax maximus L. ....................................... 277

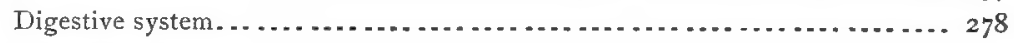

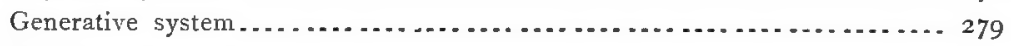

Circulatory system................................................ 280

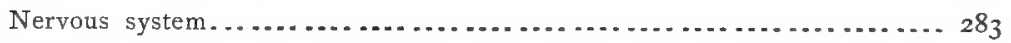

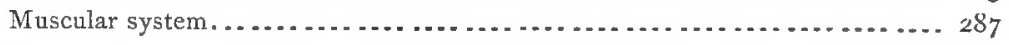

Embryology ................................................ 290

Time of laying eggs............................................ 293

Rate of growth .............................................. 294

Explanation of plates

Polygyra albolabris, plates I-I4..... . . . . . . . . . . . . . . . . . . 295

Limax maximus, plates $15-28 \ldots \ldots \ldots \ldots \ldots \ldots \ldots \ldots \ldots \ldots \ldots \ldots . \ldots \ldots 3^{02}$

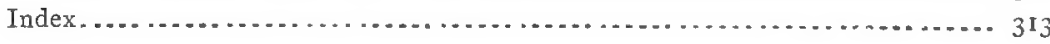




\section{PREFACE}

This work has been written for the use of individual students, as well as for classes in schools and colleges. No similar work on the snail has been published in this country, and in my own investigations I have seriously felt the need of one.

I have endeavored to write a work which will enable the student, without a previous knowledge of the subject, satisfactorily to pursue his investigations. I have, therefore, commenced at the beginning, giving explanations in regard to the instruments necessary, methods of dissection, how to collect the animals, etc., followed by a plain, but full, description of all the organs, without the use of too many technical terms, and unencumbered by theories.

I have made very full illustrations of all the organs and parts of organs, enabling the student at once to see their form and position. These illustrations are accurate copies from nature and in no case are they diagrammatic.

The manuscript of that portion of this work treating of anatomy and physiology was kindly reviewed by Prof. H. A. Pilsbry, of Philadelphia, and to him I am indebted for suggestions, specially in regard to nomenclature. I am also indebted to Prof. E. G. Conklin, of the University of Pennsylvania, who reviewed that portion treating of the embryology of $\mathrm{Li} \mathrm{m}$ a $\mathbf{x}$.

George B. Simpson 

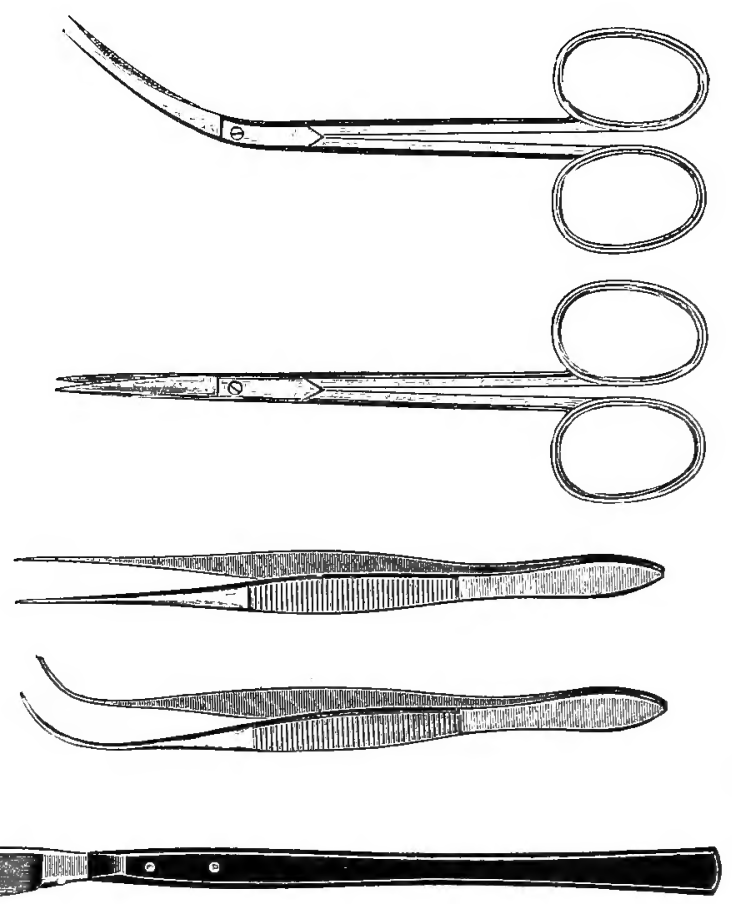

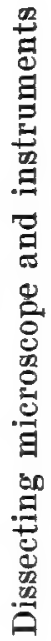

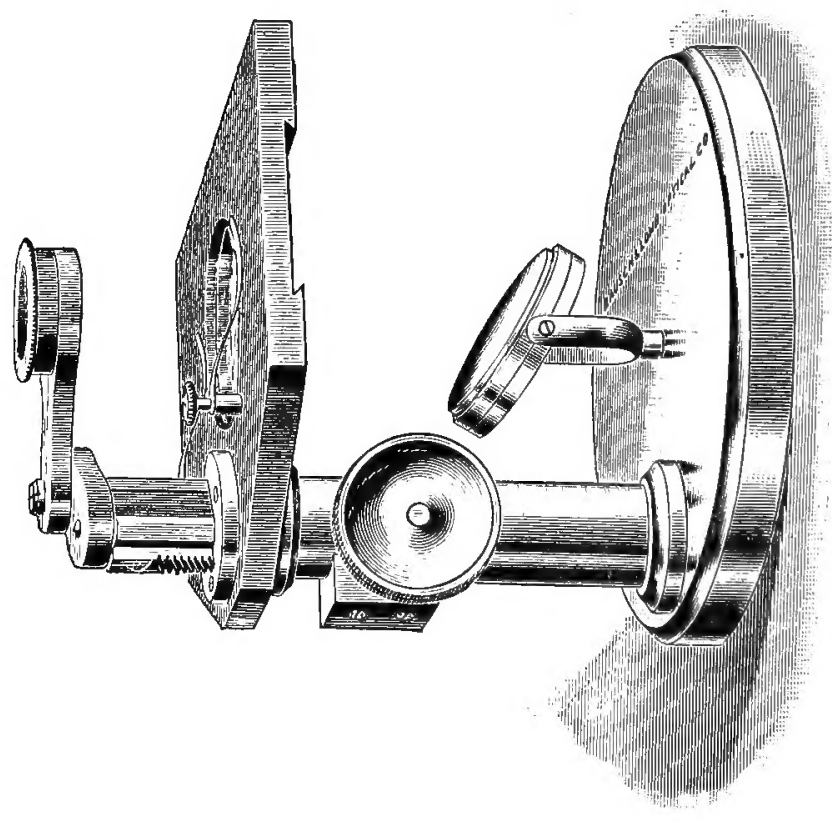




\section{POLYGYRA ALBOLABRIS AND LIMAX MAXIMUS}

\section{INTRODUCTION}

\section{Methods and apparatus}

Specimens of Polygyra and Limax may be easily kept in captivity by placing them in a box in which there are about 4 inches of earth covered with dead leaves. The earth must be kept moist. The box must be covered with mosquito netting or tarlatan. The mosquito netting will be sufficient for adult individuals, but the young of $\mathrm{L}$ i m ax would escape easily through its meshes.

For the study of the histology and embryology a compound microscope is necessary, with 2 inch, $\frac{2}{3}$ inch and $\frac{1}{6}$ inch objectives. A dissecting microscope is almost indispensable. I have used, for that purpose, one manufactured by Bausch \& Lomb of Rochester (N. Y.), known as the "laboratory dissecting microscope," fitted with a Hastings aplanatic lens. A cut of this instrument is given herewith. Two pairs of fine scissors will be necessary, one pair with straight points, the other with curved points; one or more fine scalpels, and two pairs of fine forceps, one straight and the other curved. A pair of stronger forceps and a pair of fine pliers will be needed to remove the shell of Polygyra. Dissecting needles are also necessary. These can be made by forcing the heads of fine needles, by means of a pair of pliers, into the end of a round stick of small diameter. The point of one of these needles should be bent so as to form a hook, first heating the end of the needle to a white heat.

\section{Methods of killing and manipulating}

I have tried all of the various methods recommended for killing $\mathrm{Polygyra}$ and $\mathrm{Limax}$, and find only one that is uniformly successful, and that is drowning. In using hot water and various chemicals, in nearly every case the animal is more or less contracted, and thus rendered useless for the pur- 
pose of a successful dissection. In drowning the animal, I have used a fruit-preserving jar, as being more convenient than a widemouthed bottle. The jar should be completely filled with water, so that, when the cover is fastened on, there will be no air space left. The animals being placed in the water and the cover screwed on, the jar should be left undisturbed for 48 hours; it requiring about that length of time to drown the animals. Remaining undisturbed, they will die fully extended; but, if the jar is disturbed in the meantime, more or less contraction will take place. The animal when dead should be thoroughly washed to free it from all adhering mucus, and placed in alcohol diluted with about two thirds the amount of water, additional alcohol being added from day to day till the mixture consists of about 75\% of alcohol. The animals should then be removed and placed in undiluted alcohol, when they will keep indefinitely. If placed at once in strong alcohol, the action of the fluid on the integument prevents the proper preservation of the internal organs.

To remove the shell, preparatory to dissecting the animal, break the peristome with a small pair of pliers. The remainder of the shell can be removed with a pair of forceps, carefully breaking off a small piece of shell at a time till it is removed to the apex. The columella can be removed by holding the lower part between the thumb and forefinger of the left hand, and turning the animal with the right. As the columella is like a screw, the animal readily becomes detached by this movement.

In dissecting the animal, a circular china dish about 4 inches in diameter and 2 in depth will be necessary; also a piece of sheet cork as large as will lie at the bottom of the dish, fastened to a thin sheet of lead with either string or rubber bands. It is best to have the lead of the same size as the cork. This leaded cork is to be placed in the bottom of the dish, and the dish filled with alcohol. If the animal has once been placed in alcohol, all dissections should be made in alcohol, but freshly killed specimens may be dissected in water, and many of the organs at this time present a much more natural appearance than when acted on by alcohol. Place the animal on the cork and fasten it down with small pins, 
or, better yet, with very fine, short needles, inserted through the margin of the foot. Then, with the fine pair of scissors, commencing at the head, cut through the integument along the center of the back, taking care not to injure any of the organs below. The integument is now to be removed from the dorsal part, turned back and fastened to the cork, removing the needles from the margin of the foot and putting them through the edges of the integument. All the organs of the anterior part of the snail are thus brought into view, and farther dissection of the organs can be intelligently made.

In the case of the Limax nearly all the organs will be brought into view by turning back the integument; but great care must be taken in this genus in cutting through the integument not to injure the pulmonary chamber, as it is situated very near the surface. Also every precaution should be taken that the points of the scissors shall not go below the integument, or the intestine and upper surface of the stomach will be mutilated, and a successful dissection rendered impossible.

\section{Habits}

Polygyra albolabris. The snails of this species are found in woods near fields, in ravines and in other situations. They remain concealed through the day when the sun is shining, coming forth for their food toward evening and after showers. It is at these times that they are most easily found during summer. Frequently they may be found on the under side of boards, logs and stones. During cold weather they hibernate, partially burying themselves in the ground, with the apex of the shell downward. At this time they are very easily found by scraping away the dead leaves so as to expose the surface of the ground. While hibernating the animal is completely withdrawn in the shell, the mouth of which is closed by a mucous excretion, which becomes hardened on exposure to the air. It is stated by nearly all writers on this subject that there is always a perforation in this membrane to allow the passage of air; but I have observed numerous cases where the membrane was entire. 
Limax maximus is found in gardens, where it is very destructive to vegetation. During the day it secretes itself; but it may easily be found, by the aid of a lantern, while feeding at night.

\section{POLYGYRA ALBOLABRIS Say, sp.}

\section{Shell}

The shell of $\mathrm{Polygyra}$ is turbinate, spiral; consisting in P. a l b o labris of five volutions, coiled around a hollow axis known as the columella. The columella is open at the base in immature specimens, but in adults it is closed by a growth of the shell. When the shell emerges from the egg, it consists of one volution only. Farther growth of the shell takes place in the manner hereafter described.

The shell consists of three parts or layers: the outer commonly, but wrongly, termed the epidermis-cuticle or Carpen. ter's name, periostracum, is preferable; next a prismatic part; finally a laminate part. The prismatic and laminate layers are of about equal thickness, and together form the greater part of the entire thickness of the shell.

- The cuticle is thin; in P. albolabris yellowish brown in color. It is without sensation, like the human scarf skin. Its office is to protect the shell from chemical action, which otherwise would injure or destroy it. After the death of the animal it fades and becomes brittle, or is entirely destroyed in situations in which during life it would not be affected.

The shell is formed by the thickened margin of the integument covering the visceral mass. According to Carpenter, "the shell, as before stated, is formed by the mantle of the shellfish, indeed, each layer of it was once a portion of the mantle, either in the form of a simple membrane or as a layer of cells, and each layer was successively calcified (or hardened by carbonate of lime) and thrown off by the mantle to unite with those previously formed." According to Huxley, the shell growth is not a case of conversion but of excretion, and the shell is built up by successive excretions of membranous laminae, in which granules of carbonate of lime are deposited. 
The prismatic part of the shell is apparently formed by the deposition of calcareous matter in prismatic, generally hexagonal, cells, which are themselves formed by the successive secretions of fenestrated laminae, deposited by the margin of the mantle (pl. 2, fig. 12 and 15).

The laminar part is apparently composed of numerous thin laminae varying in thickness. In many thin sections which I have examined under the miscroscope I have seen no trace of the prismatic structure in this part of the shell. The nacreous layer is very thin, forming the inner stratum of the shell, and is of a somewhat pearly appearance. This layer is a part of the laminar stratum, though it seems to be discernible, and in the broken edges of the shell is always distinct and is distinguished by its lighter color.

Till the shell reaches maturity the margin is very thin; but when mature the margin becomes greatly thickened and reflected, forming a broad peristome (pl. 1, fig. $3,4-7,12$ ). It is apparently formed by the part of the mantle depositing the prismatic layers, as nearly its entire thickness is of prismatic structure (pl. 2, fig. 13, 14).

If the margin of the shell is broken, it can be repaired by the animal; but, if any other part of the shell is broken, complete renewal is impossible, as the prismatic and cuticular layers of the shell are deposited only by the thickened border of the mantle. A mucoid substance in such cases is excreted and becomes calcified, taking the place of the missing shell; but any considerable breakage of the shell, except at the margin, is liable to be fatal to the animal. In collecting specimens, sometimes by accident the shells were broken; in nearly every case the animals died within a few days.

\section{External features}

The ventral part of the animal is expanded into a locomotor organ or foot, which is a thick, vermiform body with a ribbon-like ventral disk. The head is situated at the anterior extremity, and is obtuse; from it protrude two pair of tentacles, the upper 
and much the longer pair containing the eyes, the lower and shorter pair, the olfactory nerves. The mouth is situated at the anterior basal part of the head. Immediately below it is the opening into the pedal gland. The anterior upper part of the body is rounded; the posterior part is more acute.

The dorsal part of the animal is produced in a spirally coiled mass, containing the whole of the digestive gland, and parts of the alimentary, circulatory and reproductive organs, and is therefore known as the visceral mass.

The integument of the foot consists of a thick mucous-secreting membrane, with a muscular substratum. There are numerous mucous glands occupying nearly the whole of the membrane. The muscular substratum consists of unstriped fibers, arranged longitudinally, transversely and obliquely. Interior to this in. vestment of the foot is a muscular membrane inclosing the digestive and reproductive organs, which is sometimes called the peritoneum.

The dorsal part of the animal is inclosed in the shell and is an exact mold of the shell. The integument of this part is very thin and semi-transparent and is known as the mantle. Where the visceral sac joins the foot the mantle is very much thickened, forming a muscular collar, which is the shell-building organ of the animal.

When the animal is at rest or alarmed, the foot is contracted entirely within the shell, occupying the space at other times filled by the pulmonary cavity. The pulmonary chamber is very large and is situated in the outer part of the lower whorl. When the foot is protruded, the pulmonary rete still remains in contact with the shell, thus leaving a large cavity. It is into the space obtained by the collapse of this cavity, when emptied of air, that the animal withdraws when contracted. Thus the pulmonary chamber of testaceous snails is as much larger than the chamber of the naked slugs, as the volume of the foot superadded. 


\section{Movement}

The snail moves with a slow, gliding motion, produced by the muscles of the pedal disk. First the hinder part of the foot is drawn up, and the part immediately anterior to it is extended. This part is then contracted, and the part immediately anterior to it extended. These movements take place the entire length of the body, following each other so quickly that a gliding motion is produced. This contraction and expansion are confined to the central part of the pedal disk, the margins of the foot having a lateral undulating movement of their own.

The movement of the muscles of the middle part of the pedal disk gives rise to a very peculiar appearance, as if there were a channel through which oval drops of a transparent fluid were rushing in quick succession. Each contraction and expansion of the muscles of each part of the disk give the appearance of one of these drops of fluid, and, as these movements take place in rapid succession along the whole length of the foot, beginning at the posterior and continuing to the anterior extremity, the optical delusion of rushing drops of water is created.

If a snail is placed on a thin piece of glass, and the under part is observed while the snail is in motion, this movement can be observed, or if a Limax is held with the fingers in such a position that the under part of the body is uppermost, when it struggles to escape the appearance is the same, the action of the muscles being the same as when the animal is in actual motion.

\section{Food-carnivorous habits}

The snails which I have kept in confinement for three years have been fed on apples and lettuce, and occasionally cabbage. At first I placed lettuce in the box, but they refused to eat it. After several days I placed pieces of apple in the box, and these they ate ravenously. I fed them on apples for a month or more, when they seemed to tire of them and refused to eat. After a little time I placed lettuce in the box; this they ate, and since that time it has been their principal food. 
The popular belief that snails will feed on almost any vegetable is erroneous. I find that they are very particular regarding their food. I have placed spinach, young beet leaves and several other kinds of tender vegetables in the box, but they have refused to eat them.

Binney speaks of the carnivorous habits of $\mathrm{Circinaria}$ concava, and also speaks of Polygyra sayi devouring its own species. John Walton, in Mollusca of Monroe county, says of the cannibalistic habit, in some of the species: "I had abundant evidence the past summer in the $\mathrm{Z}$ o $\mathbf{n}$ it e $\mathbf{s} \mathbf{f} \mathbf{l} \mathbf{l}$ g i n o s a ; fully one third of the specimens of this species, taken during a special search by myself and pupils, were found devouring shells and animals, sometimes their own species, but more frequently the young of $\mathrm{P}$. albolabris, thyroides, sayi, and $\mathrm{Tr}$ iod opsis palliata. This was in July, and possibly the time of the year had something to do with the habit, as in the case of some seed-eating birds that are known to consume large quantities of insects in feeding their young and probably themselves during the breeding season".

I would suggest, in regard to their carnivorous habits, that, if the season was very dry, there may have been a scarcity of suitable vegetable food. I have raised over six hundred specimens from the egg, and I have found that, when the adult animals were plentifully supplied with food, the eggs and roung mere perfectly safe. When returning from my racation, I packed many specimens of P.albolabris in a box of dead leares; in a small box I had several hundred eggs and very small young. Several days elapsed before I could attend to them. I then procured a box, placing several inches of earth in the box, covering it with dead leaves, and placed the larger shells on the leares. Then I busied myself with the eggs. Some that were just hatching, partly out of the shell, I reserved to put in alcohol. The others I laid temporarily on a piece of paper in the box with the larger shells. After putting the specimens in alcohol I returned to the box, and was surprised to see several of the adults busily 
engaged in devouring the eggs; but I attributed this to the fact that many of the specimens, procured by me at the St Lawrence river, owing to the exceedingly dry season, had been without food for several weeks. I very much doubt that they are ever carnivorous when furnished with an abundance of regetable food. The immunity of the eggs and young in a box with more than a hundred adult specimens would seem to prove this.

Since the above observations were made two years have elapsed, and during that time I have raised many species, both of Polygy ra and Limax, from the egg to maturity and have noticed no carnivorous habits, though some of the smaller forms of $\mathrm{Limax}$ and $\mathrm{Pol}$ y g y $\mathrm{ra}$ have been raised in the same box as the large $\mathrm{Limax}$ maximus, and some of the latter had a length of 4 inches. In the same manner the smaller species of Polygyra have been safely raised with $P$. albolabris. The newly hatched young fed principally on the softer parts of the dead leaves in the box, skeletonizing them.

I do not know the exact time elapsing between the laying and the hatching of the egg, but it is certainly less than three weeks. When on a visit to the St Lawrence river in August, I collected several specimens and placed them in a box with moist earth covered by dead leaves. When, three weeks afterward, I took the specimens from the box, I found several groups of eggs, in two of which the young were just emerging from the shell.

There seems to be no uniform time for the laying of the eggs. I have had a large number of specimens in captivity for three years, and at almost any time eggs and newly hatched young could be found in the box. In some specimens collected in the winter, while hibernating, well developed eggs were found in the uterine canal.

\section{Digestive system}

The mouth is situated in the anterior part of the foot, and is bounded by thick, fleshy lips (pl. 5, fig. 1). These lips are divided into the upper, lower and lateral. The upper lip is composed of five lobes or divisions situated side by side. The lower lip has 
four divisions, of which the two lesser are situated above the two larger divisions. The lateral lips are each entire, comparatively large and somewhat crescentiform.

The mouth leads into an organ known as the buccal body (pl. 4, fig. 1). This organ is somewhat irregularly oral-shaped, and contains the masticatory organ known as the radula (pl. 4, fig. 3).

Just within the upper lip is the crescentiform, corneous lamina, known as the "jaw" (pl. 5, fig. 2), reddish brown in color, and occupying the position of an upper jaw. On the outer face of the jaw are 12 vertical ridges, with pointed ends, which project beyond the lamina. The ridges with their pointed ends closely resemble teeth. The jaw is attached to the buccal body by a band of muscular fibers, inserted in its upper convex edge. During feeding the jaw projects beyond the lips, which are protruded, having the appearance of a prehensile proboscis, which takes hold of the food and draws it to the mouth, the jaw cutting it into small pieces, acting as a chopping knife.

The food now passes into the buccal body. A reference to the figures on plate 4 will give a clear idea of the structure of that organ. The outer walls are thick and are composed of constrictor muscular fibers. On the floor of this organ are two gristly elevations, known as the odontophoral cartilages, which have, attached to their lower parts, small muscles arising from the side walls of the buccal body. Resting on the odontophoral cartilages is a cushion-shaped elevation, inclosed in a mucous membrane, known as the odontophore. Overlying this is the lingual ribbon, or radula, which is studded with an immense number, some fifteen thousand, of small teeth or denticles, arranged in transverse and longitudinal rows.

The teeth preserve the same form throughout in a longitudinal line. The central line always differs from the others, and the gradually vary in form and size, as they pass from the central line laterally. The radula, or lingual ribbon, takes its origin in the sac of the radula (pl. 4, fig. 3,4), which projects from the lower posterior part of the buccal body, continuing anteriorly from the radular sac upward to the dorsal part of the buccal body, 
then curving downward. It is connected by muscles with the floor of the buccal body. Within the sac of the radula and immediately anterior to it, the teeth are immature, in the posterior part of the sac consisting of very minute papilla-like elevations, each arising from a single cell. At the central part of the radula the teeth or denticles are fully developed. Anteriorly they are worn down, in some cases becoming smooth. During feeding the radula is moved forward and backward by the action of the muscles, acting as a rasp to triturate the food.

In addition to the muscles already mentioned, the following muscles are connected with the buccal body (pl. 4, fig. 4, 14): the buccal retractors, which have their origin, in common with the tentacular muscles and the retractor muscles of the foot, at the columella, and are inserted, as wide bands, in the posterobasal and the posterolateral parts of the buccal body. Numerous small muscles proceed from the buccal body to the integument of the lips (pl. 4, fig. 1, 9). There are two delicate muscles proceeding from the sides of the buccal body (pl. 4, fig. 1, 8), which, passing forward and downward, are inserted in the cephalic integument. Two broader bands of muscles, arising from the base of the buccal body, below the muscles just mentioned, proceed laterally, and are inserted in the integument (pl. 4, fig. 1, 7). A pair of very delicate muscles arise from the posterolateral part of the buccal body, and, passing along its sides, are inserted in the cephalic integument (pl. 4, fig. 1, 6).

The esophagus takes its origin in the dorsal-posterior part of the buccal body, and consists of a tube passing straight back between the supra and infra-esophageal ganglia (pl. 4, fig. 1, 2, 4), the commissural cords connecting the ganglia bounding it. The esophagus dilates and forms what is known as the crop. The membrane of the esophagus, as well as that of the crop, is very thin, and consists of a columnar epithelium and a basement membrane.

The columnar cells of the epithelium are long and pyramidal, broad at the base and very narrow at their attached parts. They are filled with fine, granular matter, and have each a nucleolated nucleus. Internally there are longitudinal folds of the membrane. 
The crop is elongate oval (pl. 5, fig. 3, 4), having a diameter three or four times that of the esophagus. Exteriorly it has a somewhat plicated appearance, caused by the longitudinal folds of the interior. It is situated in the first volution alongside of a part of the spermatic duct.

On each side of the crop are situated the salivary glands (pl. 5, fig. 3,4$)$. They are elongate, somewhat oval, and arborescent in appearance. They extend nearly the entire length of the crop. They are white in color, and under the magnifying glass present a beautiful appearance. They are composed of lobules, which are the dilated beginnings of the ducts, lined with cells oval in form and having a nucleolated nucleus. The glands are connected with the mouth by ducts, which extend alongside the esophagus. They are cylindric and conspicuous (pl. 5, fig. 3). ${ }^{1}$

The stomach begins almost immediately at the termination of the crop (pl. 5, fig. 3). At first it is small, but little greater in diameter than the esophagus, but rapidly and regularly increases in size nearly to its extremity. A transverse section is circular in outline. The anterior part is situated in the first volution of the shell, lying alongside the spermatic duct, continuing, having on one side the larger lobe of the digestive gland, and the albumen gland, on the other side being in contact with the hermaphroditic duct. It continues to the superior or smaller end of the digestive gland and ovotestis, where it bends somewhat abruptly downward and backward, giving origin to the intestine. Its walls are apparently striated and very thin. The contents of the stomach can be seen through the walls. Fur illustrations of the crop and intestines see plates 5, 6, 10 and 14 .

The intestine is of about the same diameter as the esophagus. Immediately on leaving the stomach, it turns backward below the stomach to the large lobe of the digestive gland, following the

1 According to A. B. Griffiths (Phys. invert. p. I09), the following constituents are found in the salivary secretions: soluble diastatic ferment, capable of converting starch into glucose, calcium, chlorin and doubtfully sulfocyanates and calcium phosphates. In the branchiate Gasteropoda the latter two substances occur, as well as mucin, but doubtfully chlorin. 
lateral and posterior border of that gland, then, turning, it proceeds forward and downward on the outer part of the digestive gland, approaching very closely to the first part of the intestine at a short distance from the stomach; then, turning, it proceeds upward and backward through the digestive gland to the border of the pulmonary sac. In its course through the digestive gland it forms an exaggerated letter $\mathrm{S}$ (pl. 5, fig. 3; pl. 6, fig. 7, 8).

The rectum continues along the border of the pulmonary sac to the anus, which is situated near the respiratory orifice (pl. 5, fig. 3,8$)$. On the outer side of the rectum, running its entire length, is a band of muscular fibers, the function of which is, probably, to shorten the rectum and to assist in expelling its contents.

The digestive gland (pl. 5, fig. 3, 9), was formerly regarded as analogous to the liver of vertebrate animals, but the organ contains a diastatic ferment, which converts starchy matters into glucose, and is comparable to the pancreas in vertebrate animals. It contains neither biliary pigments nor biliary acids. The liver of vertebrate animals is not a digestive gland in the true sense of the word, since'neither the bile nor an infusion of the hepatic tissues contains a digestive ferment. The name liver could not therefore be appropriately applied to the digestive gland of the Gasteropoda.

The digestive gland is divided into two parts, the larger and inferior of which occupies the outer part of the volution immediately beyond the heart and renal organ. The smaller and superior lobe, in conjunction with the ovotestis, occupies the apical whorls beyond the stomach.

In the digestive gland are innumerable ducts which unite and form a large duct in each lobe of the gland, the three large ducts uniting in one, which, in connection with the duct from the superior lobe of the gland, enters the stomach at a short distance from the beginning of the intestine.

The digestive gland is composed of lobules, which are formed by the enlarged commencements of the ducts, and are lined with 
polygonal cells, which become rounded on the removal of pressure ${ }^{1}$.

\section{Pedal gland}

The pedal gland (pl.4, fig. 4, 5), is situated in the middle of the basal part of the foot. It is a spongy-appearing mass, extending about two thirds the entire length of the foot, with a central circular passage connecting with the exterior by an opening immediately below the mouth, and sending forth numerous ducts to all parts of the basal portion of the foot. Its office is to secrete the mucus or slime, which the snail so abundantls exudes while moving, and which when hardened by the air presents a glassy appearance.

In the alcoholic extract $\left\{\begin{array}{l}\text { enterochlorophyll } \\ \text { lecithin } \\ \text { oleic acid } \\ \text { fatty acids } \\ \text { ash }\left\{\begin{array}{l}\text { chlorin } \\ \text { phosphoric acid } \\ \text { sulfuric acid }\end{array}\right. \\ \text { a trace of fat }\end{array}\right.$

In the aqueous extract $\left\{\begin{array}{l}\text { sugar } \\ \text { globules (coagulating at } 66-\mathrm{C} \text {. }) \\ \text { glycogen } \\ \text { sinistrin } \\ \text { hypoxanthin } \\ \text { ash }\left\{\begin{array}{l}\text { potassium } \\ \text { sodium } \\ \text { calcium } \\ \text { magnesium } \\ \text { iron (traces) } \\ \text { manganese } \\ \text { chlorin } \\ \text { phosphoric acid } \\ \text { sulfuric acid }\end{array}\right.\end{array}\right.$

Dr Griffith (Plys, invert. p. I I5) names the following substances as being found in the digestive gland of the Pulmogasteropoda: diastatic ferments, pancreatin, peptones and sodium.

1 Dr Levy (Zeit. biol. 27:398) has separated the following substances from the digestive glands of $\mathrm{Helix}$ pomatia. 


\section{Generative system}

\section{Plates $\%, 8$}

The Helicid a e and $\mathrm{Lim}$ a $\mathrm{c}$ id a e are hermaphroditic, and the hermaphroditism is most complete, having complex male and female organs separated from each other, but so arranged that self-impregnation is impossible, the union of two animals being necessary to reproduction.

The generative organs consist of the penis, vas deferens, spermatic duct, oviduct, uterine canal, albumen gland, hermaphroditic duct, consisting of the fallopian tube and spermatic duct, and the orotestis. On the right side of the foot, about on a line with the beginning of the superior tentacles, is an orifice known as the genital orifice. It presents the appearance of a short slit with the margins in contact, but is capable of great distension. It is from this orifice that the penis is protruded during coition, and into which the penis of the other animal is inserted. Leading from this orifice is a short chamber or tube, known as the cloaca, atrium, or genital vestibule, connecting with the penis and vagina. The orifices of these two organs are situated side by side, that of the penis immediately in front of the vagina.

The penis is a long, cylindric body of a glistening white color, occupying the dorsal anterior part of the foot, nearly straight, very slightly curved. Its walls are strong, thick and composed of muscular fibers. At the base of the penis the walls are very much thickened, and abruptly turned back exteriorly (pl. 8, fig. 1,2). The inner surface of the walls is plicated (pl. 8, fig. 3). The lining membrane along the bottom of the penis is elevated into a very strong muscular fold (the "pilaster"), nearly filling the interior of the penis (pl. 8, fig. 3). The plications of the inner surface of the walls are surmounted by papillae (pl. 8 , fig. 4). The plications of the lining membrane of the penis, and the muscular fold as seen in the penis laid open longitudinally, and in the transverse sections, under a low magnifying power or hand lens present a very beautiful appearance.

The vagina and the spermatheca or receptaculum seminis are 
connected with the genital restibule, the origin of the vagina being immediately posterior to that of the penis. The raginal body is cylindrically oval in form, having a length of from two and one half to three times the diameter. The walls of the vagina are strong, thick, and consist of muscular fibers. Internally thei'e are a number of strong regular, longitudinal muscular elevations, covered by a double membrane. Near the base these folds are plicated, but become smooth above. At its extremity the vagina narrows into a thin-walled tube or duct, which is of varying length, sometimes short, at other times as long as the vagina. This duct becomes dilated above, forming the receptaculum seminis. The latter organ is elongate oval in form, having very thin walls, and with minute longitudinal folds along the interior (pl. 8, fig. $10,11,14)$. These folds sometimes give a striated appearance to the exterior. The organ is in contact with and closely adhering to the oviduct.

During coition the penis is inserted in the vagina, and is there closely held by the muscular walls and longitudinal folds, the spermatozoa finding their way into the receptaculum seminis, afterward passing down through the vagina, and fertilizing the egg as it leaves the oviduct.

In addition to being a receptacle for the spermatozoa, the receptaculum seminis, according to Dr Leid $y^{1}$ " secretes a mucoid matter, which probably facilitates the passage of the ova through the cloaca. The mucus matter in the bladder is frequently found to contain an immense number of an infusorial parasite, which I have described under the name Cryptoicus." 2

Dr Leidy's description is given at the end of the article on the generative organs.

0votestis. The ovotestis, in common with the superior organ of the digestive gland, occupies the apical volutions of the animal (pl. 7, fig. 1, 12). It is lighter in appearance than the digestive gland, and is composed of a number of bundles or fasciculi of short ceca. Each fasciculus is composed of numerous ceca, is

1 Terrestrial moll, and shells of the United States, p. 234.

2 Jour. acad, nat. sci. new series, v. I. 
broadly pointed at the base, rapidly expanding, circular and convex at the opposite extremity, having very much the appearance of a composite flower. The ceca are sometimes simple, but usually bifurcate or trifurcate. The ceca of each fasiculus connect with a tube, which in turn connects" with a duct leading into the hermaphroditic duct. Each cecum seems to have four walls, forming an inner and outer chamber (pl. 7 , fig. 7 ), a tube within a tube. In the onter chamber or tube are produced the ora and in the inner, the spermatozoa.

The hermaphroditic duct leads from the ovotestis to the uterus and penis. It is an extremely convoluted organ, so twisted and confused in $\mathrm{P}$. a l b ola b $\mathrm{r}$ is as apparently to be composed of short, cylindric, contorted tubes, agglutinated together. In some other species of $\mathrm{Helicidae}$ and in $\mathrm{Limax}$ it is more nearly straight, being flexuous, sometimes slightly folded or spiral, but not convoluted. This duct is invaginated in the same manner as the ovotestes, the outer tube carrying the ova and the inner the spermatozoa.

Just before reaching the albumen gland the hermaphroditic duct becomes constricted into a delicate thread-like tube. It then enters an accessor: gland, which is somewhat the form of a cornucopia, the large end of which is composed of several follicles. The gland rapidly narrows to its opposite extremity. It is partially imbedded in the substance of the albumen gland. Its purpose has not been clearly determined, though from the size and persistency it is undoubtedly important. At the small extremity of the glaud the male and female organs become separated, the fallopian tubes passing into the uterine canal, and the epididymis continuing as a spermatic duct on one side of the utrine canal (pl. 7, fig. 1, 9, and pl. 14, 2?).

Albumen gland. The albumen glind, which is situated at the extremity of the uterine canal, is a large boat-shaped or linguiform gland, of a yellowish color (pl. 7 , fig. 1, 14). The walls of the gland are composed of cells filled with albumen. The interior of the gland is hollowed out by an elongate chamber or duct. The function of the organ is to supply the ova with albumen. 
The spermatic duct, as it proceeds along the uterine canal, is invested with a yellowish mass, which has been called the prostate gland. In structure it is composed of rery closely packed, simple, tubular follicles, which are lined with pyramidal, epithelial cells, containing at their base a nucleolated nucleus.

At the termination of the uterine canal the male and female organs become entirely separated, forming the vas deferens and the free oviduct (pl. 7, fig. 1, 6, 7, and pl. 14, fig. 1, 18, 19). The vas deferens becomes enlarged, and for some distance assumes a spiral or twisted form; it then contracts, becoming a long, simple tube, somewhat folded on itself, in order to adapt itself to the restricted space which it occupies. It continues to the extremity of the penis, the walls of which are very thick and muscular. The interior passage or duct is, for the greater part of its length, trilobate in section. As it enters the penis it is somewhat enlarged and the orifice is plicated. It is surrounded by thickened lips and folds, which project into the penis. This fold has a plicated membrane (pl. 8, fig. 6), resembling the membrane of the fold of the penis previously described, and the outer part is nearly in contact with that fold.

The urethra is situated between the lining membrane of the penis and the membrane of the muscular fold (pl. 8. fig. 2).

The retractor muscle of the penis is inserted in the ras deferens at a short distance from the end of the penis (pl. 14, fig. 1, 17).

Uterine canal. The uterine canal is a large long tube or canal, with plicated or sacculated folds. It is much greater in diameter than the accompanying prostate gland. The walls are mostly composed of polygonal cells, each cell having several nuclei (pl. 7, fig. 1, 8 and pl. 14, fig. 1, 21 ). It is within this organ that the eggs are completed.

0viduct. The oviduct (pl. 7, fig. 1, 7, pl. 14, fig. 1, 20) is about the same size as the twisted part of the ras deferens, and continues from the uterine canal to the vagina, entering that organ near its mouth.

During coition the penis is everted, passing out of the genital orifice, and entering the vagina of the second animal, coition continuing for several hours. 
The position of the generative organs in the animal can be clearly understood from plate 23 , figure 9 .

The penis occupies the dorsal anterior part of the foot; the ragina the anterior right lateral part. The receptaculum seminis closely adheres to the prostate gland. The vas deferens is situated between and beneath the penis and vagina; on account of its great length being disposed in irregular folds. The prostate gland and uterine canal enter the first volution of the animal and are disposed alongside the pulmonary cavity. The albumen gland lies between the large lobe of the digestive gland and the stomach. The constricted, thread-like part of the hermaphroditic duct crosses the stomach from the base of the albumen gland, and the convoluted part of the duct lies in the inner margin of the volution, alongside of a part of the stomach. The ovotestis, in conjunction with the superior lobe of the digestive gland, occupies all the apical parts of the animal.

The generative organs of the other species of helicoid snails, though varying in detail, are sufficiently similar to those of P. a l bolabris to enable the student to recognize them without difficulty, with the exception of those of Gastrodonta intertexta, G. gularis, G. ligera and G. suppressa, which species have accessory organs, that will be described later on.

The vas deferens is usually about twice the length of the penis, or less. In Polygyra exoleta it is longer, but in no species, as far as I am aware, is it as long as in $\mathrm{P}$. a $1 \mathrm{~b}$ o l a b r is. In P. tridentat a and in P. exole t a it has the same form us in $\mathrm{P}$. a l bol a b ris, that is, enlarged, glandular, annulated or somewhat spiral in appearance at its beginning; while, on the contrary, in P y r m idula solitaria it has this form at its termination. In $\mathrm{Omphalin} \mathrm{a} \mathrm{fuliginos}$ it is for a great part of its length expanded, so that its diameter is equal to that of the penis.

In some species, as in Polygyra a u riculata and $P$. s a y $i$, the penis is very long and bent on itself, while in others, as Pyramidula solitaria, it is short, stout and clavate. 
In Polygyra profund a the base of the penis is included in a sheath formed by a continuation of a part of the genital chamber, in the form of an inverted cone. In Circinaria c o n c a va it is long and cleft or bipartite at the summit.

The lining membrane usually has a number of rugae, longitudinal and oblique. Sometimes, as in P. a $\mathrm{lb}$ bl a b r is and $\mathrm{Pyr}$ a$\mathrm{midula}$ alternata, there is one very large fold. In many species, as in $\mathrm{P}$. a l b ol abris, the surface of the membrane is papillated, but in some others it is smooth.

The vagina and receptaculum seminis vary in form. In the greater number of species the vagina is not as large and muscular as in $\mathrm{P}$. a $1 \mathrm{~b}$ o $\mathrm{la} \mathrm{br}$ is, and the duct leading to the receptaculum seminis is generally longer.

In $\mathrm{H}$ elix aspera and other European species there are several accessory organs not found in P. a I bolabris or in I i m ax. They are the flagellum, the dart sac and the accessory mucous or digitate glands.

The flagellum is an elongated diverticulum of the penis and is much coiled. The dart sac is an elongated, clavate, appendage from the base of the oviduct. It has powerful muscular walls, and contains in its interior the dart or spiculum amoris, attached to a nipple-like protuberance at the bottom of the sac. The dart is four-bladed, calcareous, and growing by the addition of calcareous particles, deposited at its base from the vascular protuberance to which it is affixed. If broken off it is speedily renewed in like manner. Before coition the dart sac is everted from the genital orifice, the dart thus becoming exposed. It is probably an excitatory organ.

The mucous or digitate glands, according to T. Rymer Jones, " consist of a series of branched ceca, derived from two excretory ducts, by which a milky fluid, secreted by the ceca, is poured into the egg passage prior to its termination".

The receptaculum seminis of $\mathrm{H}$ elix a s p r a differs greatly from that of P. albolabris and $\mathrm{Limax}$ maxi. $\mathrm{m} \mathrm{u} s$, consisting of an elongated duct, which subdivides into two 
cecal diverticula, a longer and stouter coiled one, and a shorter one with globular head, which during life is concealed in the first coil of the intestine.

It is a remarkable fact that, while the flagellate form of the penis, and the accessory organs, viz, the dart sac and multifid vesicles, are very common in European species of $\mathrm{Helix}$, they are very rare in east American forms. A flagellate form of the penis does not exist in a single one of the latter forms. An analogue of the multifid vesicles exists in only four of the species occurring in New York. In Gastrodonta intertexta and G. $\mathrm{g}$ u $\mathrm{l}$ a $\mathrm{r}$ i s there is a single pair of follicles. In G. $\mathrm{l}$ i g e r a and G. s u p press a there is but one short follicle. The dart sac exists in the above-named species.

\title{
Description of a new species of entozoa
}

\author{
BY DR JOSEPH LEIDY
}

Plate 13, fig. 6

In September 1846 I first gave an account in our proceedings of a new genus and new species of Ertozoa, inhabiting the fluid contained in the spermatheca of $\mathrm{Helix}$ al b o labris, $\mathrm{H}$. $\mathrm{tr}$. dentalis and H. alt $\in$ rnata. Since then $I$ have verified the observation, and also have detected it in other species of Helix, viz, elevata and throides, and have also de. tected it in an allied genus, Bulimus decollatus. The name which $I$ gave it at that time I was not aware had been previously applied to a genus of In secta $\mathrm{brachelytra}$, with the only difference of the latter having a neuter termination. I will therefore change the name.

Cryptoicus minutissimus; forma mutabilissima; organisatione interno cellularium et granulosum, C. h e l i c is. Coloris expers; forma plerumque elongata, tusiforme, vel ovata; caudis duabus adversis, una longior quam altera. Structura interno stomachos duos et granulos numerosus parvos exhibit. Long $\frac{1}{12} \overline{5}-\frac{1}{10}$ lin. Habitat in spermatheca $\mathrm{Helices} a l b o l a b r i s$, tridentata et Bulimus decollatus.

This singular entozoon is a polygastric animalcule. Its varied forms and movements are curious to observe; at one moment globulose, then oval, ovate, fusiform, sigmoid, crescentic, etc. It appears as if it would outvie the kaleidoscope in its changes. Sometimes it collects in bunches, adhering by the end of the cauda to each other, and frequently it may be observed to contract upon either of the large cellules, causing them to project beyond 
the outline of the animal. The motions are vibratile rotary, with a lateral progression, or whirling in circles like the insect $\mathrm{G}$ y r inus. Cryptoicus from its position might be mistaken for the spermatozoa of the animal, but may be readily distinguished; the spermatozoa of $\mathrm{Hel}$ i ces having either a uniform sigmoid or a spiral body, with an enormous proportionate length of tail, and a slow vibratile motion.

Plate 13, figure 6 , represents some of the varied forms of the animal highly magnified.

\section{Circulatory system}

Method of injecting the blood vessels. I have found the following method to be the best in obtaining a complete injection of the circulatory system, and by it I have obtained the most beautiful results, plainly showing all the minute ramifications of the arteries and veins.

The necessary materials are an ordinary hypodermic syringe, with as fine a needle as it is possible to obtain, the finer the better; as an injection which would not pass through the finest hypodermic needle certainly would not pass through the fine arteries and veins. The distal extremity of this needle should be blunt or slightly bulbous. A curved sewing-needle and very fine thread are also necessary. As an injection fluid I hare used and found perfectly satisfactory Dr Seiler's carmine gelatin. This is sold by the ounce and comes in a solid mass.

A day or two before making the injection, some of the gelatin should be placed in cold water in a wide-mouthed bottle. The water will soften the gelatin. When it is proposed to use the injection, the bottle can be set in a pan of hot water. Within a short time the gelatin will be completely dissolved. It should be thin enough when hot to enter easily the arteries and veins, but of sufficient consistency to harden when cold. No rule can be given as to the exact proportion of water and gelatin. The right degree of fluidity must be determined by each student. Use only filtered water with the gelatin, as a small particle of dirt in the water might prevent a successful result.

Take the animal as soon after death as possible; wash away the mucus. Then, as previously described, remove the shell, 
wholly or till the heart can be plainly seen. The latter method is, I think, preferable, as it avoids the danger of rupturing some of the blood vessels, as sometimes happens when the entire shell is removed. Cut through the peritoneum, alongside the rectum, taking care not to injure the large vein which accompanies the rectum; turn back the walls of the pulmonary cavity till the heart is exposed. C'sing the curved needle pass a thread under the ventricle. Place the animal in warm water, as hot as can be comfortably borne by the hand, and before injecting be certain that the animal is thoroughly warmed through; also place the syringe in hot water, having both the syringe and injecting fluid warm. Draw some of the fluid into the syringe; then, holding the needle upward, expel a drop or two of the fluid, so as to be certain that no air remains in the syringe. Leaving the animal in warm water, with the point of an extremely sharp scalpel make a slight incision in the walls of the ventricle just large enough for the point of the needle to enter. Insert the needle, bring the two ends of the thread together and tie them just back of the point of the needle, to guard against the escape of the injection through the incision. Some assistance would be useful in this operation, as one hand will be occupied with the syringe. Gently press the piston, slowly injecting the fluid, stopping immediately when the injection is complete, as much pressure will rupture the walls of the blood vessels.

STometimes a rery fine injection of the arteries can be made by merely inserting the point of a hypodermic needle in the ventricle, the rest of the process being as described above. But the injection is liable to escape where the needle enters the wall of the ventricle.

The injecting is a very delicate process, and partial, or even a complete failure at the first attempt should not discourage the student. The most frequent cause of failure is in not keeping the animal and syringe warm enough, the injecting fluid rapidly hardening in the blood ressels, preventing their full injection.

When the animal is fully injected, place it at once in cold water; this rapidly hardens the gelatin. The remainder of the 
shell can now be removed and the animal immediately dissected, or it can be placed in alcohol for future use. The alcohol must be at first very weak, gradually increasing its strength each day.

The advantage of a gelatin injection over a fluid one is that, as the gelatin becomes hardened, dissections can be made without danger of the escape of the injection from the severed blood vessels. As the injection is a brilliant carmine, the blood vessels stand out in bold relief from the light background of the various organs.

Heart. The heart (pl. 9, 1, pl. 10, fig. 1, pl. 14, fig. 1, 30, 32) is situated in the outer portion of the first volution, just anterior to the peristome, and is plainly visible from the exterior. Its pulsations can be observed even through the shell. Ordinarily the pulsations number about 45 or 50 a minute, in an adult individual; but are variable, sometimes being much faster, and during hibernation slower. In a young individual the pulsations seem to be much faster, sometimes equaling 150 a minute. The heart consists of a single auricle and ventricle, inclosed in an oval pericardiac sac. The ventricle and auricle are pyriform, placed base to base, the bases being somewhat truncated. The ventricle is about twice the size of the auricle.

In composition the walls consist of unstriped muscular fibers, granulated, showing oval nuclei on the application of acetic acid.

The interior of the heart is lined with tesselated epithelium. consisting of granulated cells. The interior of the walls of the aorta have a similar structure.

The wall of the pericardium is rery thin and transparent. The pericardial fluid is very abundant, and, according to $\mathrm{Dr}$ Leidy, is sometimes inhabited by an entozoon, named by him Distoma ragans. Between the auricle and rentricle is a valve, so disposed as to permit the passage of the blood only from the auricle to the ventricle.

Arteries (pl, 9, fig. 1). The ajkx of the ventricle gives origin to one large aorta, which almost immediately subdivides. one branch proceeding posteriorly, and supplying the digestive gland,

${ }^{1}$ Jotr. acad, nat, sci. new series. v. i Philadelphia. 
hermaphroditic duct, stomach, ovotestis and albumen gland; the other and larger of the two proceeds anteriorly, supplying the remaining organs of generation, muscles, crop and all the organs contained in the foot.

The posterior aorta passes on the outer part of the inferior lobe of the digestive gland, giving off numerous branches to this gland, the intestine and also to the albumen gland. Just after giving off this latter branch, it crosses a portion of the stomach, and for a short distance disappears in the substance of the lobe of the digestive gland; then emerging it continues along the lower inside edge of the volution to the apex of the animal, giving off branches to the superior lobe of the digestive gland, and to each of the fasciculi of ceca composing the orotestis.

The anterior aorta, at a short distance from the heart, gives off a branch to the stomach. On the stomach this branch subdivides into two branches; each of which gives off numerous branches, covering the stomach with their ramifications. This artery, before reaching the stomach, gives off a branch, which continues to the hermaphroditic duct.

At a short distance from the branch to the stomach is a large branch, which continues on the surface of the prostate gland and uterine canal, giving off numerous small branches to these organs.

At a short distance beyond this branch is another, which shortly subdivides; the larger of the two divisions continuing to the muscular collar, and supplying blood to it, and to the adjacent parts. The smaller of the two divisions continues with the retractor muscles of the foot. From the larger of the two subdivisions a branch is given off, which continues to the crop, supplying the crop and. the overlying salivary glands. A small branch continues with each salivary duct to the buccal body.

The main aorta continues, without branching, to the infraesophageal ganglia, where it suddenly turns downward and backward, continuing posteriorly in the base of the foot. Just at the turn it gives off three branches, which proceed directly anteriorly; the central and largest of which supplies the buccal body. The two lateral ones, which are very minute, proceed 
to the cephalic integument. A branch is also given off, which proceeds alongside the nerve to the muscular collar. Branches also accompany the commissural cord, forming a complete circle. From this, on the left side, arteries proceed to the tentacles; from the right side an artery proceeds, which subdivides; one branch proceeding to the penis, the other to the vagina; these organs being covered by numerous ramifications. From the artery near the ganglia proceed the arteries supplying the tentacles of the right side.

Veins. The arteries break up into smaller and smaller branches, and finally into a network of capillaries, that meet a similar network leading to the veins, which empty into large veins or sinuses; the principal ones of which are three in number. The first begins in the apex of the volutions, receiving the veins from the superior lobe of the digestive gland, continuing on the outer edge of the volution to the beginning of the pulmonary chamber, receiving in its course several large veins. These divide, one division passing along the edge of the pulmonary chamber, alongside the rectum to the thickened muscular collar, passing along the inner edge of this to the base of the pulmonary chamber. The other division passes along the base of the pulmonary chamber, uniting with the first described division at the muscular collar, forming a sinus completely incircling the pulmonary chamber, and known as the circulus venosus pulmonis, or pulmonary circulus.

The arteries of the foot, as in the visceral part of the body, break up into capillaries, that enter the capillaries of the reins, which empty into a large vein or sinus, situated below the pedal gland. From this sinus proceed numerous veins, which finally connect with the pulmonary circulus.

From the pulmonary circulus arise many veins, which form a large vein leading to the heart, and known as the pulmonary rein. These veins are known as the efferent veins. They alternate with much regularity with a series of veins leading from the pulmonary rein, but intimately connected with the efferent ressels, which are known as the afferent veins (pl. 11, fig. 1-4).

Circulation. The circulation is as follows: the blood leares 
the heart by the aorta, and is distributed by the arteries to the different parts of the body, and passes from the minute branches of the arteries into a flexus of capillaries spreading over the whole body; passing from them into the veins, and from the veins into the sinuses previously described; finally all the blood entering the pulmonary circulus; and thence the pulmonary veins, where, circulating freely through efferent and afferent vessels, it becomes thoroughly aerated.

The renal organ or kidney is supplied with blood, which has previously been aerated, but only a small part of the blood passes each time through it.

Though the veins are situated in the substance of the body, and their walls are much thinner than those of the arteries, they are not simply lacunae or wall-less passages in the body, as they have frequently been described. The walls though thin are distinct.

Blood. In animals of the simplest structure all the fluids seem to be of the same nature and seem to be "only water charged with organic particles, but in animals higher in the scale of being the fluids cease to be of the same nature, and there is one, distinct from all others, destined to nourish the body. This fluid is the blood. It not only nourishes the body, but is the source from whence is derived all the other secretions, such as saliva, urine, bile, etc."

In the higher animals the blood is of a red color; but in the Invertebrata it is of different densities and of various colors.

The blood of the Helix and Limax consists of a nearly transparent fluid in which float solid corpuscles.

For the following facts in regard to the composition of the blood I am indebted to Dr Griffith's Physiology of the Invertebrata.

In the majority of the Invertebrata the carrięr of oxygen to the tissues is haemocyanin, contained in the blood, but in many of the Annelida, as well as in nearly all of the vertebrates, the transport of oxygen from the surrounding medium (air or water), to the living tissues is made by the hemoglobin of the blood. This substance, as is well known, forms an oxygenized condition which is very unstable, and which is carried by the blood across the tissues of the animal, and is there dissolved, yielding its oxygen to those tissues which require it. 
In Gasteropoda, as well as in Cephalopoda, Crustacea and Arachnida the function of respiration is brought about by an albuminoid substance analogous to hemoglobin, but containing copper instead of iron, this substance, which Frederica names haemocyanin, forming a very unstable combination.

The saline matter contained in the blood of the Helix is about $1.075 \%$; in $\mathrm{Li} \mathrm{m}$ a $\mathrm{x}$ about $1.115 \%$.

Touching the color of the blood, Mac Munn ${ }^{1}$ says in regard to the blood of on exposure to the air, and gave no absorption bands, but absorbed a little of the violet end of the spectrum. On treatment with ammonia its color was not so well marked, and it had a partially reddish tinge, but no bands could be seen, and after, treatment with acetic acid did not remove the color."

One time I drowned 12 individuals of $\mathrm{P}$. a l bolabris, leaving them, as usual, in the water about 48 hours. The blood in the arteries of all these specimens had coagulated and turned a dark purple black in color, so that the course of the arteries could be as distinctly traced as if they had been injected. I am unable to account for this phenomenon, as of scores of specimens, treated in the same manner, these were the only specimens coagulated and colored, though the others were kept in the same box and fed on the same kind of food.

\section{Nervous system}

The nervous system (pl. 12) consists of five distinct sets of ganglia, and four ganglionic swellings, and the commissures connecting them or proceeding from them. The principal ganglia are the supra-esophageal, the infra-esophageal, consisting of two sets, and the two buccal ganglia. The ganglionic swellings, or ganglia, are situated at the extremity of the tentacles. The ganglia corresponding to the one situated on the dorsal surface of the stomach in Lim ax maxim us I have not observed in Polyg y r a.

When the animal is extended, the supra-esophageal ganglia are situated just above the esophagus, immediately posterior to

1 Quart. jour. micro. sci. 1885 
the buccal body, but varying somewhat in position according to the degree of contraction of the body.

The infra-esophageal ganglia are situated below and just posterior to the buccal body, and are connected with the supraesophageal ganglia by a double commissure. The buccal ganglia consist of two small masses, situated just below the surface of the posterior dorsal part of the buccal body. They are connected with each other and with the supra-esophageal ganglia.

The esophageal ganglia and the connecting commissures are enveloped by an essentially opaque sheath, and it requires very careful manipulation to remove this so as to determine the form of the ganglia. This is best effected by two small needles fixed in the end of small round sticks, as described on page 241, using one in each hand. The points of the needles should be inserted just below the surface of the sheath, and a little of it torn away with each insertion, being very careful not to introduce the needle far enough to penetrate the ganglia beneath. The fine forceps, mentioned on page 241, will be found useful in removing the loosened parts of the sheath. In this operation it is necessary to proceed very slowly. Any undue haste will almost certainly result in the destruction of the ganglia.

The supra-esophageal ganglionic mass, before the removal of the sheath, has the appearance of a single quadrangular mass, wider than long, the posterior margin incurved. The double commissures proceeding from the posterolateral extremities, appear as single large, flattened nerves. When the sheath is removed, the supra-esophageal ganglionic mass is seen to be composed of two sets of ganglia, connected by a commissural cord, the ganglia of each set being aggregated together, the two ganglionic masses being precisely similar in detail. The principal one of the supra-esophageal ganglia (pl, $12, a$ ) is subquadrangular or sub. ovate in outline, about two and one half times as long as wide, slightly constricted at the middle. Attached to the lower outer part of this ganglion is a smaller ganglion, about one fourth the size of the preceding one. Attached to the posterior part of these ganglia are three comparatively small, nearly round ganglia (pl. 
$12, a)$, so aggregated as to have, on a superficial examination, the appearance of an oblong mass.

The infra-esophageal ganglia have, before the remozal of the sheath, the appearance of a flattened, circular mass, with a central opening through which passes a large artery. When the sheath is removed, it is seen that the ganglia form two masses aggregated together, making a sub-circular mass. The upper mass is composed of five subovate ganglia, of nearly equal size (pl. 12,b). One is situated dorsally and centrally, and two on each side of this one. The lower part consists of two larger ovate ganglia, joined to each other and to the ganglia above them.

The buccal ganglia are small, somewhat kidney-shaped bodies (pl. 12,n).

The ganglia of the superior tentacles are subpalmate in form, the palm being unduly developed, and the fingers very short (pl. $12, e)$.

The ganglia of the inferior tentacles are pear-shaped (pl. 12, $i$ ). The commissures connecting the supra and infra-esophageal ganglia are of equal size. The upper commissures proceed from the posterior part of the outer supra-esophageal ganglia, and are connected with the anterior part of the lower ganglia of the upper fart of the infra-esophageal ganglionic mass (pl. 12, c). The lower commissures proceed from the outer ones of the small, nearly round ganglia of the supra-esophageal ganglionic mass, and are connected with the lowest two ganglia of the infra-esophageal ganglionic mass, or, as they are sometimes designated, the pedal ganglia (pl. 12, c).

From the inner anterior part of the principal supra-esophageal, or cerebral ganglia, proceeds a large, conspicuous nerve, which connects with the ganglia at the extremity of the superior or ocular tentacles (pl. 12, $d, e$ ). This nerve, after entering the tentacle, gives off a nerve which proceeds to the eye, the optic nerve (pl. 12, $f, g$ ); also from the outer anterior part of each ganglia a nerve proceeds to the mouth and adjacent integument.

From the central anterior part proceed two very delicate nerves which continue to the integument of the superior tentacles. 
From the lateral ganglia of each mass proceed two very conspicuous nerves; the inner one (pl. 12, l), continuing to the mouth, the outer one continues anteriorly, branching; one branch $(k)$ going to the mouth and adjacent parts, the other $(i)$, continuing to the ganglion at the extremity of the inferior tentacles.

The nerves previously described give off branches to the anterior part of the body, also to the penis and vagina.

From the lower inferior part of the principal ganglion proceeds a commissural cord (o), connecting with the buccal ganglion.

The anterior extremities of the buccal ganglia are connected by a commissural cord.

From the buccal ganglia nerves pass off: first, two nerves, anteriorly, to the surface structure of the buccal body; second, two branches, which penetrate posteriorly into the buccal body; third, a branch accompanying the salivary duct to the salivary gland; fourth, a branch to the esophagus; fifth, a nerve to the anterior part of the buccal body.

From the infra-esophageal ganglionic mass proceed the follow. ing described nerves: from the dorsal ganglion a very conspicuous nerve (p), which takes the same general direction as the cephalic artery, continuing alongside the uterine canal. At the point where vhe arteries give off branches to the muscles and the crop the nerve passes through the loop thus formed, and also gives off branches both to the muscle and to the crop. It then continues, slightly diminished in size, along the uterine canal to the albumen gland. The main part continues along the albumen gland; a branch accompanies the hermaphroditic duct to the ovotestis, giving off iilaments to the stomach and digestive gland. Another branch pro. ceeds to the heart and renal organ. From this branch a smaller branch proceeds to the adjacent parts of the digestive gland. The nerve is easily traced to the digestive gland, but from that point the nerves are very fine, and careful study is necessary to distin. guish them.

From each of the two ganglia adjacent to the dorsal one, a very large nerve passes to the muscular collar $(r)$; bifurcating just be- 
fore entering the collar, one branch passes through the muscles, the other continuing in the pulmonary chamber.

From the inferior part of the lateral ganglia proceed five nerves on each side $(u)$, continuing to the integument.

From the pedal ganglia proceed two large nerves, running nearly directly backward and parallel to the central part of the base of the foot, giving off several branches. From the pedal ganglia there are about 12 other nerves, supplying the base of the foot.

The ganglia are composed of cells or globules, varying very much in size, round or polygonal from mutual pressure, haring a nucleus which occupies one half or two thirds the globule. The nucleus has several transparent nuclei. The nerves consist of bundles of tubuli. The walls of the tubuli are transparent.

\section{Special organs of sense}

Touch. The sense of touch is extremely acute in every part of the foot; the integument and base of foot being liberally supplied with nerves. The tentacles are specially sensitire, but I hare not been able to touch any part of the foot so lightly that it was not immediately felt by the animal. In motion the animal depends more on the sense of touch than on eyesight.

Taste. There is no doubt that the animal possesses some sense of taste, but, from long observation, I think that in the selection of food the animal depends more on the sense of smell than that of taste.

Light. The eyes of both $\mathrm{H}$ elix and Lim a $\mathrm{x}$ are situated at the extremity of the superior tentacles, and are conspicuous. haring the appearance of bright, black specks. Under a low power can be seen the globular eyeball invested by a transparent tunic, corresponding to the cornea; the crystalline lens Iring under the delicate cornea; the choroid, which forms two thirds of a sphere, transparent and having a single layer of irregularly round or oval, black pigment cells. Pol y g y ra is nocturnal in its habits, and perhaps at that time it can see more clearly; but in all my experiments with different individuals, many of them conducted with only sufficient light to distinguish the animal, I have seen 110 evi- 
dence that $\mathrm{Pol}$ y g y a is possessed of sight, with the single exception that young individuals placed on a table, by a window, seemed to crawl away from the light, but in adult individuals the light did not seem to make any difference. I have very frequently moved a stick or some bright object directly in front of the extended tentacles, as the animal was moving, but with no effect whatever. Often I have observed the animal running directly into an object, withdrawing its tentacles and changing its course only when the tentacles touched the object.

Smell. That the snail possesses olfactory organs admits no dispute, but the location of these organs has been a matter of doubt. $\mathrm{I}$ have had many snails in captivity for three years, and I have frequently experimented with them to determine what degree of olfactory sense they possess. After leaving them without food for several days, I have put in one corner of the box a small head of lettuce, concealing it by a few of the dead leaves. In a short time the snails would appear from under the leaves, and on the surface would raise the anterior portion of their bodies in the air, with extended tentacles, turning from one side to the other, having exactly the appearance of a quadruped sniffing the air in the endeavor to locate some object. Having decided on the position of the lettuce, they would invariably move directly toward it, and this sometimes from a distance of 18 inches. I have repeated this experiment again and again but always with the same result. It was impossible for the animals to see the lettuce on account of the screen of leaves, and, as previously asserted, I am satisfied that their power of vision is extremely limited, at least by daylight or by artificial light.

The discrimination in regard to food must be due also in a great degree to the sense of smell. I hare placed in my box of snails young beet leares, spinach and other tender regetables, which it would naturally be supposed would be acceptable to the snails; but they invariably refused to eat them, though deprived of other food, and in no case were these articles even tasted, showing, I think, that they were rejected on account of their odor.

It being admitted that they possess olfactory organs, it remains 
to locate them. Dr Leidy ${ }^{1}$ and Dr Sochaczewer, ${ }^{2}$ believed that the olfactory organs are situated in the pedal sinus.

The latter author made the following experiment:

Having cut off the tentacles of $H$ elix pomatia, the wound was allowed to heal. The snails were then placed on a flat plate, the edge of which was smeared with turpentine; both the mutilated and unmutilated specimens turned away from the edges; this shows that the tentaculae are not the seat of the olfactory organs.

I do not think that this experiment is at all conclusive, or in fact has any bearing on the matter, as the foot both of $\mathrm{H}$ eli $\mathrm{x}$ and of $\mathrm{Limax}$ is so extremely sensitive that on the first contact with any substance smeared with turpentine the animal would turn quickly away; the effect being essentially the same as if the animal had come in contact with heated metal. The fatal defect of this experiment is that the sensitiveness of the foot was not taken into consideration. I have tried the same experiment as far as surrounding the animals with turpentine, but they never turned away till they came in contact with the turpentine. If they turned away on account of the smell, they would do so before touching the turpentine.

If one observes a snail, when in motion, it will be seen that the superior tentacles are usually held, essentially, in one position, occasionally striking an object, apparently not seeing it; but the inferior tentacles are constantly in motion, and are bent down toward the object on which the animal is moving, but not touching it. Taking into consideration the limited power of sight, it seems to me that the snail must be assisted by the sense of smell.

That these tentacles have an important function to serve is evi. dent from their anatomic character. A large nerve proceeds from the principal of the cerebral or supra-esophageal ganglia, which connects at the extremity of the tentacle with a very conspicuous ganglionic swelling (pl. 13, fig. 4, 5), which gives off numerous nerve fibers to the extremity of the tentacle. That the tentacles are not tactile organs is evident from two facts; first, they would 
be unnecessary, as the foot is well supplied with nerves, and is very sensitive; second, though the tentacles are bent down toward the object on which the animal is moving, I have never seen them touch the object. Furthermore, the tentacular ganglia are anterior to all others, with the single exception of the ganglia of the superior tentacles, and are attached by their nerves to the cerebral ganglia, which, taken in connection with the anterior position of the tentacles themselves, corresponds to the position of the olfactory organs in vertebrates. When the tentacle is withdrawn, the olfactory sense still exists; the olfactory organ then closely corresponds to the olfactory organ of fishes. Negatively, the olfactory organ certainly does exist; but the nerves at the mouth, which have been considered by some authors as olfactory nerves, are undoubtedly nerves of taste; while the pedal sinus is clearly for the secretion of mucus, which the animal so abundantly exudes while in motion. Taking into consideration the anatomic details of the inferior tentacles, and innumerable observations of the use of these organs by the animal, I have no hesitation in affirming that they are olfactory organs.

In some forms of Gasteropoda no tentacles exist, and it will be interesting to determine whether in the absence of tentacles the olfactory sense is deficient. In relation to this Albany Hancock, ${ }^{1}$ says:

Being engaged at present in the investigation of the anatomy of some members of this family, my attention was naturally directed to this point, and I think that I have obtained satisfactory proof that these hornless animals have really the sense of smell highly developed. The head lobe in the Bullidae is, in fact, nothing else than the dorsal (superior) and labial (inferior) tentacles fused in one continuous mass. This Cuvier asserted long ago; and it can be very easily proved on anatomical grounds - . It may therefore suffice to say at this moment, that the nerves which supply the oral (inferior) and dorsal (superior) tentacles in the Gasteropoda go to this lobe, the former to the anterior and the latter to the posterior portion of it; a pretty clear proof of its real nature.

Hearing. The so-called auditory organs consist of two trans-

1 Ann. and mag, nat. hist. 1852 . 
parent vesicles, situated beneath the sheath of the supra-esophageal ganglia, one on each side, placed immediately on the ganglia and connected with nerves proceeding from the cerebral ganglia. They are extremely minute, and are filled with a transparent fluid, containing a number of small bodies, composed of concentric layers of carbonate of lime, frequently hollow at the center, called otoliths. During life, and for a short time subsequent, these bodies have a peculiar vibratory motion.

The size and situation of these bodies, and their nerves, would naturally lead to the conclusion that as auditory organs they would be of little, if any, use. As with Anodonta, I have tried numerous experiments to test the sense of hearing. Any noise which does not jar the animal, has no effect on it. And I have no hesitation in saying that the sense of hearing, if ever possessed, has been lost.

These remarks apply both to $\mathrm{P}$ ol y g y ra and to $\mathrm{Li} \mathrm{max}$.

Sense of direction. Snails in common with most animals, with the exception of man, have what has been called the sixth sense; that of direction or locality. I had for several months a large box, containing about one hundred snails, in one corner of my library. At the time I was making sections of shells to illustrate this work. I one day examined the snails in the box, and picked dut three which were to all appearances dead. These I took out for the purpose of making sections of the shell. Not having time then, I laid them on the window ledge, in the opposite corner of the room, about 12 feet from the box. Several hours later I looked for them, and, not finding them, thought they had been accidentally brushed from the ledge. Looking on the floor for them, I noticed the peculiar, glass-like trail made br a snail while moving. Then, examining carefully the spot where I had laid them, I found that, though apparently dead, they were alive, and I easily traced the three snails by their trails, which led in an absolutely straight direction to the box in which they had been kept, and I found them under the edge of the mosquito netting, which had been tied orer the box, as near to the interior of the box as it was possible for them to reach. Afterward I experi- 
mented several times by placing individuals in rarious parts of the room, and once in another room. They almost invariably returned to the box.

\section{LIMAX MAXIMUS $L$.}

The animal has a thick vermiform body, with a broad, ribbon. like pedal disk, having very much the appearance of the so-called foot of the Polyg y i a. The mouth, tentacles, etc., are situated as in that genus. The auterior part of the body is rounded. The posterior is acute and dorsally keeled.

The mantle is situated on the anterior dorsal part of the body, and is somewhat shield-shaped. The anterior margin is rounded; the posterior margin angular. It consists of a thick, fleshy membrane. The anterior part is free from the body, and, when the animal contracts, the head is concéaled beneath it, the mantle coming down before the head like a lnask. The posterior part is not movable. It contains the rudimentary shell, and covers the pulmonary chamber, heart and renal organ.

The respiratory orifice is situated on the right side of the mantle, about midway of its length; the mantle being notched or curved around the orifice.

The genital orifice is situated anteriorly on the right side as in Polyg y r.

The body is divided into two cavities; the smaller containing the pulmonary chamber, the heart, renal organ, and a part of the rectum, the larger containing the digestive and reproductive organs, the nerve ganglia and the principal muscles.

Lim a $x$ differs from Polygy a in that all the organs are contained in the vermiform body, corresponding to the foot of Polygyra, and in being possessed of only a flat, rudimentary shell. P o l y g y a resembles a $\mathrm{L}$ i m ax "with the greater portion of the mass squeezed out on the back, and arranged in a turbinate manner", and covered by a shell.

The integument consists of a thick mucous membrane, with a muscular substratum, as in the foot of $\mathrm{Pol}$ y g $\mathrm{y} \mathrm{a}$. It is nearly uniformly developed, but is thickest on the mantle, tail and pedal 
disk. On the head and upper part of the body, anterior to the tentacles, it is very thin.

The mantle and body have black markings, which vary in intensity on different individuals.

\section{Digestive system}

\section{Plates 15, 16}

The esophagus is very short, and has a diameter of about .6 $\mathrm{mm}$. It leads into the crop, somewhat abruptly expanding to a width of about $4 \mathrm{~mm}$ and continues essentially in a straight line for nearly three fourths the length of the body, slightly diminishing in diameter. It then contracts, quickly expanding to nearly its former diameter, to form the stomach, continuing for about one fifth the length of the previous part, gradually diminishing in size, then turning abruptly forward and ending in a position nearly parallel to the constricted part.

The intestine leaves the posterior part of the stomach, and proceeds anteriorly through the digestive gland, where it turns to the left, and, making a broad curve in the gland, again proceeds anteriorly, in contact with the previously described portion for a part of the distance; then, turning to the right, it forms a loop over the retractor muscles, near their origin; again proceeding posteriorly on the dorsal surface of the crop, nearly to the constrictor of that organ; again abruptly bending forward and continuing in contact with the last described part, passing under the pulmonary chamber, terminating at the anal aperture near the respiratory orifice.

The latter two convolutions are oblique to the crop and lie on its dorsal part. In nearly all the specimens which $I$ have examined they are empty and flat, even when all the other parts of the intestine are flled with the remains of food. They are very unlike the rest of the intestine in appearance. Their abrupt turning backward and simultaneous decrease in size, and their dissimilarity in appearance to the rest of the intestine are very misleading, and it requires careful dissection to show the continuity with the rest of the intestine, as they greatly resemble a cecum. 
Salivary glands. The salivary glands are situated on the anterior part of the crop, the one dorsally and the other latero-ventrally. They vary in shape and size (pl. 23, fig. 5,6 ) the dorsally situated one being the smaller. They consist of numerous lobuli, which are conglomerate. From each gland proceeds a conspicuous duct, which enters the buccal body, one on each side of the esophagus.

Digestive gland. The digestive gland consists of three principal lobes, divided into lobules. It, in conjunction with the ovotestis, occupies the posterior part of the animal, and also invests the greater part of the stomach, and the posterior lateral part of the crop. See plate 15 , figure 3 , for its position, and plate 23 , figures 7 and 8 , for its form.

\section{Generative system}

\section{Plates 15, 17}

The general appearance of the generative organs is the same as in $\mathrm{P}$ ol $\mathrm{y} \mathrm{g} \mathrm{y} \mathrm{r}$ a, varying only in details, with the exception of the orotestis.

The penis and anterior part of the other organs pass obliquely over the anterior part of the crop (pl. 15, fig. 2), a part of the uterine canal and spermatic duct lying vertrally and to the left of the crop. The ovotestis is situated at the posterior end of the animal, on the dorsal part of the digestive gland.

The penis is a long, cylindric body, comparatively much longer than in Polygyra albolabris. The posterior end is curved and bent on itself. It is destitute of the outer fold or so-called prepuce existing in $\mathrm{P}$. a l bolabris.

The retractor muscle of the penis is long andinserted, together with the vas deferens, on one side slightly anterior to the extremity.

When exserted, a thin, erect membrane is shown extending backward from the meatus; and also membranous folds at the meatus.

The vagina and receptaculum seminis are much smaller than in P. albolabris.

The vas deferens is short, its length being equal to or less than 
that of the penis. For about one half of its length it is thickened, annulated and glandular, becoming cylindric and filiform, entering the penis on the side, just anterior to the extremity.

The uterine canal is conspicuous, but does not present so distinctly a sacculated appearance as in P. a l bolabris.

The albumen gland is large, flattened, rounded at each extremity, broadest at the anterior, gradually diminishing to the posterior.

The hermaphroditic duct is short, Hexuous, but not conroluted, as in P. a lbol a bris.

The ovotestis consists of an oval, flattened mass, formed by an aggregation of ceca. It is nearly four times as long as wide; situated on the dorsal part of the posterior end of the digestive gland. It differs greatly from the ovotestis of $\mathrm{P}$ o $1 \mathrm{yg} \mathrm{g} \mathrm{ra}$.

\section{Circulatory system}

Plates 18, 19

Heart. The heart is situated at the lower left side of the pulmonary chamber. It consists of a single auricle and ventricle, each pyriform, placed base to base, the bases being truncated. The auricle is anterior to the ventricle and about one half its size.

Arteries. The aorta (pl. 18, fig. 1) proceeds from the apex of the ventricle, and almost immediately divides into two principal branches, the anterior and posterior of about equal diameter. The aorta divides before leaving the pulmonary chamber, giving the appearance of two aortae proceeding from the heart.

The anterior artery proceeds for a short distance lateralls, then anteriorly. It supplies the stomach, salivary glands, penis. receptaculum seminis, buccal body and nerve ginglia. At the ganglionic mass it turns abruptly backward, and proceeds along the middle of the ventral part of the animal, immediately above the pedal sinus; "ontinuing for about one half the length of the animal, then bifurcating and entering the foot.

Where the artery bends for ward a large branch is given off to the crop. This branch almost immediately subdivides, the principal branch froceeding anteriorly on the dorsal part of the crop. 
Near the esophagus it bifurcates, a branch proceeding to each of the salivary glands, and anterior part of the crop. In its progress to the anterior part of the crop it gives off four branches, two on each side of the crop. These branches in turn give rise to numerous others.

The second principal branch (3'), proceeds posteriorly for some distance, giving off comparatively few branches.

At the subdivision of the anterior and posterior crop arteries there are two smaller branches $\left(4,3^{\prime \prime}\right)$, the first of which proceeds to the uterine canal, the second directly to the ventral part of the crop, giving off several branches principally posteriorly.

At the ganglionic mass, where the aorta turns downward and backward, a branch continues forward under the buccal body (18), giving off small branches to the buccal body, muscles, lips, etc. Branches from the anterior artery accompany the commissural cords connecting the two principal ganglionic masses, forming a complete circle, as in P. a l b o la b r is (14), giving off branches to the tentacles (15).

Just previous to its turning backward the anterior artery puts out a branch, which subdivides and supplies the penis and vagina (11, 12).

The posterior aorta gives off branches to the stomach, intestine, digestive gland, uterine canal, hermaphroditic duct, ovotestis, etc. the first branch follows the course of the intestine, entering a lobe of the digestive gland, and ramifying through it. Very near this the artery gives off a branch, which proceeds along the hermaphroditic duct to the ovotestis. Two small branches have previously been given off to the hermaphroditic duct. Several small branches are now given off to the intestines at frequent intervals.

From the opposite side of the artery a branch proceeds to the upper attenuated end of the principal lobe of the digestive gland, giving off numerous branches throughout the lobe.

The next branch continues along the outer surface of the large lobe of the digestive gland, giving off numerous branchlets, which ramify throughout the lobe.

Immediately after the anterior artery bends abruptly toward the 
anterior portion of the animal, the large artery, which supplies the stomach, gives origin to a comparatively large branch to the digestive gland, and gives off numerous branches, both to the intestines and digestive gland. The next branch proceeds from the same side of the artery, continuing to the digestive gland, giving off numerous branches and finally forming a network in the lobes of the digestive gland (pl. 18; fig. 9).

The next branch is from the opposite side of the artery, and continues on the posterior part of the stomach. This branch is prominent. At about one half the distance from the artery to the ventral part of the stomach it bifurcates, one branch again bifurcating; one branch containing latero-anteriorly and the other dorsoanteriorly. The main branch continues to the ventral part of the stomach, bifurcating; the branches continuing mainly on the rentral part of the stomach.

The next prominent branch is from the opposite side of the artery. The principal artery of this branch continues to a lobe of the digestive gland, and ramifies through it; a smaller branch continues to the intestine.

The next conspicuous artery is from the large artery which supplies the uterine canal and the so-called prostate gland.

Pulmonary cavity. The pulmonary cavity lies below the mantle and is of essentially the same shape. It is situated immediately below the shell cavity, and contains the heart, renal organ, the posterior part of the rectum and the anus. It is separated from the visceral cavity by the muscular peritoneum or diaphragm.

The respiratory orifice is situated on the right side of the bods, at the edge of the mantle (pl. 23, fig. 1, 1). This orifice opens and closes at regular intervals; the normal respiration seems to be from 16 to 18 times a minute, though it is frequently variable. When open the orifice is circular, and is closed by muscular fibers which surround it.

The pulmonary veins, or rete, are situated mostly on the roof of the cavity. They are numerous, anastomosing, and occupy nearly the whole surface (pl. 19, fig. 2).

Veins. The veins are situated mostly in the substance of the 
body, not being on the surface as is frequently the case with the arteries. As in P. a I b o l a b r is, they are not simply lacunae or spaces in the body, but have a distinct wall.

The branches of the arteries grow smaller and smaller, and finally consist of an anastomosing network, which communicates with a similar network of veins; these capillaries gradually coalescing, forming larger branches, which combine to form large veins, connecting with the sinus of the pulmonary cavity. There are two veins parallel with, and in close contiguity to the pedal gland or sinus.

The two largest veins are situated in the integument of the sides of the body, one on each side. They are connected with the arteries by innumerable ramifications. They are illustrated on plate 18, figures 2 and 3 ; but only the large vessels are shown, the smaller ones not being represented. There are also smaller veins in the lateral anterior parts of the integument, and a large vein in the dorsal part of the integument.

The blood proceeds from the heart through the arteries, entering the veins from the arteries, and carried by them to the renal organ and the pulmonary cavity, where it is aerated, and returned by the large pulmonary veins to the auricle, thence to the ventricle.

Kidney. The kidney is situated in contiguity to the heart (pl. 19, fig. 3), and is a large subovate, glandular organ. From the lower right side proceeds a duct, which continues along the lower part of the pulmonary cavity to the rectum, continuing alongside of this; curving near the extremity, the parts of the curve being in apposition to the rectum, and opening in close contiguity to the anus.

\section{Nervous system}

\section{Plate 29}

The two principal ganglionic masses are the supra and infraesophageal $(1,2)$.

The supra-esophageal ganglia are situated above the esophagus, and just posterior to the buccal body, when the animal is extended. Of course when the animal is contracted the relative positions are altered. The ganglionic mass consists of three pairs 
of ganglia; the three pairs being united by an extremely short. broad commissural cord, which is very inconspicuous; the inner pair of ganglia having somewhat the appearance of coalescing.

The outer pair are larger than the others and somewhat obscurely kidney-shaped. The anterior margin being rounded and continuous; the posterior part being bilobed, the inner lobe larger than the outer.

The second, or median, pair of ganglia are in contact with the inner part of the first mentioned pair for their entire length. They are curved, broadest at the base, and tapering to a point, very narrow at their widest point.

The third, or inner, pair are nearly in contact at their anterior part, gradually diverging posteriorly. They are comparatively narrow, though twice the width of the second pair, and are about four times as long as wide. They are each obscurely divided into four lobes, of which the anterior is subtriangular, the posterior nearly round, and the remaining two subquadrangular.

The infra-esophageal ganglionic mass is much larger than the supra-esophageal, (2), and consists of six pair of ganglia, aggregated more or less in one mass.

With the exception of the first pair the ganglia are regularly bilaterally arranged; one of each pair being on opposite sides of a. median line.

The first pair consist of a large and a small ganglion, the larger one being ovate with a length about equal to twice its greatest diameter. Immediately anterior to this is a small ganglion, about one third the size of the first mentioned ganglion.

The next pair are situated one on each side, and partially underneath the first pair. They are subovate in form and are about one and one half times the size of the first mentioned pair.

The next pair are each about the size of the first mentioned ganglion, and are oval or subovate in form, and are situated mostly underneath the second pair, their anterior ends projecting. The posterior ends of the second pair project, laterally, beyond the third pair.

The fourth pair are subovate in form and situated beneath the second and third pair. 
The fifth pair are situated below the fourth pair. Their inner margins are nearly in contact.

The large cephalic artery passes through the ganglionic mass, bounded above and below by the third and fifth pair of ganglia, and laterally by the fourth pair.

The sixth pair are below the fourth and fifth pair of ganglia, and when the ganglionic mass is viewed from above are almost hidden from sight.

The ganglionic masses are connected by two pairs of commissural cords, the upper ones of which proceed from the second pair of the supra-esophageal ganglia, and continue to the under part of the fourth pair of infra-esophageal ganglia. The inferior pair of cords proceed from the posterolateral part of the lower lobe of the inner, or third pair of supra-esophageal ganglia, and continue to the lower part of the sixth pair of infra-esophageal ganglia.

Two smaller ganglia are situated near the dorsal surface of the posterior part of the buccal body, one on each side of the esophagus, just as it leaves the buccal body. They are comparatively small, a little less than three times as long as wide, and are divided into three nearly equal lobes, (3) the anterior one being broader and shorter than the other two, which are nearly round.

The two ganglia are connected by a strong commissural cord proceeding from the posterior lobes.

The buccal ganglia are connected with the cerebral ganglia by two commissural cords, which proceed from the under surface of the inner pair of cerebral ganglia, to the outer and under part of the anterior lobes of the buccal ganglia.

There are ganglionic swellings in the extremities of both the superior and inferior tentacles. That in each superior tentacle is digitate in form, the palm being exaggerated in size and the fingers short. From each of these processes, or fingers, numerous fibers proceed to the thin integument at the end of the tentacle. The ganglia of the inferior tentacles are pyriform, the largest end being nearest to the extremity of the tentacle, and giving off numerous fibers to the extremity of the tentacle.

A small ganglion is situated near the first branching of the 
aorta on the dorsal part of the stomach. It is subovate in form, gradually enlarging from its posterior to its anterior extremity, and is about four times as long as wide (4).

From the outer anterior part of the principal ganglia proceeds a stout nerve to the extremity of the superior tentacle (5). Within the tentacle this nerve gives origin to a slender nerve proceeding to the eye, the optic nerve. From a point closely contiguous to the first mentioned nerve, but nearer to the anterior margin, proceeds a nerve, smaller than the first, which near the anterior extremity of the animal bifurcates, one branch going to the mouth ( 7$)$, the other to the ganglia at the extremity of the inferior tentacle (6). From a point slightly nearer to the anterior margin proceeds a nerve, which near the mouth bifurcates and gives off nerves to the mouth and adjacent parts of the integument $\left(7^{\prime}\right)$. From the anterior lobe of the inner ganglia nerves proceed to the muscles and integument of the superior pair of tentacles (8). From the inner part of the principal ganglia proceed commissural cords, which unite with the anterior lobe of the buccal ganglia $\left(3^{\prime}\right)$.

The posterior lobes of the buccal ganglia are united by a short, broad commissural cord $\left(\Im^{\prime \prime}\right)$.

From the anterior lobe of each buccal ganglion arise two nerves, which proceed to the anterior part of the buccal body, giving off numerous branches (9).

From the inner part of each median lobe arises a nerve which continues posteriorly alongside the esophagus (10); and from the posterior lobe two nerves, which supply the posterior part of the buccal body (11).

The cephalic artery passes through the infra-esophageal gang. lionic mass, the ganglia forming a ring, and in an uninjected specimen might easily be mistaken for a large nerve.

From the posterior part of the dorsal ganglia proceed five nerves, three of which are of nearly equal diameter; the other two are smaller. The one to the left is free for a short distance, then buries itself in the substance of the retractor muscles, continuing to the origin of the muscles in the muscular layer. 
The median nerve is directed posteriorly to the right $\left(21,21^{\prime}\right)$, and furnishes nerves to the pulmonary cavity, respiratory orifice and anus.

The nerve from the right of the ganglion continues posteriorly to the large artery, entering the foot, to a minute oblong ganglion (4). The ganglion gives off five nerves, of which the larger arises in the outer anterior part, and proceeds along the intestine in close contiguity to the artery.

Immediately anterior to this is a small nerve proceeding to the pulmonary cavity.

From the opposite anterior part proceeds a nerve supplying the hermaphroditic generative organs.

From the posterior part proceed two nerves supplying the stomach and digestive gland.

In the inferior part of each of the second pair of infra-esophageal ganglia arises a large nerve which passes posteriorly and outward, entering the integument just anterior to the pulmonary chamber; the branches of these nerves supplying that organ and the heart.

From the posterior part of these ganglia proceed two very large nerves, which continue to the postero-basal part of the animal, parallel to and at a short distance from the pedal gland, giving off several branches to the base of the foot $\left(12,13^{\prime}, 13^{\prime \prime}\right)$.

In the inferior part of the other ganglia arise five other pairs of nerves (15-19), which are inserted in the integument at the sides; and other more numerous nerves, which are inserted in the foot.

\section{Muscular system}

Plates 19, 20

The principal muscles, viz, the retractor muscles of the anterior part of the body, the buccal body and the tentacles, have their origin in the inner muscular layer, just posterior to the pulmonary cavity on the right side.

They at first consist of two broad, flat, somewhat connected bands (pl. 19, fig. 1, 2). At about one half the distance to the nerve ganglia these bands are subdivided, giving origin to the 
ocular tentacular muscles (3), and the retractor muscles of the buccal body (5). The superior, or ocular tentacular muscles, shortly subdivide, giving origin to the muscles of the inferior, or olfactory tentacles (4), which are much smaller than those of the ocular tentacles.

The muscular sheath of the supra-esophageal ganglia is connected with the superior tentacular muscles by two flat muscular bands on each side (pl. 20, fig. 1, 2).

In the anterobasal part of the animal arises a set of three. muscles on each side (pl. 19, 20, fig. 1), the posterior one (1) arising under the muscles of the superior tentacle, and inserted near the lips of the animal. The middle one (8) is inserted in the muscles of the inferior tentacle. The anterior and largest muscle (9) passes over the superior tentacle muscles and is inserted at the mouth.

Posterior to these a muscle on each side has its origin in the basal part of the animal, and is inserted in the muscle of the inferior tentacle (10).

In figure 2, plate 20 , the retractor muscles have been cut close to the buccal body, and that organism has been turned forward to show its under side, and also the base of the anterior part of the body cavity.

On each side of a basal median line, and at a short distance from it, a thin, flat band of muscular fibres arises, which is inserted at the extreme anterior end of the body at the mouth, immediately below the anterior end of the buccal body (1). These two bands of muscles, at their anterior part cross each other at an angle of about $45^{\circ}$. Their function is to contract the basal part of the anterior portion of the body.

On each side of the buccal body the lower part of the lateral lips can be observed, showing as a white mass, somewhat regu. larly longitudinally divided. From the posterior part of each mass proceed two muscles, one broad, the other narrow, uniting with the muscles of the inferior tentacle (pl. 19. fig. 2, 3).

On the right side of the figure the lip and its muscles are shown in their natural position; on the left side of the figure the lip and 
its muscles, as well as the muscle of the inferior tentacle, are turned forward in order to show a short, broad muscle, which has its origin in the anterior basal part of the body, and is inserted principally in the muscles of the inferior tentacle, but some of the fibers are inserted in the large muscles of the lip (pI. 20, fig. 2, 4).

On the under side of the buccal body, toward the posterior part, are several moderately broad, horizontal bands of museles, which are partially concealed by overlying longitudinal muscles (10). Pands of muscles are situated on the ventral surface of the buccal body, proceeding from the posteroventral part and diverging to the sides $(6)$. Strong bands of muscles originate in the middle ventral part of the buccal body, and, slightly diverging, are inserted in the anterobasal part of the animal, just under the anterior part of the buccal body (5). A band of muscles is situated on each side of the buccal body, proceeding from the posteroventral to the anterolateral part of the buccal body (7).

Numerous fibers have their origin in the anterior part of the buccal body, and are inserted in the integument of the mouth. The entire outer walls of the buccal body are composed of muscular fibers, both transverse and longitudinal.

Looking down on the buccal body, the following muscles can be observed: a pair of delicate muscles, one on each side, arising in the inferior posterolateral part of the buccal body, and inserted in the cephalic integument; another delicate pair arising in the anterolateral part of the buccal body, and inserted in the integument, near the base of the inferior tentacles; a pair which proceed laterally from'the anterior basal part of the buccal iody, being inserted in the integument each side of that body.

The integument or skin of the animal is composed of two layers, the inner of which is composed of interlaced muscular fiber; and the viscera are inclosed by a very thin muscular peritoneum. The first layer is composed of unstriped muscular fibers, arranged transversely, longitudinally and obliquely.

The peritoneum is composed of muscles arranged transversely and longitudinally, and gives rise to the retractor muscles previously described. 


\section{EMBRYOLOGY OF LIMAX MAXIMUS}

When the ova have reached a certain stage of maturity they leave the ovary. This process is known as ovulation. They pass through the hermaphroditic duct (pl. 16, fig. 1, 10), to the albumen gland (9), and thence to the oviduct ( 7 ); from which they are discharged, that is, laid.

The composition of the egg is as follows: in the interior of the egg is the germinative vesicle, or egg nucleus, which contains a still smaller vesicle, or germinative dot; surrounding these is the yolk, which is a liquid of varying consistency. In the snail it is transparent. These parts of the egg are formed in the ovary. The albumen surrounds the yolk, and in the case of $\mathrm{Limax}$ is semitransparent, less so than the yolk. This substance is not formed in the ovary, but is secreted by the albumen gland (pl. 16, fig. 1,9). The albumen is surrounded by a membrane, which in L imax is semi-transparent, so that, when the egg is viewer under the microscope by transmitted light, the movements of the embryo can be observed, though not distinctly enough for study.

In the eggs of the Polygyra the outer covering is still membranous, though much thicker than in $\mathrm{Limax}$, and it is opaque. After the escape of the young $\mathrm{P}$ o I y g y ra, it has very much the appearance of a calcareous shell.

Soon after fertilization the egg undergoes the process of segmentation, that is breaks up into cells. It first divides into four equal cells; and then smaller cells are formed from the division of the first four, so as to lie outside of them. The smaller cells now subdivide and spread over the first four. The cell mass is dilated, becoming hollow. The Iarge cells subdivide and sink into the hollow of the sphere, forming an elongated groore, the origin of which at the surface is known as the blastopore. This orifice subsequently closes up. The invaginated cells, formed by the subdivision of the large cells, are known as the endoderm. The outer layer, formed by the division of the smaller cells, is known as the ectoderm. This condition of the egg forms the gastrula stage (pl. 24, fig. 10-14).

A dilatation of the ectodermal walls now takes place, a con. 
siderable space being left between the ectoderm and endoderm (pl. 25, fig. 6 and succeeding figures).

The body of the animal as first observed consists of a slight swelling of the upper side of the cell mass (pl. 25, fig. 7).

In the following descriptions it must be remembered that the ventral surface of the animal is uppermost.

The swelling above mentioned very soon shows a tendency to divide into two parts (pl. 25, fig. 9, and pl. 24, fig. 17), the anterior part of which is the foot proper, the posterior part the mantle, shell sac, etc.

Even at this early stage the embryonic shell can be observed, consisting of a few dark colored crystalline plates, not yet united.

At this stage the mouth appears at the position formerly occupied by the blastophore; which has disappeared or been closed, and consists of an invagination of cells, bounded by lateral lips (pl. 24, fig. 20).

The shell sac and mantle enlarge much the faster proportionally, as shown in plate 25, figures 11, 12 .

In figure 12, and more distinctly in figure 13, the development of the tentacles is shown, which at this stage have the appearance of flat circular disks.

The body is very small; from its extremity a circular semitransparent appendage, the podocyst, is developed, consisting of two walls, which are connected by reticulated muscular cells. The body now rapidly develops, as shown in figures 15 and 16, plate 25.

The shell has also increased in size, consisting of numerous crystalline plates, not yet united.

The ectodermal sac and podocyst have also increased in size. The surface markings are now apparent, and the beating of the heart is plainly visible beneath the mantle.

The smaller tentacles, the lateral lips of the mouth, the odontophore and the beginning of the alimentary canal have appeared; the pedal sinus is also apparent.

At this stage (pl. 25, fig. 17-21), the ectodermal sac and podocyst have reached their greatest development, and hereafter gradually diminish in size till completely absorbed. 
The podocyst is now an object of great beauty, to which no drawing can do justice. It undergoes a rhythmic movement of dilatation and contraction, sometimes being so expanded as to include the rest of the embryo, then contracting to less than one half that size. The ectodermal sac also undergoes a similar contraction and expansion, sometimes in harmony with, and again alternating with that of the podocyst.

The whole embryo, from the stage represented by figure 11, has a rotatory motion.

In the stage represented by figure 19, I have first observed the "primitive kidneys." They are situated on each side of the endoderm, and consist of a series of curved elongate cells, within which concretions are developed, and terminate in a duct (pl. 28, fig. 4).

The cells proper are apparently angular or of different shapes (pl. 28, fig. 1, 2); but this is due to mutual pressure, as when the sac is ruptured the cells flow out perfectly spherical, as shown in figure 3.

As development proceeds a movement of the cells takes place from the ectodermal sac into the constantly enlarging body (pl. 26, fig. 1). The alimentary canal accompanies the cells; the anus alone remains in its original position.

In the stage represented by figure 5, plate 26 , the ectoderm so closely bounds the endoderm as not to be apparent. The ectodermal cells have been largely absorbed into the body, or, rather, changed into body tissue, and the podocyst is very much reduced in size. The tentacles are assuming their mature form, and the mouth and lips are very distinct. The intestine is nearly complete and the larger endodermal cells have, in great part, been converted into the substance of the digestive gland. The respiratory orifice, the mantle and shell are well formed.

Heretofore the embryo has been represented with the ventral part uppermost, but in figure 2 , plate $2 \bar{T}$, it is represented, in a reverse position, as in adult condition.

In this stage the endodermal cell mass has been almost entirely changed into the alimentary canal and its appendages, the podo- 
cyst has been almost entirely absorbed, and the various organs are approaching their perfect condition. Figure 1, plate $\mathbf{2}$, represents the appearance of the embryo in the egg capsule at this stage (8). The absorption of the podocyst continues for a short time longer, when the animal becomes completely formed and emerges from the egg.

A careful study of the figures on plates 24-28, and their explanations, will perhaps show more clearly the development of the embryo than the preceding text.

It occasionally happens that there are two ova in one egg capsule, and in one instance I have observed four embryos in one egg capsule (pl. 27, fig. 4, 5).

\section{Time of laying eggs}

In the latter part of September I had a number of specimens sent to me. Within a very few days a majority of them laid eggs. Of course the very short time of confinement, only two or three days, made no difference in the time of laying. Others did not lay their eggs till the middle of November, when naturaily they would have been hibernating for a month. It would seem therefore that some of the animals lay their eggs in the fall, and others not till the following spring.

The eggs are laid on the surface of the ground, under dead leaves, logs, stones, or any sheltered space, where the requisite moisture can be obtained. They are laid in a cluster. The number in the clusters observed by myself varied from 50 to 130 . They are soft and before leaving the animal must be very much compressed; for a mass of eggs occupies a larger space than the animal itself. When first laid they are of beautiful appearance, semi-transparent, resembling globes of liquid. Light transmitted through them becomes a beautiful golden color. They are usually round, but sometimes oval, and when they are in apposition a part is frequently pressed in till it is concave, but, as the embryo grows, this part is pushed out, the egg becoming regularly round or oval.

It would seem probable that all eggs laid at the same time 
would hatch out at about the same time, but I had several clusters of eggs laid within 24 hours of each other, kept in the same box, and necessarily under the same conditions, and when some of these were hatched out, the embryos of other clusters were not more than half developed. This statement has been questioned, but I am absolutely sure of the correctness of my observations in this respect.

Several of the clusters had not been fertilized, as shown by the non-development of the embryo.

Binney declares that eggs that had been several times subjected to a great heat in an oven, so as to become perfectly dry and shriveled, when placed in a moist place regained their lost form, and young were produced from them. While not doubting this statement, my experience has been that, when the egg became dry and shriveled, the embryo was killed; though when supplied with moisture the vitality under adverse circumstances was wonderful.

Embryos that I have dissected from the egg and placed in water retained life from 24 to 48 hours. Even when the power of motion was lost, the heart continued to beat.

\section{Rate of growth}

Even under the same conditions the rate of growth of all the animals is not uniform. I have at this writing more than 100 animals that were hatched at about the same time. They have been kept in the same box and of course under the same condi. tions. But they vary decidedly in size, some being not more than half the size of others.

At least two seasons are required for an animal to reach maturity. I have now specimens that were hatched nearly 10 months ago, which have been kept in a warm room during cold weather, therefore not hibernating, and supplied with an abundance of food; yet some of them are not half grown. They prob. ably developed as rapidly as in natural conditions. Naturally they would hibernate during cold weather, and the growth would not be as great in 10 months as in confinement. 


\section{EXPLANATION OF PLATES}

\section{Polygyra albolabris}

PLATE 1,

FIG.

1-3 Dorsal, profile and ventral views of an adult shell, natural size.

4 A profile view, showing a more flattened form than in fig. 2.

5, 6 Ventral and profile views of a young shell, the peristome being as yet unformed.

7 Ventral view of an adult shell, showing the form of the under side of the peristome.

8 Profile view of a shell just after leaving the egg, $\mathrm{x} 10$, the perpendicular line to the left of the figure showing the natural size. Figures 9, 10 and 11 are also enlarged, the perpendicular lines to the left of the figure showing the natural size as in fig. 8 .

9-11 Showing succeeding stages of the form of the shell before reaching maturity.

12 An adult shell.

13 In this figure a part of the lower volution of the shell is broken away to show the interior.

14 A section of a shell. The outer part of the shell is ground away in order to show the columella.

15 A section. The columella has been ground down to show its interior.

FIG.

PLATE 2

1 An egg natural size and enlarged.

2 A view showing the shell within the egg.

3 A view showing the shell emerging from the egg.

4 Dorsal and profile views of a shell, newly hatched, natural size and enlarged. 
FIG.

5, 6 Profile and ventral views of a shell about one month old, natural size and enlarged.

7 Dorsal and lateral views of a shell about three months old, natural size.

8,9 The same, $\times 3$.

10 Surface of the shell, $\mathbf{x} 10$.

11 The same, $\mathrm{x} 20$.

12 Transverse section of the prismatic layer of the shell, $\mathbf{x} 100$.

13 A section of a part of the peristome, $\mathrm{x} 40$.

14 A section of the peristome and a part of the shell, $x 10$.

15 A section of the shell; cuticle; outer layer; median larer; inner layer.

16 A section of the volutions, $x 2$.

17 One volution more highly magnified, $\mathrm{x} 6$.

18 A transverse section of the peristome, $\mathrm{x} 2$.

\section{PLATE 3}

FIG.

1 Dorsal view of a shell and extended animal. The smaller figure represents a newly hatched animal. Both figures are natural size.

2 Profile view of shell and extended animal, natural size.

3 An animal from which the shell has been removed, showing protruding penis; 1 penis; 2 anus: 3 stomach; 4 orotestis; 5 intestine; 6 digestive gland; 7 kidney : 8 pulmonary vein.

4 The same view as in figure 3 , the volutions being partially uncoiled to show the position of the generative organs. For explanation of the organs see plate 2.3 , figure 9 .

5 Ventral view, the animal being retracted within the shell; 1 , respiratory orifice.

6 Laterobasal surface of the integument, $\mathbf{x} 6$.

7 A part of the integument of the dorsal part of the foot, $x 6$. 


\section{PLATE 4}

FIG.

1 The buccal body, enlarged, from above; 1 the buccal body; 2 esophagus; 3 salivary ducts; 4 nerves uniting cerebral and buccal ganglia; 5 retractor muscles; 6 depressor muscles; 7 levator muscles; 8 protractor muscles; 9 labial muscles.

2 The buccal body. The dorsal wall is cut through, and separated, displaying a part of the interior; 1 buccal body; 2 muscular wall of the buccal body; 3 lateral lips; 4 radula, or lingual ribbon; 5 sac of radula; 6 esophagus; $\gamma$ salivary duct.

3 The buocal body laid open, from above; 1 lateral lips; 2 muscular wall of the buccal body; 3 odontophoral cartilage; 4 radula; 5 sac of radula; 6 retractor muscles.

4 Longitudinal section of the buccal body; 1 odontophoral cartilage; 2 radula; 3 sac of radula; 4 muscular wall; 5 jaw or dental plate; 6 esophagus; 7,8 muscles connected with the radula; 9 opening of the pedal sinus; 10 pedil sinus; 11 muscular sole of animal; 12 infra-esophageal ganglia; 13 supra-esophageal ganglia; 14 retractor muscles; 15 tentacular muscle.

5 A section of the animal showing: 1 pedal sinus; 2 large veins; 3 small veins; 4 mucus glands; 5 muscular sole of foot.

6 Perpendicular section of the buccal body; 1 esophagus; 2 salivary ducts; 3 lingual ribbon or radula; 4 sac of radula; 5 odiontophoral cartilage.

7 Vertical section, the same as figure 6, the esophagus, etc., have been removed, bringing into view the radula; 1 radula; 2 odontophoral cartilage. 
PLATE 5

FIG.

1 A view from the under side of the head, showing the mouth and lips, $\times 5$.

2 The jaw, $x 10$.

3 The digestive organs; 1 the buccal body; 2 esophagus; 2 ' the crop; 3 salivary ducts; 4 salivary glands; 5 stomach; 6 intestine; 7 rectum; 8 anus; 9 digestive gland; 10 ducts of digestive gland; 11 ventricle; 12 auricle; 13 pericardium; 14 kidney or renal organ all $\times 2$.

4 Crop and salivary gland, $\mathrm{x} 6$.

5 Heart and kidney as seen from the exterior.

FIG.

\section{PLATE 6}

The lettering on each of the figures refers to the same organ.

1-6 Transverse sections of the body from the buccal body to near the posterior extremity of the foot.

1 genital opening; 2 penis; 2 ' sac of radula; 3 esophagus; 4 salivary duct; 5 tentacular muscles; 6 vas deferens; 7 peritoneum; 8 pedal sinus; 9 oviduct; 10 ragina; 11 uterine canal and spermatic duct; 12 the mantle.

7 The stomach and a part of the intestine as seen from above.

8 The stomach as seen from below, showing also the ducts of the digestive gland and their connection with the stom. ach.

\section{PLATE 7}

\section{Generative organs}

FIG.

11 genital aperture; 2 penis; 3 onter fold or prepuce; 4 vagina; 5 receptaculum seminis; 6 vas deferens; 7 free oviduct; 8 uterine canal; 9 spermatic duct; 10 talon, or accessory gland of the hermaphroditic duct; 11 hermaphroditic duct; 12 ovotestes; 13 retractor muscle of the penis; 14 albumen gland, all $\times 3$. 
FIG.

2 An enlargement of a part of the generative organs: $1 \mathrm{her}$ maphroditic duct; 2 talon; 3 albumen gland.

3 Accessory gland, or talon, seen from above, $x 6$.

4 The same as seen from below, х 6 .

5 The orotestes, $x 5$.

6 The cecal tubes of the ovotestes, $\times 30$.

7 A transverse section of the ceca of the ovotestes, showing the spermatic within the ovarian tube, $\mathrm{x} 30$.

\section{PIAATE 8}

Frg.

1 An exterior view of the penis, $x 3$.

2 A longitudinal section of the penis, showing the corrugated fold, or pilaster, of the interior, and the manner of the formation of the outer fold, or prepuce, $\mathrm{x} 3$.

3 The penis opened from the dorsal part, showing the corrugations of the lining membrane, and the corrugated fold, pilaster, of the membrane, $\mathbf{x} 3$.

4 A part of the corrugated and papillate lining membrane, $\times 10$.

5 A transverse section of the vas deferens, $\mathbf{x} 6$.

6 A tranverse section of the vas deferens, showing its entrance into the penis, $\mathbf{x} 6$.

7-9 Sections of the penis, figure 9 being beyond the pilaster, $\mathbf{x} 6$.

10 An exterior view of the vagina and receptaculum seminis, $\mathrm{x} 4$.

11 A longitudinal section, showing the muscular folds of the vagina, $\mathbf{x} 4$.

12 A transverse section of the vagina, and of the oviduct at its entrance into the vagina, $\mathrm{x} 6$.

13 A transverse section of the vagina at the point indicated by the dots in figure $11, \times 6$.

14 A transverse section of the receptaculum seminis, $\mathbf{x} 6$. 
PLA'TE 9

Arteries

Oirculatory system, 1 auricle; 2 ventricle; 3 posterior aorta; 4 anterior aorta; $3^{\prime}$ artery to albumen gland; $3^{\prime \prime}$ artery to digestive gland; 6 artery to stomach; 7 artery to hermaphroditic duct; 8 artery to uterine canal and spermatic duct; 9 artery supplying muscular collar, pedal muscles and crop; 10 artery to pedal muscles; 11 artery - to muscular collar; 12 artery supplying crop; 13 arteries to salivary ducts; 14 artery to base of foot; 15 artery supplying nerve commissures; 16 arteries to the tentacles; $16^{\prime}$ artery to buccal body; 17 artery to vagina; 18 artery to the penis; 19 artery to the intestine; 20 artery to the ovotestes.

\section{PLATE 10}

FIG.

11 Pericardial cavity; 2 auricle; 3 ventricle, $x 6$.

2 Showing the stomach and under or inner face of the digestive gland, and the arteries supplying that part of the animal: 1 auricle; 2 ventricle; 3 stomach; 4 intestine; 5 ducts of digestive gland; 6 artery to the smaller or superior lobe of the digestive gland; 7 arteries to the orotestes; 8 kidney; 9 rectum; 10 digentive gland, $\mathbf{x} 3$.

3 The outer part of the digestive gland and its arteries.

The numbering has the same signification as in figure 2.

4. The stomach and its arteries, $\mathbf{x} 3$.

5 The crop and salivary gland and their arteries, $x 3$.

6 Showing the arteries of the ceca of the ovotestis.

FIG.

PLATE 11

1 An enlargement showing the heart and the veins of the pulmonary cavity: 1 auricle; 2 ventricle; $\$$ the large pulmonary vein leading to the auricle; \& the afferent veins; 5 the efferent reins; 6 the large vein or venus kinus incircling the pulmonary carity. 
FIG.

2-4 Figures showing the position of the pulmonary cavity, in relation to the volutions of the animal.

\section{PLATE 12}

Nervous system

$a$ supra-esophageal or cerebral ganglia; $b$ infra-esophageal ganglia; c commissures connecting the supra andinfra-esophageal ganglia; $d$ nerves to the ocular or superior tentacles; $e$ ganglionic enlargement at the extremity of the ocular tentacles; $f$ optic nerve; $g$ eje; $h$ nerves to olfactory, or inferior, tentacles; $i$ ganglionic enlargement at the extremity of the inferior tentacle; $k$ nerve to mouth; $l, m$ nerves supplying the mouth and adjacent parts; $n$ buccal ganglia; $o$ commissural cords connecting the supra-esophageal and buccal ganglia; $p$ nerves supplying the generative system and the visceral mass; $r$ nerves to the muscular collar and pulmonary cavity; $s$ nerves supplying the basal parts of the animal; $t$ nerves supplying the laterobasal parts of the foot; $u$ nerves to the integument on each side.

\section{PLATE 13}

The same lettering refers to the same muscles in each figure. FIG.

1-2 The retractor muscles of the buccal body, foot and tentacles enlarged. 1 retractor muscles of the buccal body; 2 retractor muscles of the foot; 3 retractor muscles of the ocular tentacles; 4 muscles continuing to the lips and tentacles; 5 muscles of olfactory tentacles; 6 muscles of mouth; $\%, 8,9$ muscles of the buccal body; $\gamma$ levator muscle; 8 protractor muscle; 9 depressor muscles. Figure 1 shows the muscles as seen from above; figure 2 is a lateral view.

3 An enlarged section of the tentacles: 1 integument; $2, \mathscr{2}^{\prime}$ tentacular muscles; 3, 3' tentacular nerves; $4,4^{\prime}$ tentacular ganglia; 5 optic nerve; 6 eye; 7 muscles to the mouth; 8 nerves to mouth. 
Fig.

4 An enlargement of the ganglion of the ocular tentacles, optic nerve and eye, x 12.

5 An enlargement of the nerve and ganglion of the olfactory tentacle, $\mathbf{x} 12$.

6 Cryptoicus minutissimus, highly magnified.

PLATE 14

Polygyra albolabris dissected and the organs separated: 1 buccal body; 2 esophagus; 3 crop; 4 stomach; 5 intestine; 6 rectum; 8 anus; 9 superior lobe of digestive gland; 10 inferior lobe of digestive gland; 11 ducts of digestive gland; 12 salivary ducts; 13 salivary glands; 14 penis; 15 vagina; 16 receptaculum seminis; 17 retractor muscle; 18 glandular portion of the vas deferens; 19 vas deferens; 20 spermatic duct; 21 uterine canal; 22 spermatic duct; 23 albumen gland; 24 hermaphroditic duct; 25 accessory gland of duct, or talon; 26 ovotestes; 27 renal organ or kidney, the primary ureter along its upper side; 28 secondary ureter; 29 opening of ureter, or renal duct; 30 ventricle; 31 auricle; 32 pericardiac cavity; 33 pulmonary vein; 34 large blood vessel connecting with pulmonary rete; 35 pulmonary rete; 36 supra-esophageal ganglia; 37 tentacular nerve; 38 nerves to mouth and inferior tentacle; 39 superior tentacles; 40 integument; 41 muscles from buccal body of integument; 42 superior tentacular muscle; 43 inferior tentacular muscle; 44 retractor muscles; 45 muscular peritoneum; 46 muscular collar; 47 cephalic artery; 48 nerve to muscular collar.

\section{PLATE 15}

\section{Limax maximus}

The same letters apply to the same organ in each figure. FIG.

1 The dorsal part of the integument is cut and turned back, showing the various organs in position.

2 The pulmonary chamber, heart, etc. are turned back, showing the under side of the organs, and the parts concealed by them in figure 1 . 
FIG.

3 The organs are separated, and each organ is shown more distinctly. 1 buccal body; 2 salivary ducts; 3 salivary glands; 4 crop; 5 intestines; 6 rectum; $\gamma$ stomach; 8 digestive gland; 9 penis; 10 retractor muscle of the penis; 11 receptaculum seminis; 12 uterine canal; 1 $\mathbb{2}^{\prime}$ spermatic duct; $12^{\prime \prime}$ albumen gland; 13 hermaphroditic duct; 14 orotestes; 15 nerves to the basal part of the body; 16 large veins in the integument of the sides of the animal; 17 ventricle; $17^{\prime}$ auricle; 18 kidney; 19 duct of kidney; 20 pulmonary veins; 21 respiratory orifice; 22 insertion of retractor muscles; 23 tentacular muscles; 24 mantle; 25 integument; 26 arteries.

PLATE 16

FIG.

1 The under side of the head, showing the mouth; 1 anterior or upper lip; 2 lateral lips; 3 four corrugations of the integument surrounding the mouth; 5 triangular appendages.

2 View from above, the integument and dorsal part of the basal body cut open and turned back: 1 corrugations of the integument surrounding the mouth; 2 lateral lips; 3 buccal body; 4 jaw; 5 radula; 6 esophagus; 7 salivary ducts; 8 muscles of ocular tentacle; 9 muscles proceeding from the anterobasal part of the animal, and in. serted in the olfactory tentacular muscle; 10 muscle proceeding from the anterobasal part of the animal to the mouth; 11 muscles of the olfactory tentacles; 12 muscles from integument to anterior part of buccal body; 13 penis.

3 Digestive organs, etc.: 1 buccal body; 2 esophagus; 3 salivary ducts; 4 salivary glands; 5 crop; 6 stomach; 7 intestine; 8 rectum; 9 anus; 10 arteries, $\mathrm{x} 3$.

4 Enlargement of the under side of the upper salivary gland.

5 Dorsal view of an adult individual. 
FIG.

6 Transverse section of a specimen: 1 mantle; 2 envelop of the shell; 3 shell; 4, 5 pulmonary veins; 6 pulmonary cavity; 7 mucous part of the integument; 8 muscular substratum of integument; 9 muscular peritoneum; 10 muscular and mucous basal integument; 11 visceral cavity.

PLATE 17

Generative organs

FIT.

11 genital opening; 2 penis; 3 vas deferens; 4 spermatic duct; 5 retractor muscle of the penis; 6 receptaculum seminis; $\gamma$ free oviduct; 8 uterine canal; 9 albumen gland; 10 hermaphroditic duct; 11 ovotestes.

2 Penis retracted, $\mathbf{x} 3$.

3 Penis exserted, $\mathbf{x} 3$.

4 Orotestes, $\mathbf{x} 4$.

5 Ceca of the orotestes, enlarged.

6 A still farther enlargement of the ceca.

7 A transverse section of the penis and ras deferens, $\mathbf{x} 6$.

\section{PLATE 18}

Circulatory system, $\mathrm{x} 3$

FIG.

11 aorta as it leaves the ventricle; 2 anterior aorta; 3 arteries to the crop; 4 arteries to the uterine canal; $3^{\prime \prime}$ arteries to the stomach, intestine and digestive gland; 5 artery to the lower salivary gland; 6 artery to upper salivary gland; 7 posterior aorta; 8 arteries to the intestine; 9 arteries to the digestive gland; 10 artery to ovotestes; 11 artery to penis; 12 artery to vagina and receptaculum seminis; 13 artery to buccal body; 14 artery to commissural cords; 15 arteries to tentacles; 16 artery to basal part of the body. 
FIG.

2-3 Large lateral veins situated in the integument on each side of the body. Only the larger veins are shown, but they are connected with the arteries by a fine network of veins and capillaries, $\mathbf{x} 3$.

4 Showing the arteries and veins of the large lobe of the digestive gland, $\times 3$.

51 pedal sinus; 2 lateral veins.

11 origin of retractor muscles; 2 principal muscular bands; 3 retractor muscles of the ocular tentacles; 4 retractor muscles of the olfactory tentacles; 5 retractor muscles of the buccal body; 6 muscles proceeding from the olfactory tentacular muscles to the mouth; 7 muscles proceeding from the anterobasal part of the animal to the mouth; 8 muscles proceeding from the anterolateral part to the olfactory tentacular muscles; 9 muscles proceeding from the anterolateral parts of the animal to the mouth; 10 muscles proceeding from the anterobasal part to the olfactory tentacular muscles; 11 muscular fibers from the buccal body to the mouth.

2 Pulmonary veins, $\mathrm{x} 4$.

3 Under side of the pulmonary cavity, x 4: 1 auricle; 2 ventricle; 3 pulmonary veins; 4 respiratory orifice; 5 kidney; 6 duct or secondary ureter of kidney; 7 anus.

\section{PLATE 20}

Muscular system, $\mathbf{x} 6$

Fig.

11 buccal body; 2 muscular sheath of ganglia; 3 muscles of the ocular tentacles; 4 muscles of olfactory tentacles; 5 muscles arising in the basal part of the animal and connecting with the olfactory tentacular muscles; 6 muscles arising in the olfactory tentacular muscles and connecting with the mouth; 7 muscle arising in the basal part of the animal, beneath the ocular tentacular 
FIG.

muscles and connecting with the mouth; 8 muscles arising in the anterobasal part and connecting with the muscles of the olfactory tentacles; 9 muscles arising in the anterobasal part and connecting with the mouth; 11 muscular fibers from the buccal body to the lips; 12 muscles of the buccal body; 13 esophagus; 14 salivary ducts.

2 Buccal body turned back to show the muscles beneath: 1 broad oblique bands of muscles arising in the anterobasal part and inserted in the extreme anterior part of the animal; 2 ocular tentacular muscles; 3 olfactory tentacular muscles; 4 muscles arising in the anterobasal part of the animal, and inserted in the ocular tentacular muscles; 5 muscles arising on the under side of the buccal body and inserted in the lips; 6 oblique muscles of the under side of the buccal body; 7 retractor muscles of the buccal body; 8 retractor muscles; 9 pedal sinus and bordering veins.

\section{PLATE 21}

The numbering of the horizontal lines corresponds to that of the figures. The same lettering refers to the same organ in all the figures.

Transverse sections of $\mathrm{Limax} \mathrm{maximus,} \times 3$. An outline showing the position of the sections.

The section, figure 1 , was made at the place designated by line 1 , and so on to figure 12 .

0 salivary ducts; 0 ' salivary glands; 1 mantle; 2 shell cavity; 8 shell; 4 kidney; 5 heart; 6 penis; 7 arteries; 8 receptaculum seminis; 9 uterine canal, spermatic duct and albumen gland; 10 crop; $10^{\prime}$ intestine; $10^{\prime \prime}$ esophagus; 11 rectum near anus; 12 pulmonary vein; 13 respiratory orifice; 14 pedal sinus; 15 large lateral veins; 16 smaller lateral veins; 17 veins contiguous to and parallel with the pedal sinus; 18 digestive gland; 19 hermaphroditic duct; 20 ovotestes; 21 ocular tentacular muscles; 20 cartilaginous cushion supporting radula; 22' radula. 
PLATE 22

Nervous system

1 supra-esophageal ganglia; 2 infra-esophageal ganglia; 2 commissural cords connecting the supra- and infra-esophageal ganglia; 3 buccal ganglia; 3 ' commissural cords connecting the cephalic or supra-esophageal and the buccal ganglia; $3^{\prime \prime}$ commissural cord uniting the buccal ganglia; 4 stomachic ganglia; 5 nerves to the ocular tentacles; 6 nerves to the olfactory tentacles; $\gamma$ nerves to the mouth; $\gamma^{\prime}$ nerves to the lips and adjacent integument; 8 nerves to the integument of the integument of the ocular tentacles; 9 nerves to the anterior part of the buccal body; 10, 11 nerves to the posterior part of the buccal body; 12 large nerves running to the posterobasal part of the animal; $19,1{ }^{\prime}$ branches of the preceding; 14, 15 nerves from the pedal ganglia to the basal part of the body; 16-19 nerves from the pedal ganglia to the sides of the body; 20 cord connecting pedal and stomachic ganglia; 21 nerve to retractor muscles; 22 nerve to pulmonary cavity.

\section{PLATE 23}

FIG.

1 A profile view of a small specimen of $\mathrm{Limax} \operatorname{maxi-}$ $\mathrm{m}$ u s : 1 respiratory orifice; 2 genital orifice.

2 The radula, profile view, $\times 6$.

3 The same, as seen from above, $\mathbf{x} 6$.

4 The jaw and its retractor muscle, $\mathrm{x} 6$.

5 Dorsal view of upper salivary gland, $\mathrm{x} 3: 1$ salivary duet; 2 arteries; 3 nerves; 4 artery to the stomach.

6 Lower salivary gland: 1 salivary duct; 2,3 arteries; 4 nerve, $\mathbf{x} 3$.

7 The digestive gland detached from the intestine, etc. dorsal view, $\times 3$.

8 The same as seen from below; the points $a$ are in apposition when the gland is in its natural position: 1 hermaphroditic duct; 2 arteries. 
FIG.

9 Polygyra albolabris, showing the generative organs in situ: 1 genital opening; 2 penis; 3 vagina; 4 vas deferens; 5 spermatic duct; 6 uterine canal; 7 talon; 8 albumen gland; 9 hermaphroditic duct; 10 ovotestes; 11 salivary gland; 12 stomach; 13 rectum; 14 beginning of rectractor muscles; 15 buccal body; 16 tentacular muscles.

\section{PLATE 24}

FIG.

1 A group of eggs, natural size.

2-5 Various forms of eggs, $\mathrm{x} 4$.

6, 7 Transverse sections of round and oval eggs.

8 The germinative vesicle, $x 48$.

9 The under side of the germinative vesicle at the beginning of segmentation, $\mathbf{x} 48$.

10, 11 The ovum during segmentation as seen from above, $\mathbf{x} 48$.

12 A side view of the same, $x 48$.

13 The segmented mass as seen from below, showing blastopore, endoderm and ectoderm, $\mathbf{x} 48$.

14 A vertical section of the same, showing 1 the blastopore; 2 the archenteron; 3 cleavage cavity; 4 ectoderm; 5 endoderm.

15 Cells. The dark cells are from the ectoderm; the light from the endoderm, $\times 250$.

16 Showing the endodermal cell mass surrounded by a transparent sac or wall, $\mathrm{x} 32$.

17 Showing the early stages of the formation of the foot and shell sac, $\mathrm{x} 32$.

18 A stage slightly more advanced, showing the beginning of the tentacles and shell, $\mathrm{x} 32$.

19 A stage still more advanced showing the beginning of the podocyst at the extremity of the foot, $x 32$.

20 A view of the same, from below, showing the podocyst and the mouth of the animal, $\mathbf{x} 32$. 
PLATE 25

This plate shows the gradual development of the embryo from the germinative vesicle.

FIG.

1 The germinative vesicle within the egg, natural size and $\mathrm{x} 8$.

2 Germinative vesicle, $\mathrm{x} 16$.

3 Under side of same at the commencement of segmentation, x 16 .

4 The segmented ovum, x 16.

5 The endodermal cell mass, inclosed by a transparent sac or wall of ectoderm, $\mathbf{x} 16$.

6 Showing the transparent sac greatly developed on one side of the cell mass, $\mathbf{x} \mathbf{1 6}$.

7 The beginning of the development of the body form, as shown by a slight elevation from the cell mass, $\mathrm{x} 16$.

8 A stage slightly more advanced, x 16.

9 The elevation is divided into two lobes, representing the body proper and the shell sac, $\mathbf{x} 16$.

10 The embryo within the egg, natural size and $\mathbf{x} 8$.

11 A stage more advanced than in figure 9. The podocyst is here plainly shown, x 16 .

12, 13 Still more advanced stages, x 16 .

14 An emibryo within the egg, $x$.

15 In this stage the tentacles are rapidly developing; the body and podocyst are distinct, and the development of the buccal body and alimentary canal has begun, x 16 .

16-19 Gradual development of the embryo. In figure 16 the endodermal cell mass has reached its greatest size, gradually becoming absorbed in succeeding stages, $x 16$.

18 The embryo within the egg, showing the same stage as in figure $19, \times 8$.

20,21 Ventral and profile views of the embryo within the egg, x 8; showing a stage more advanced than that represented by figure 19 . 
PLATE 26

FIG.

1 Showing the same stage as represented by figures, 20, 21 in plate 25. The podocyst in this stage reaches its greatest size, and in the succeeding stages rapidly diminishes in size, $\mathbf{x} 14$.

2 Ventral view of an embryo of the same stage as represented in figure 1; showing the base of foot, tentacles, mouth, lateral lips and corrugations surrounding the mouth, $x 25$.

3 A profile view of the same, showing the tentacles and the "primitive kidney" on the side of the endodermal mass, $\times 30$.

4 A more advanced stage, $\mathrm{x} 14$.

5 A still more advanced stage. The tentacles have begun to assume their adult form; the internal organs are assuming definite form; and the endodermal mass and podocyst are greatly reduced in size by absorption, $\mathbf{x} 14$.

\section{PLATE 27}

FIo.

1 Showing the position of the embryo within the egg just before emerging, $\mathbf{x} 8$.

2 The same removed from the egg, $\mathrm{x} 16$.

3 A fully developed specimen. The integument is cut along the dorsal line and drawn back, so as to show the internal organs. See plate 15 for a description of the various organs.

4 An egg containing two embryos, $x 8$.

5 An egg containing four embryos, $x 8$.

6 The tentacles and protruded mouth of an embryo; ut superior tentacle; $l t$ lower tentacle; $t m$ buccal mass; $d p$ jaw ; $m$ retractor muscle of jaw, $\mathbf{x} 10$.

7-9 Abnormal eggs. These are of frequent occurrence, $\mathbf{x} 4$. 
PLATE 28

FIG.

1 A group of cells after segmentation, greatly enlarged.

2 A group of cells at a later stage; the larger and smaller cells grouped in polygonal masses, and distorted from mutual pressure, greatly enlarged.

3 The cells liberated from one of the polygonal masses, showing their true form, greatly enlarged.

4 The primitive kidney showing the cells and their calcareous concretions, greatly enlarged.

5, 6 Groups of cells from the position indicated by the lettering 5 and 6 , figure 5 , plate 26 , greatly enlarged. The latter containing calcareous concretions as in the "primitive kidney."

7-13 Showing the gradual development of the shell, $\mathrm{x} 30$.

14 The fully formed shell, dorsal view, $x$ 2. The under side of the shell has very much the appearance represented in figure 13 . 

Plate I
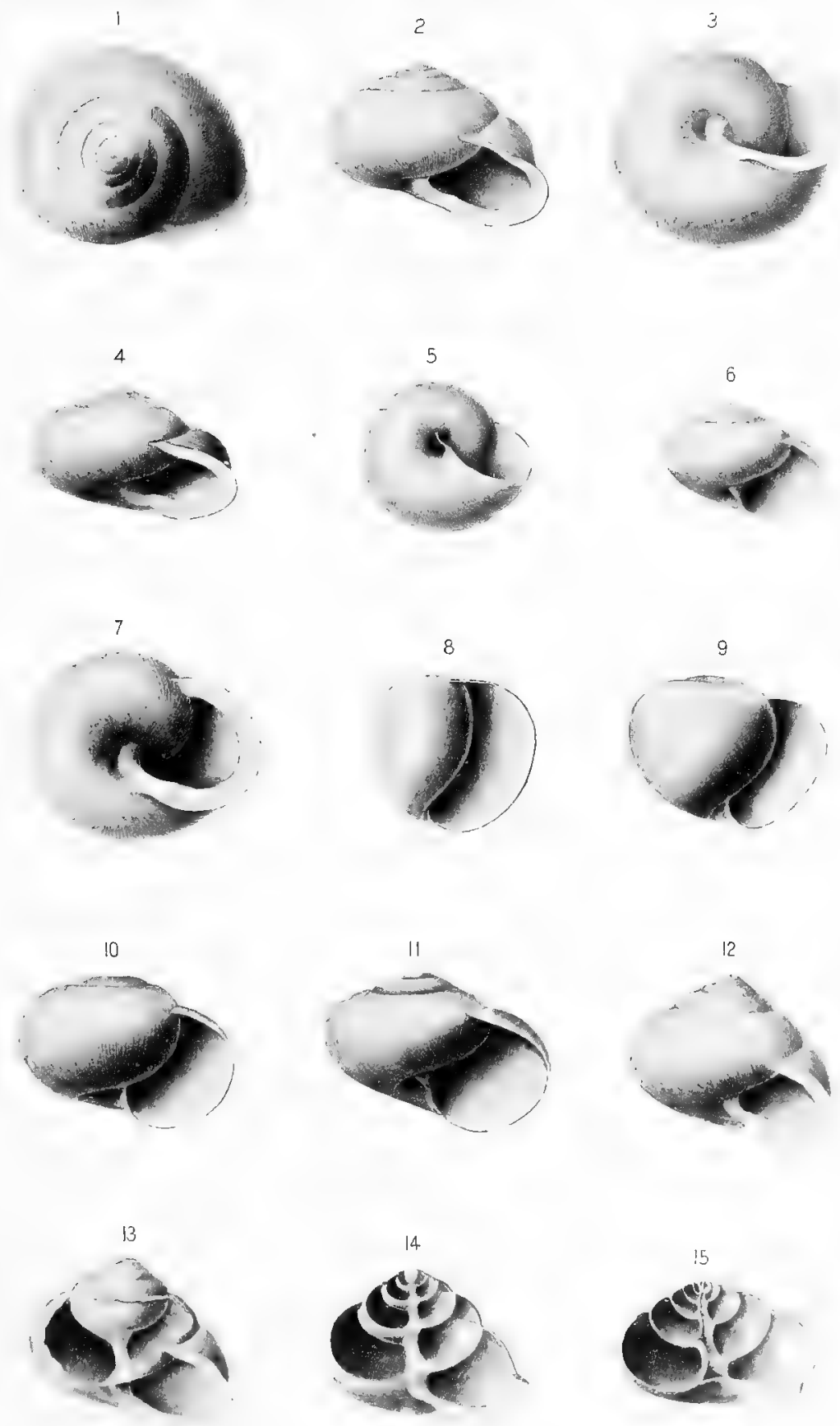

Plate 2

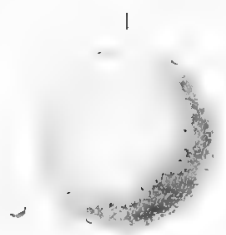

2

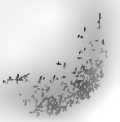

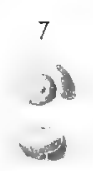

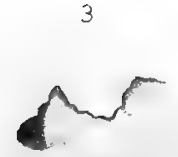

6
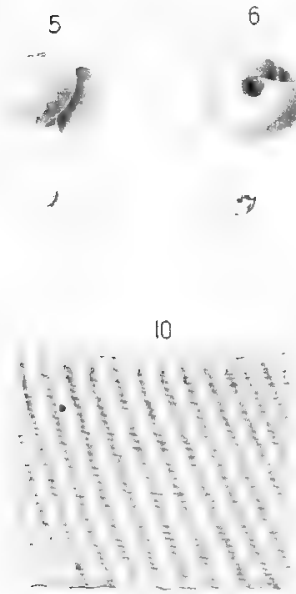

13
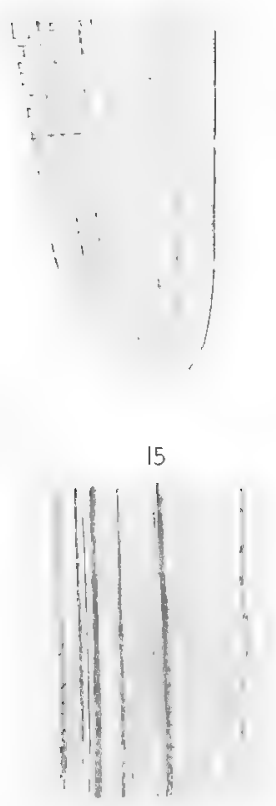

19

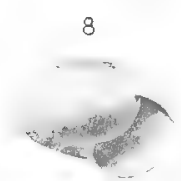

12

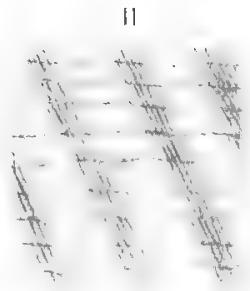

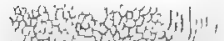
on 6. $5, n$,

3 ty पi in

14

16
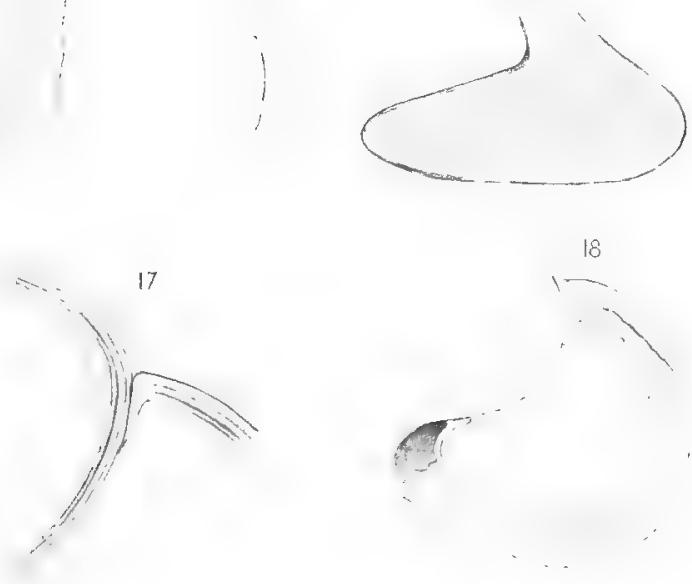

Plate 3
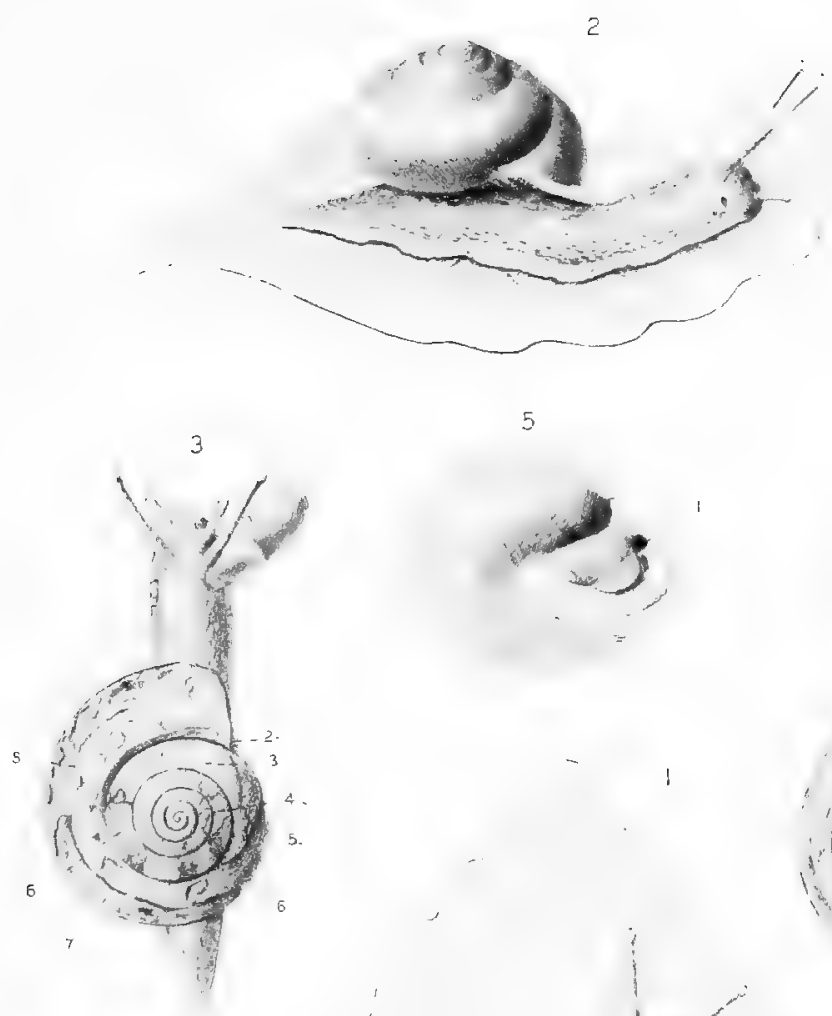

5
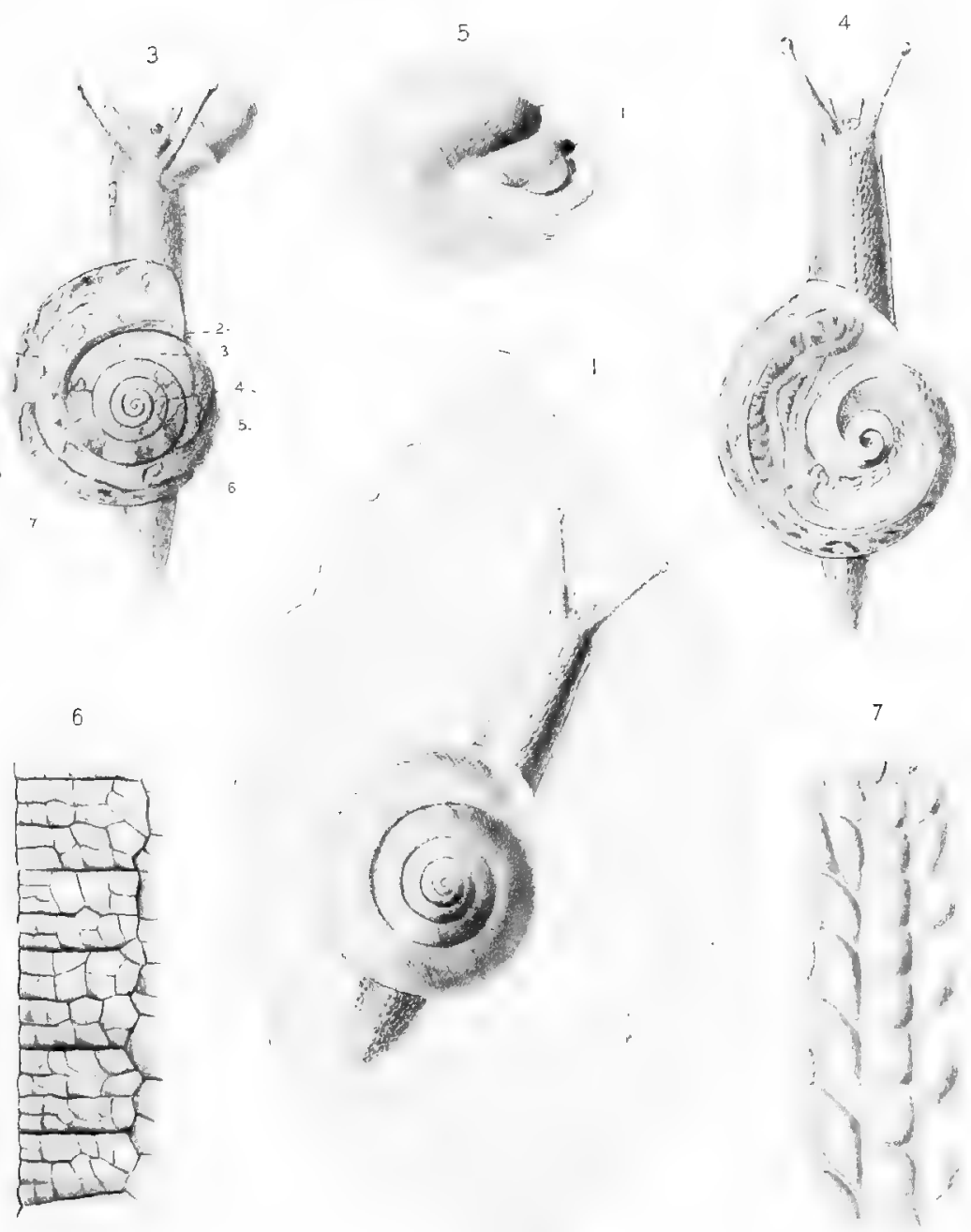

Plate 4

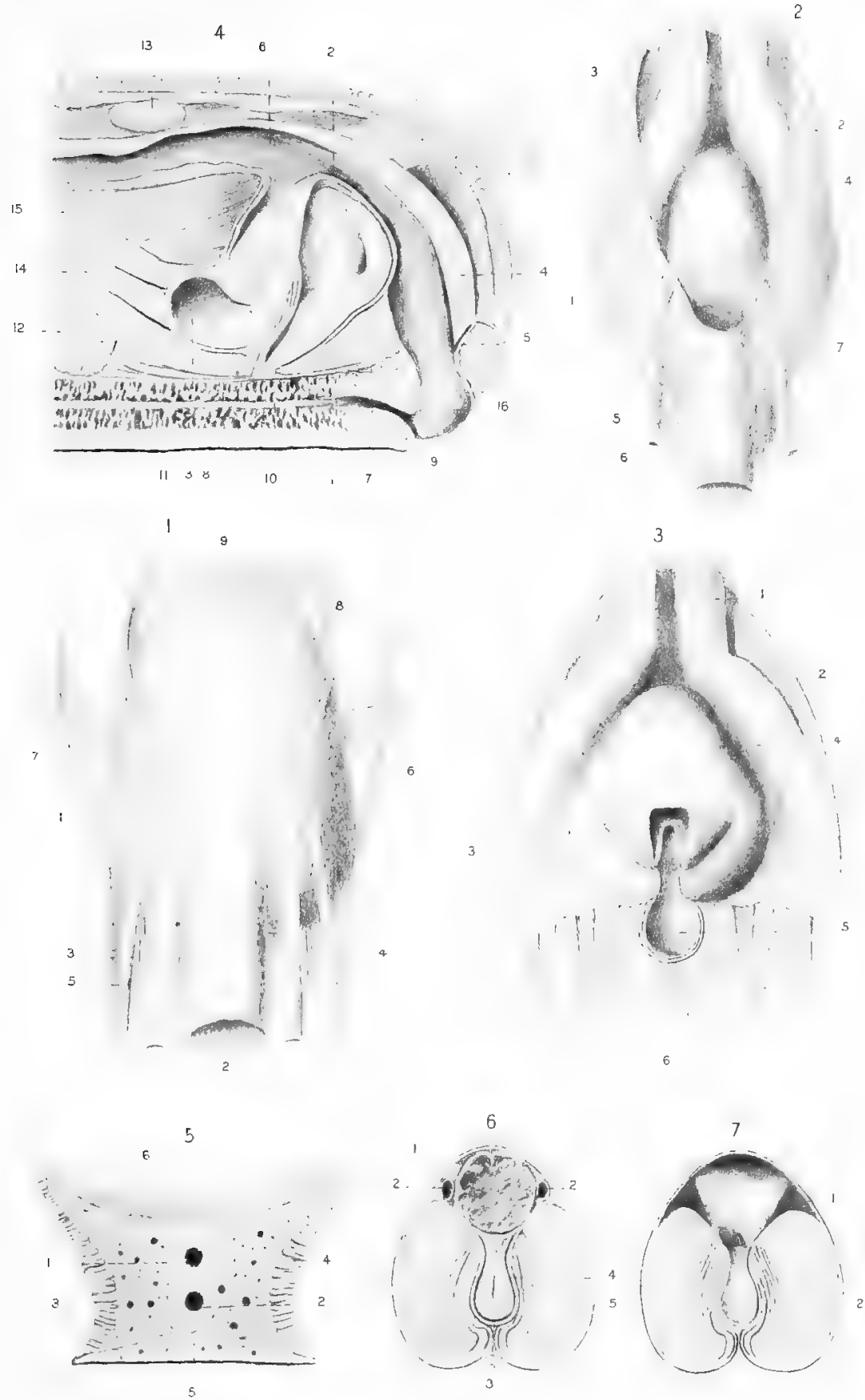



Plate 5

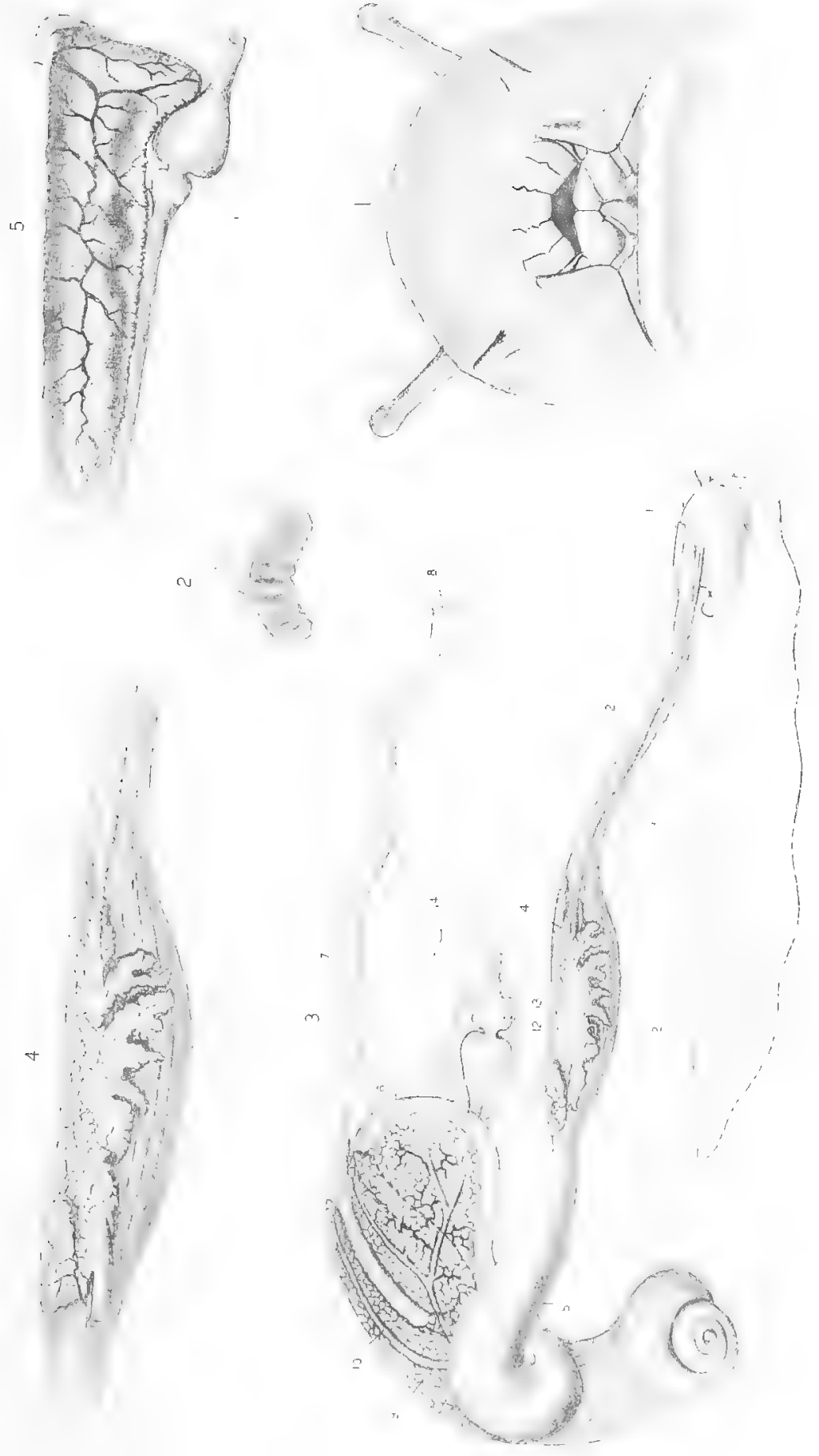



Plate 6
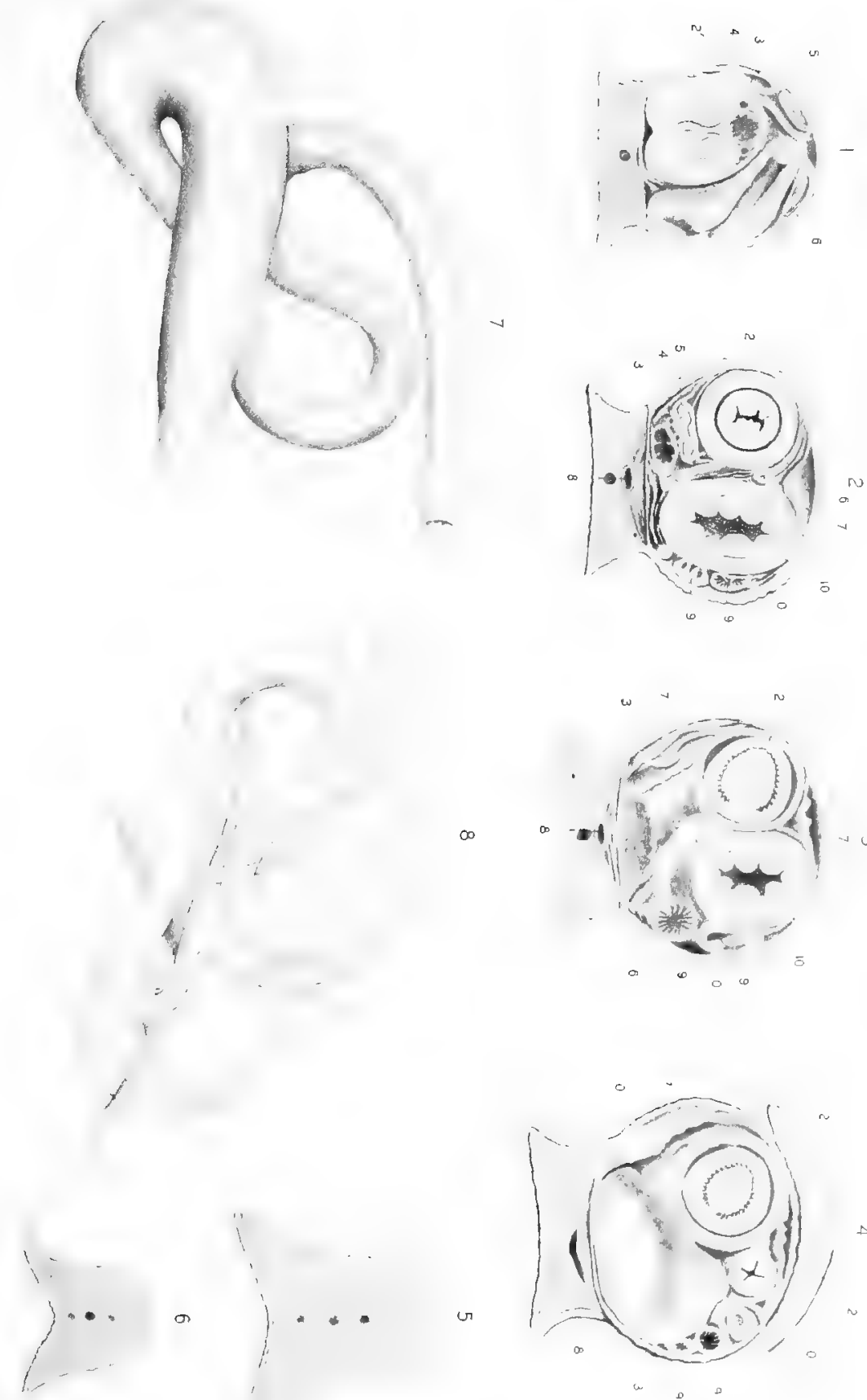


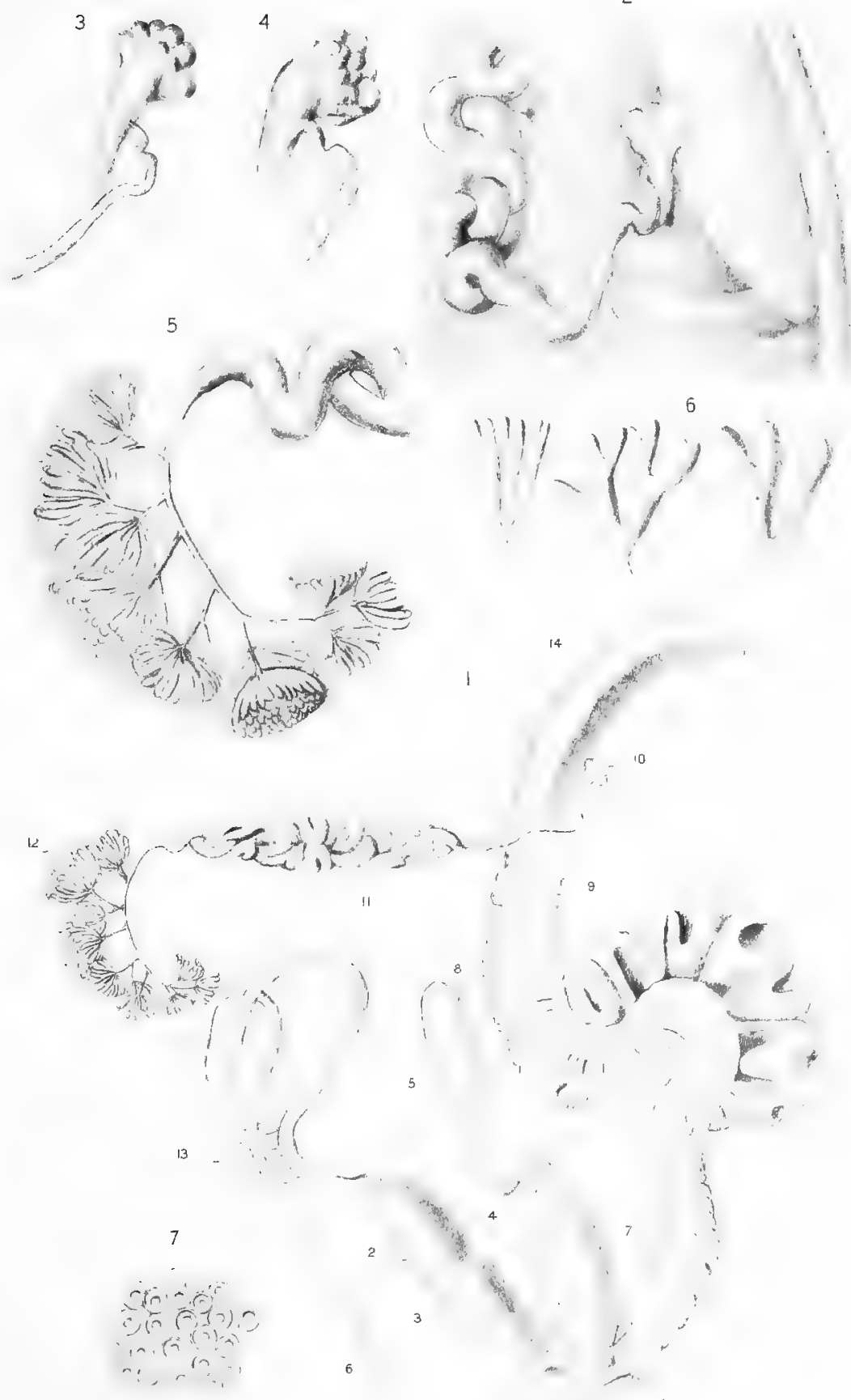

Plate 8
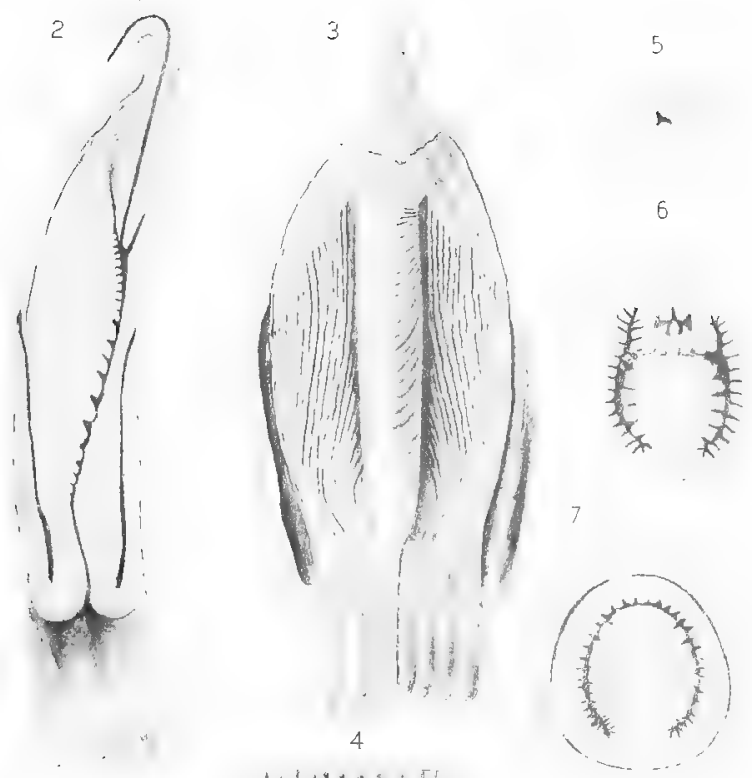

10

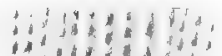

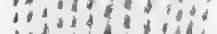

indis libe.

indity ine

i.iol lilit

initilis.

init till

in is lin

i" 11 in

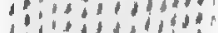

i,

13
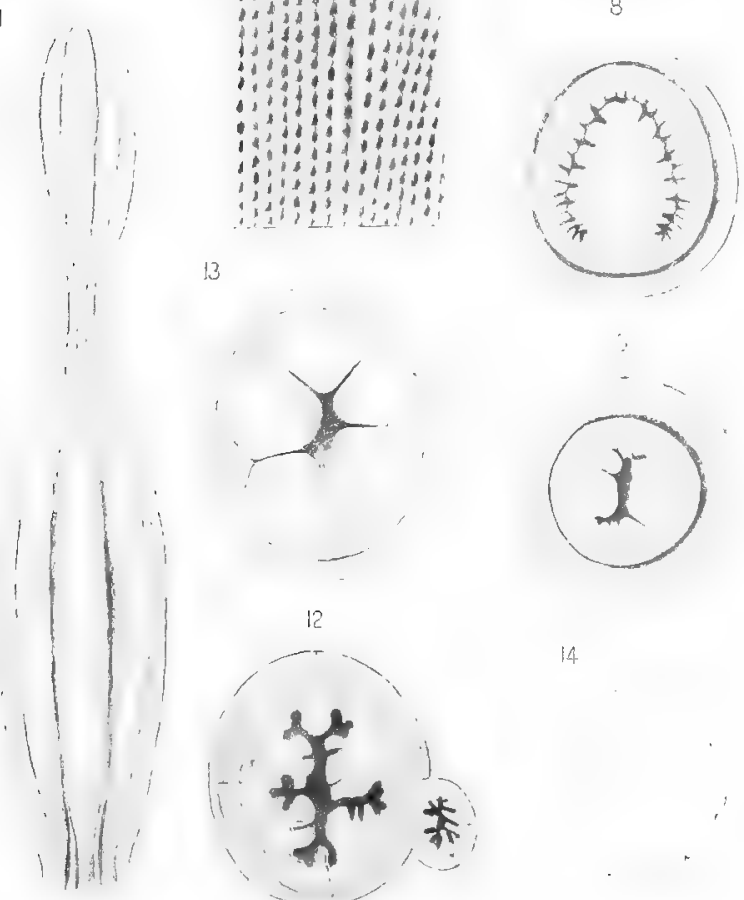

12

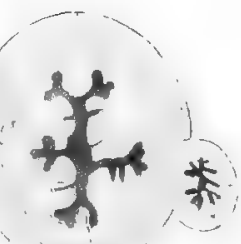



Plate 9

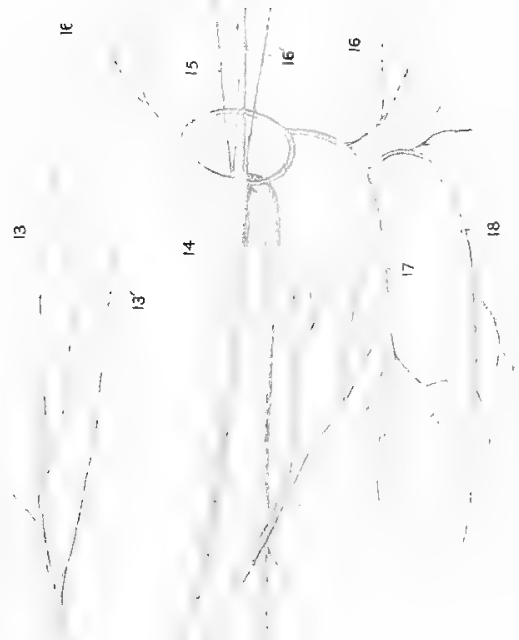

이
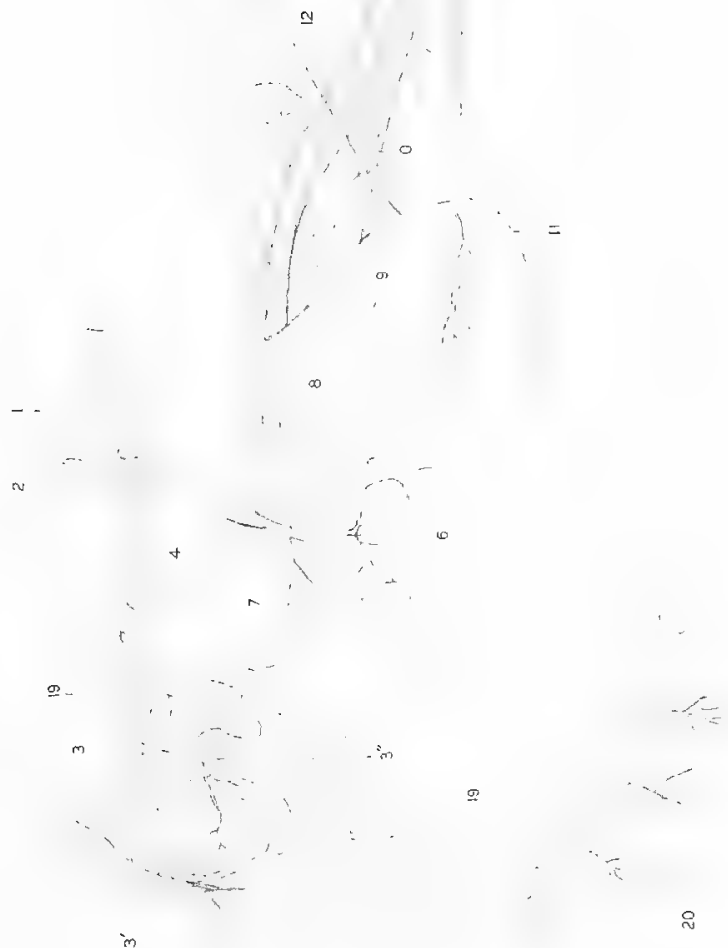


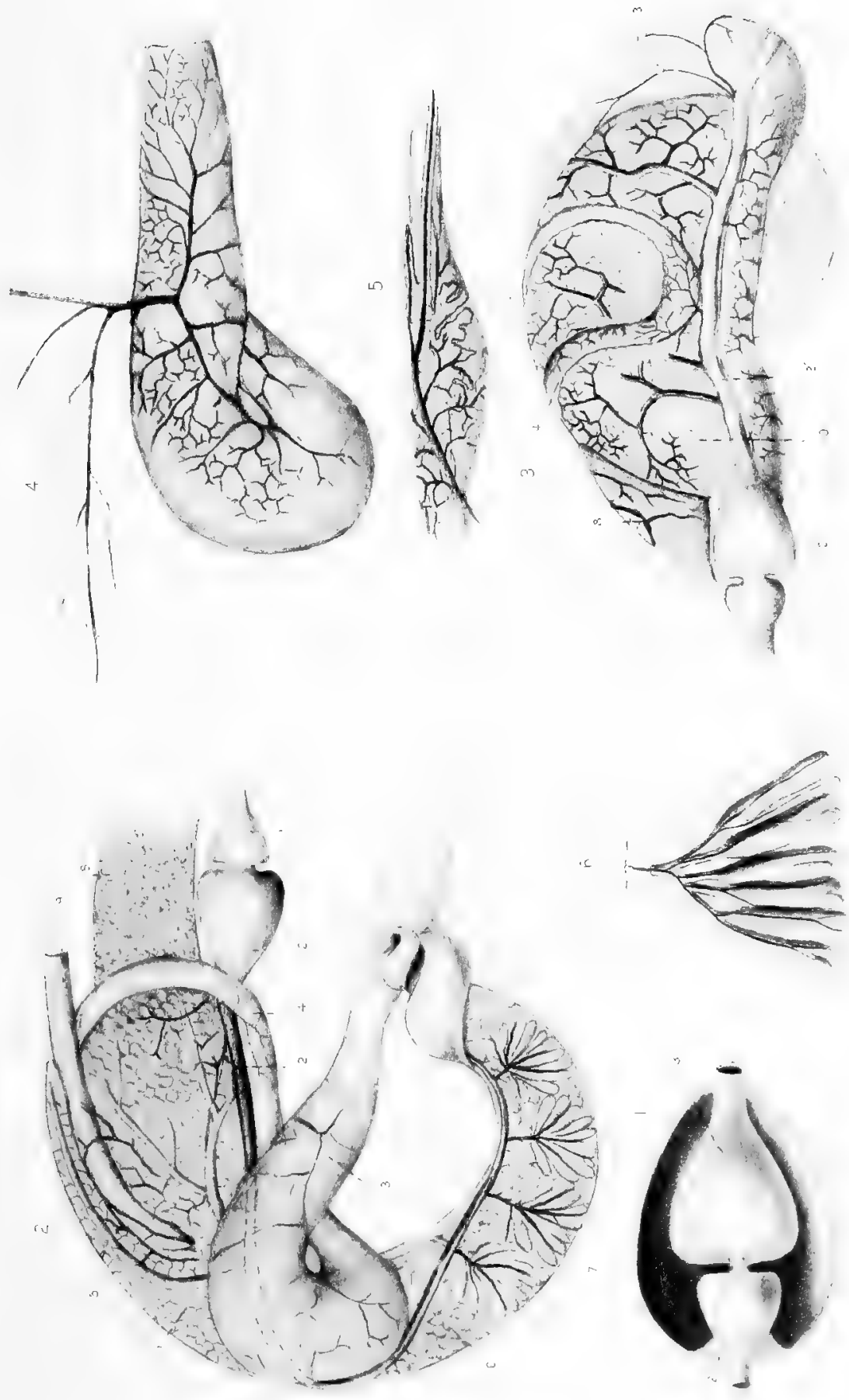

Plate II
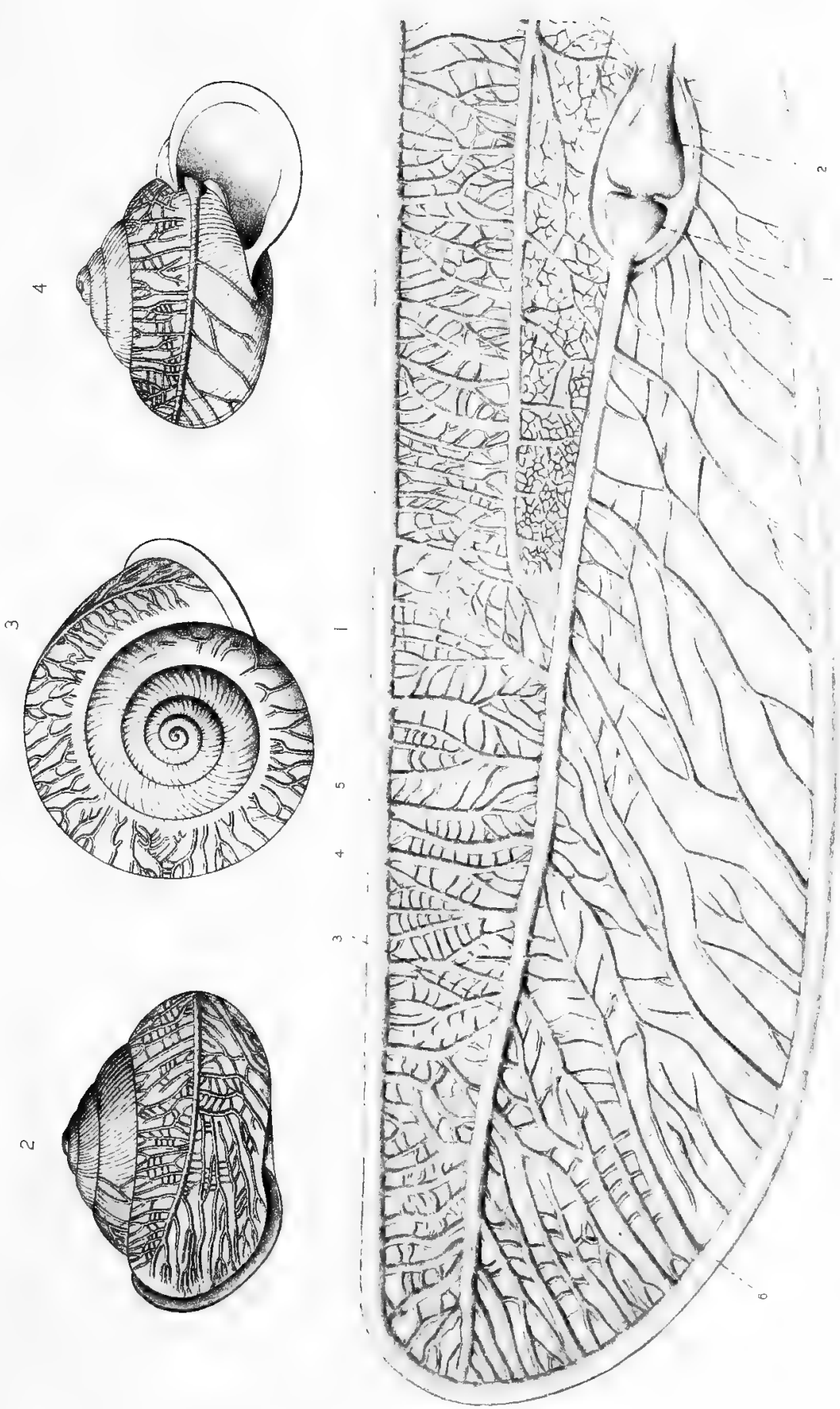

Plate I2

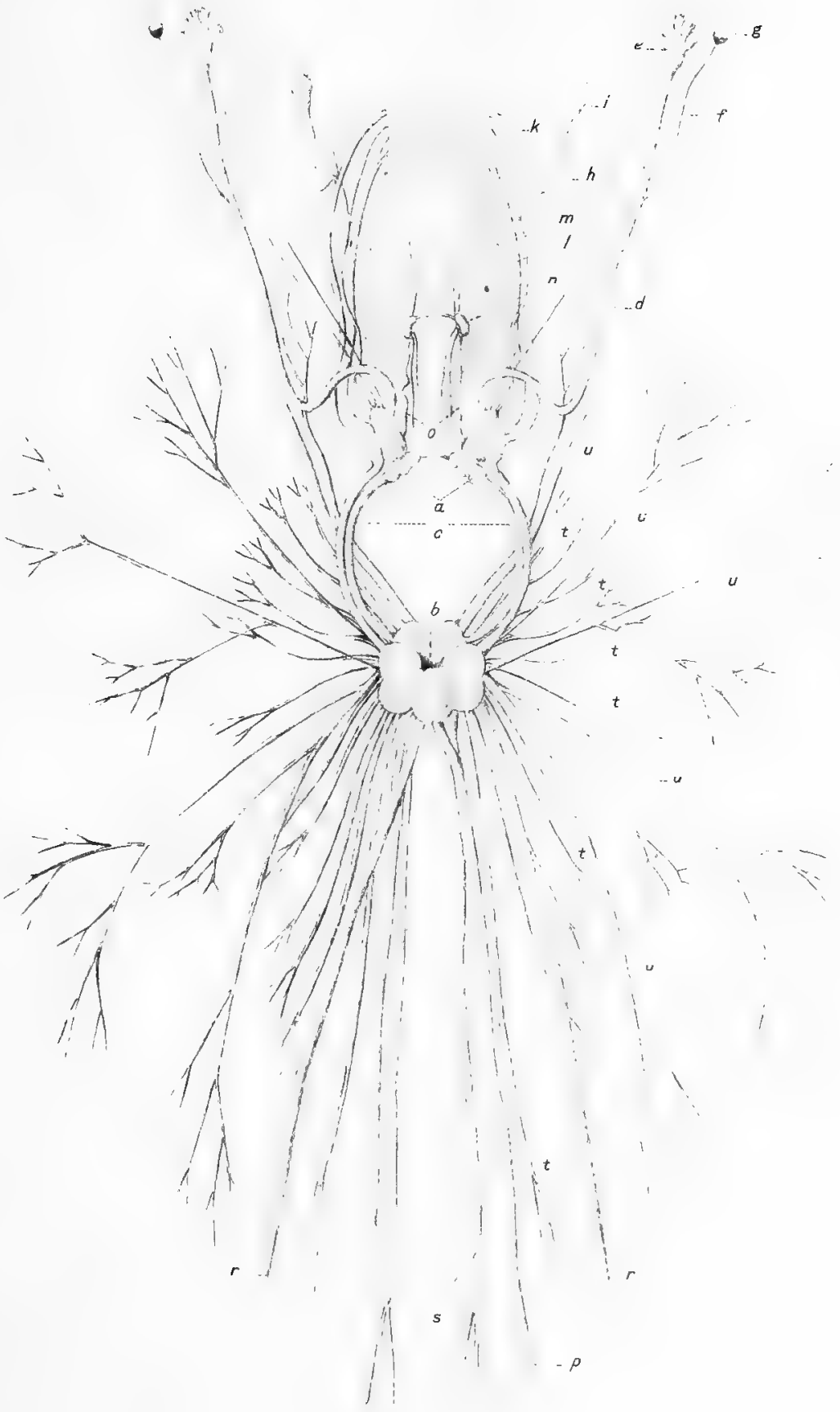





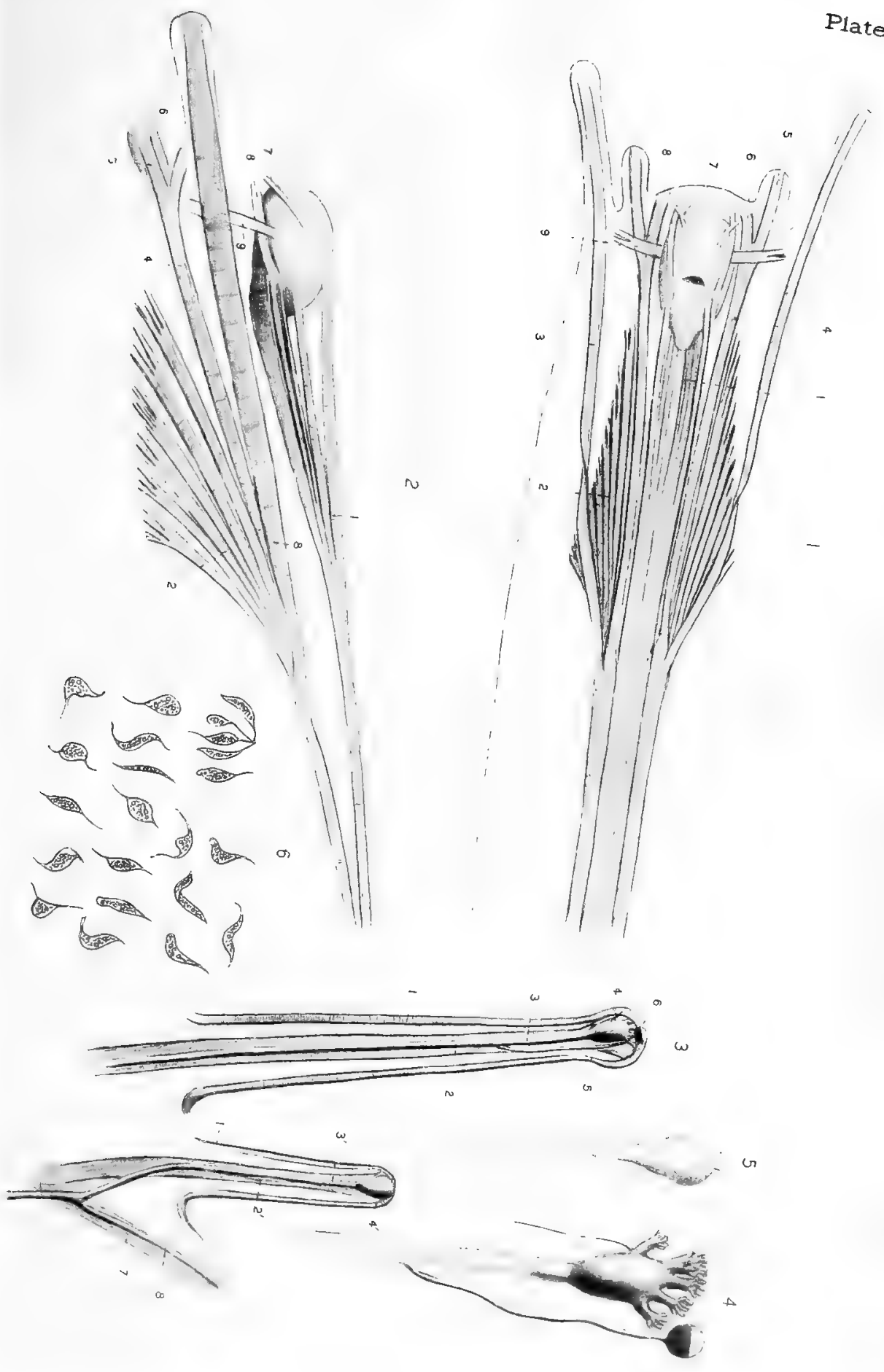



Plate I4

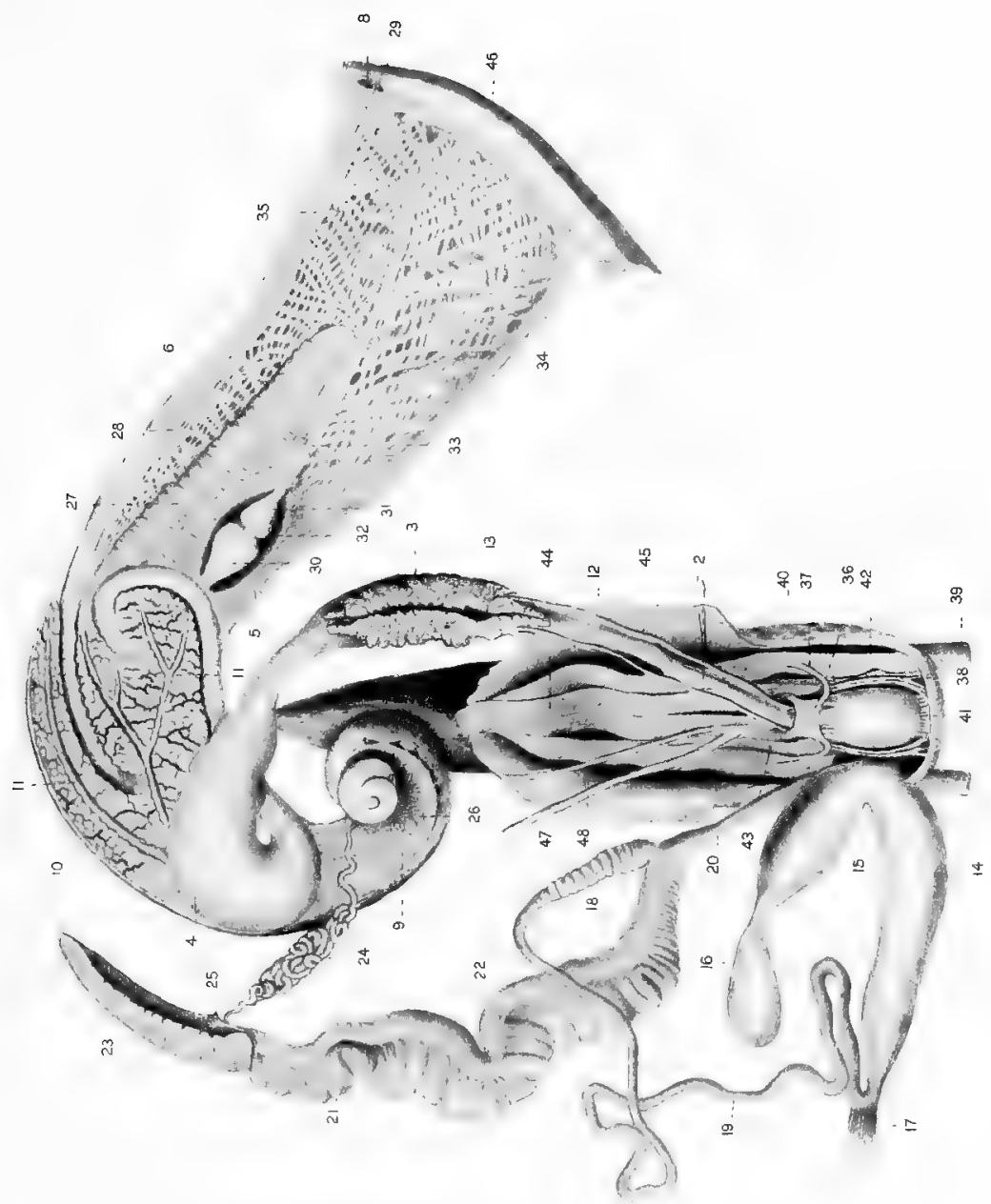




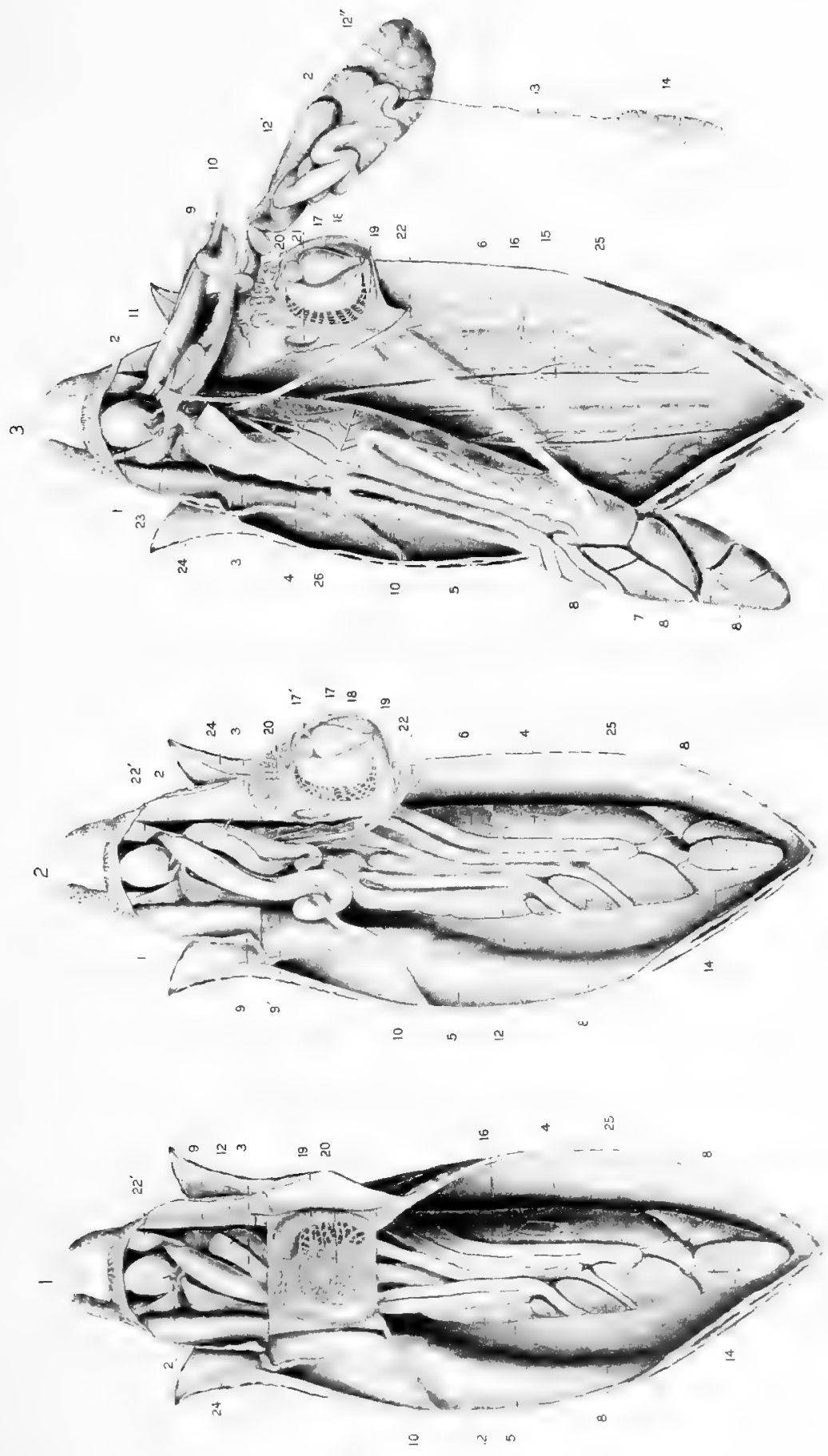

Plate I6
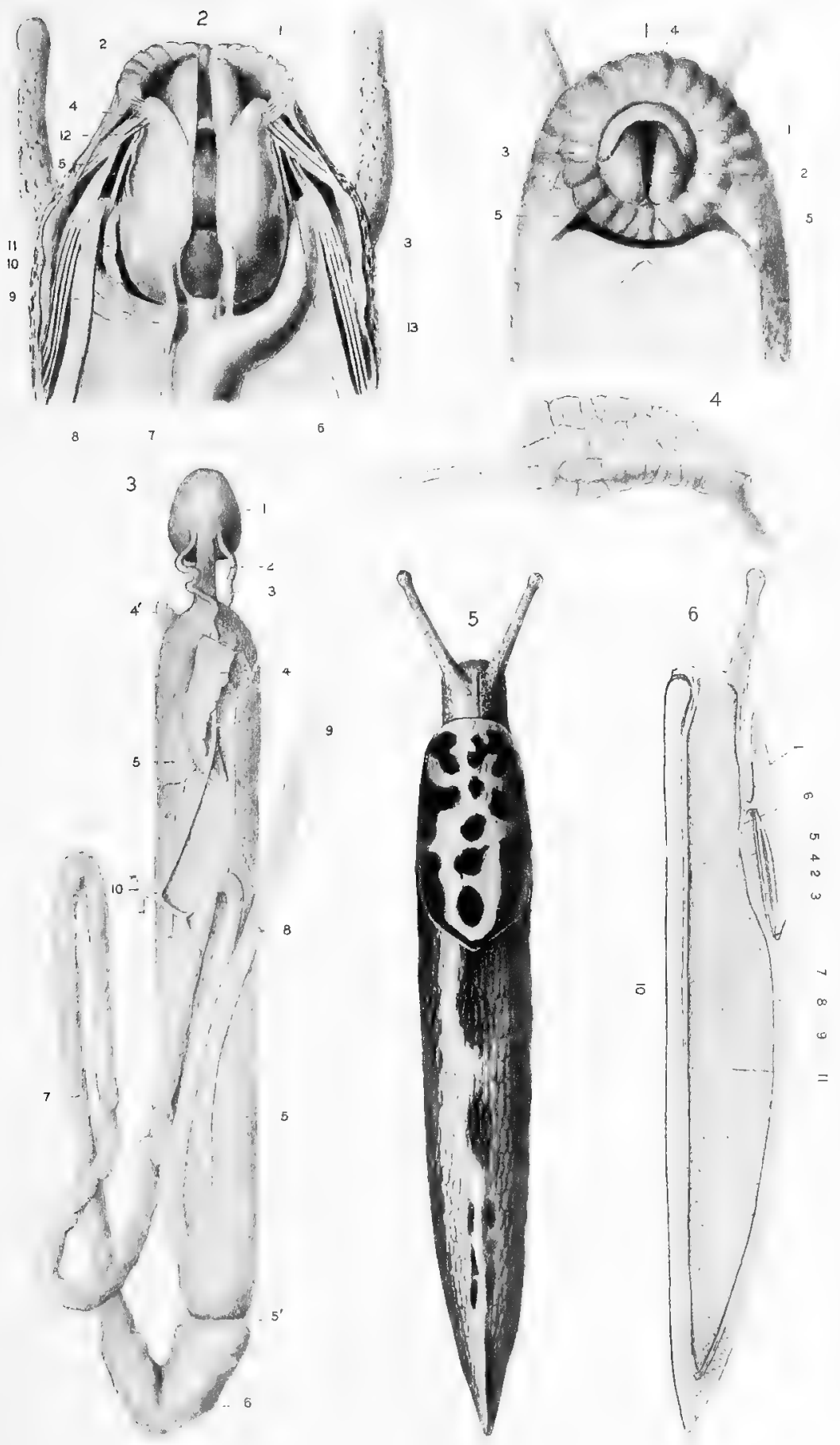



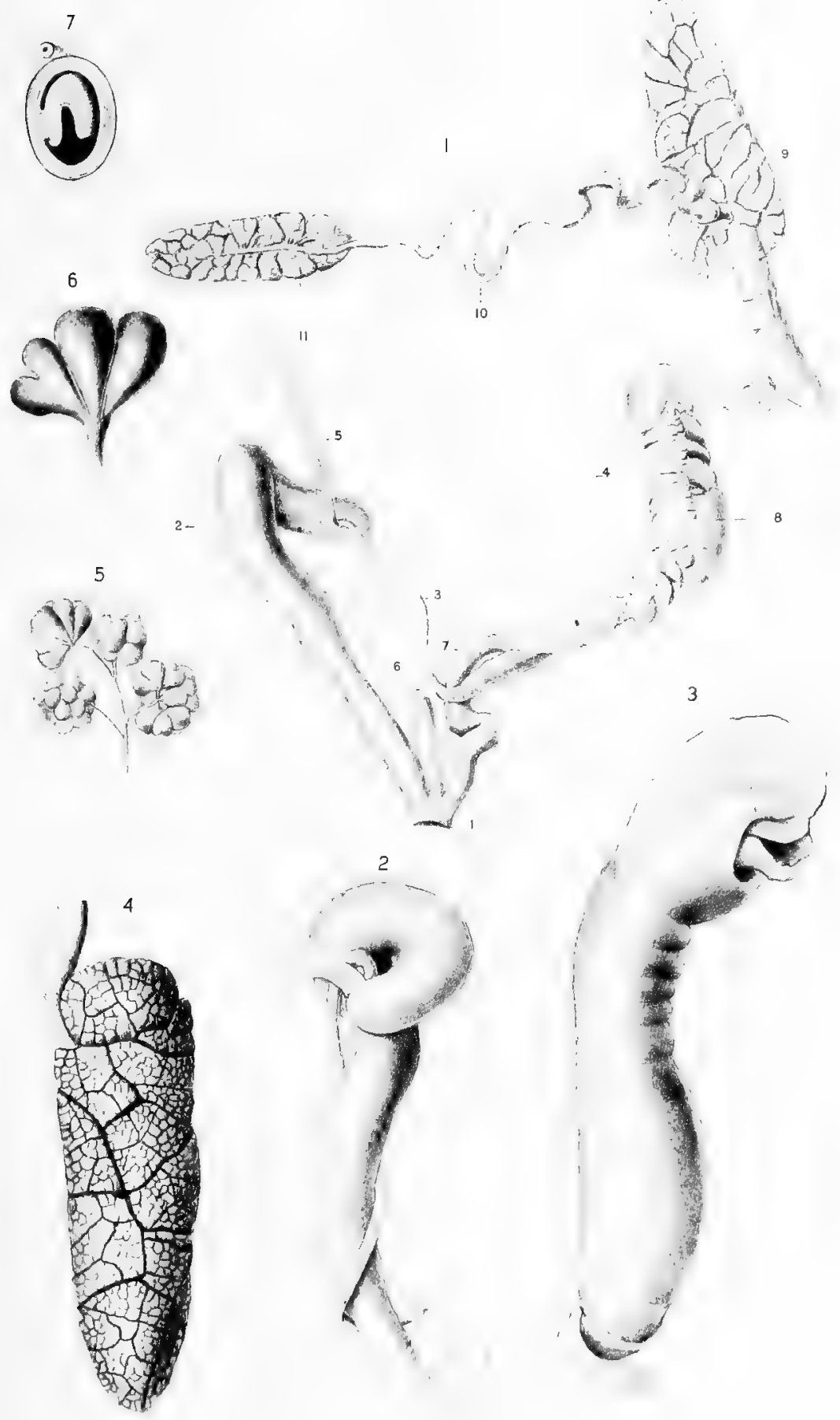





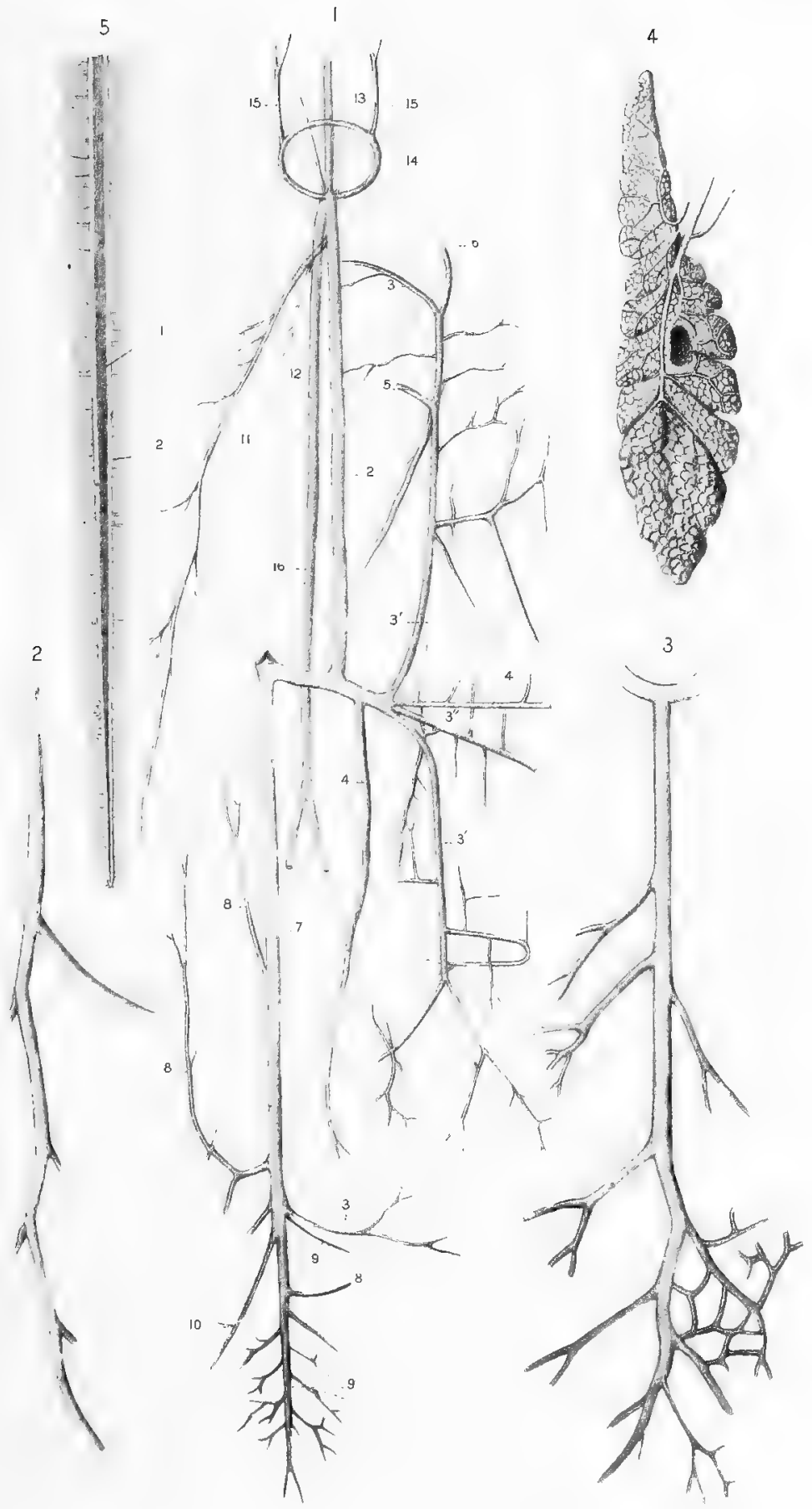



Plate Ig

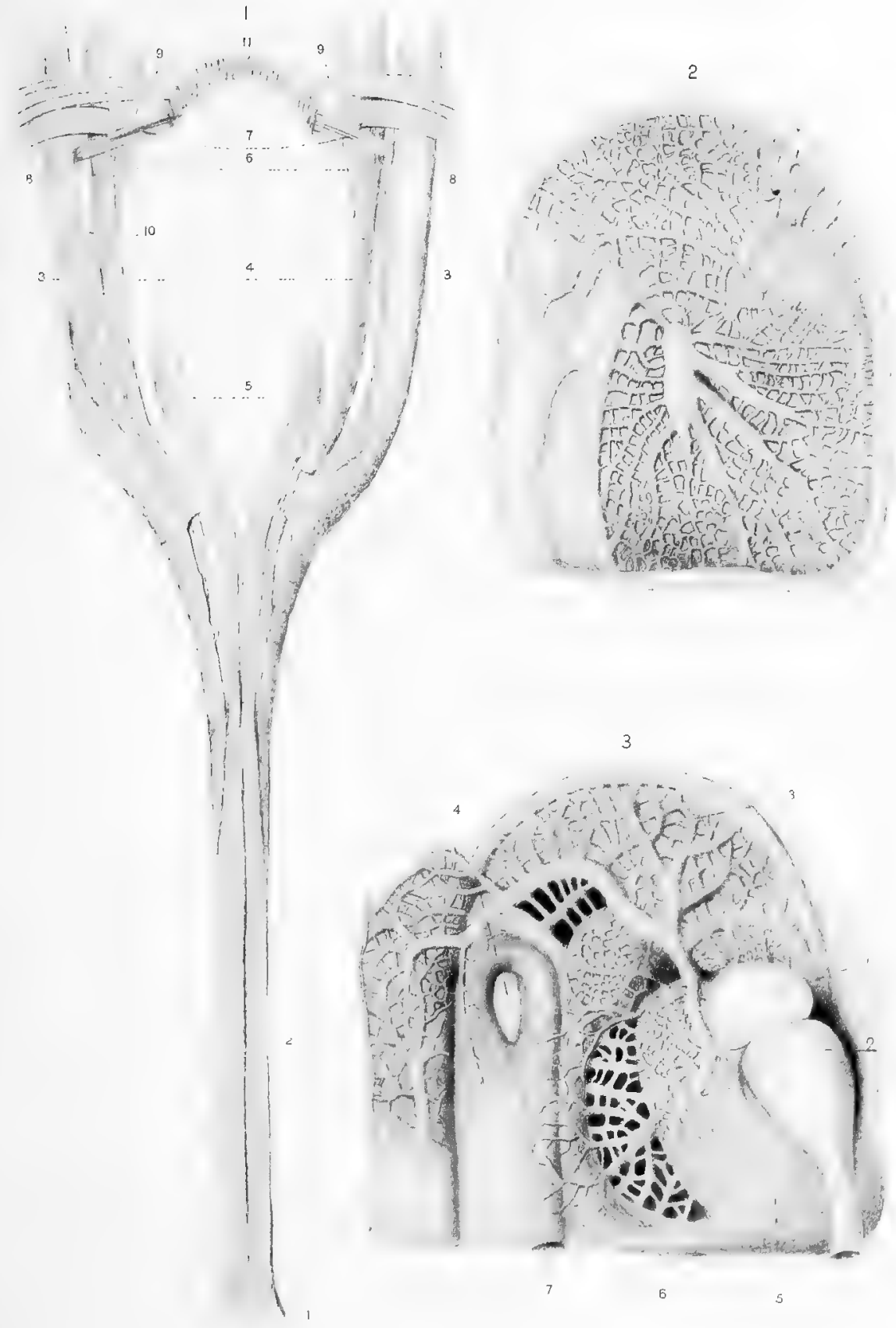




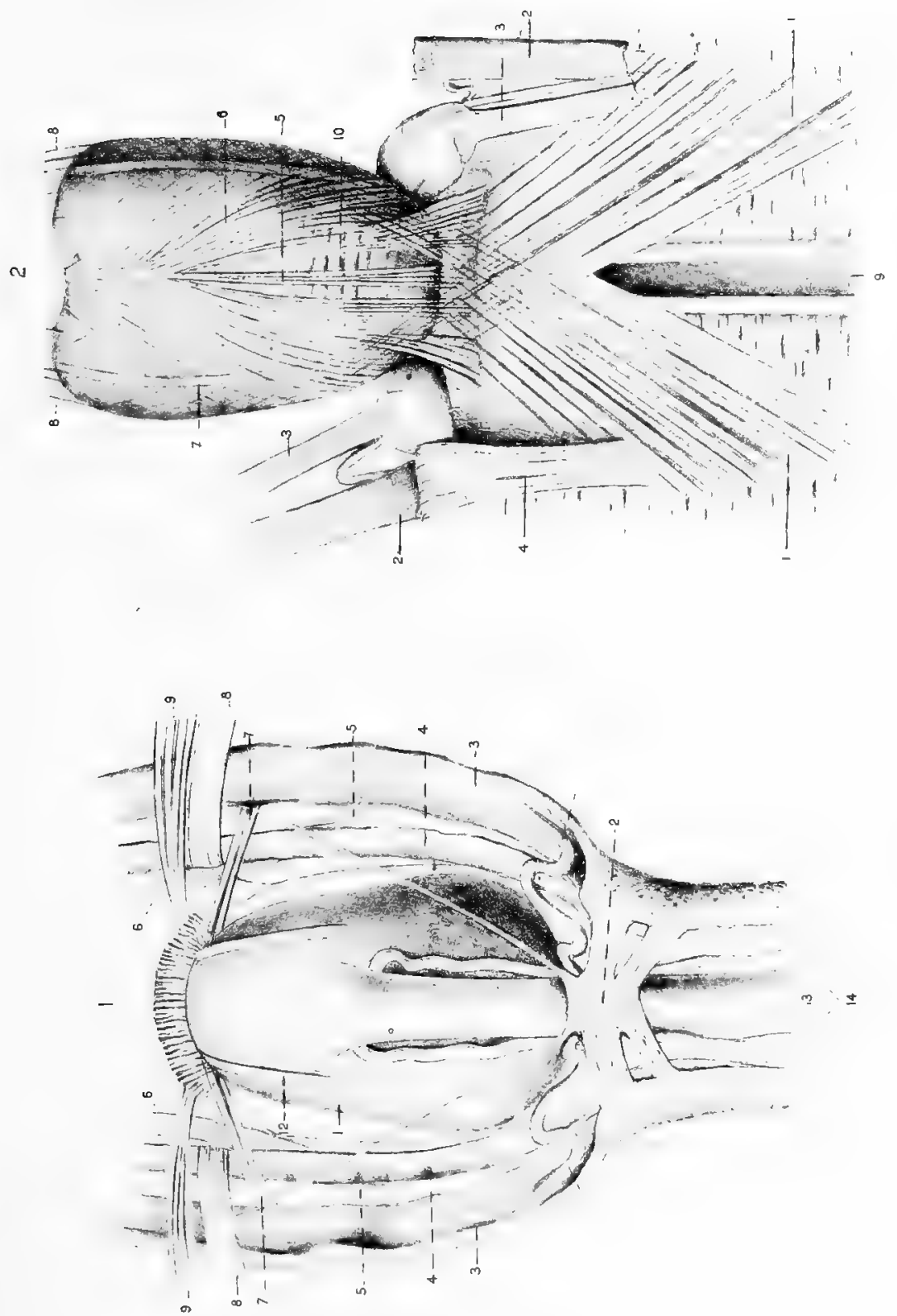


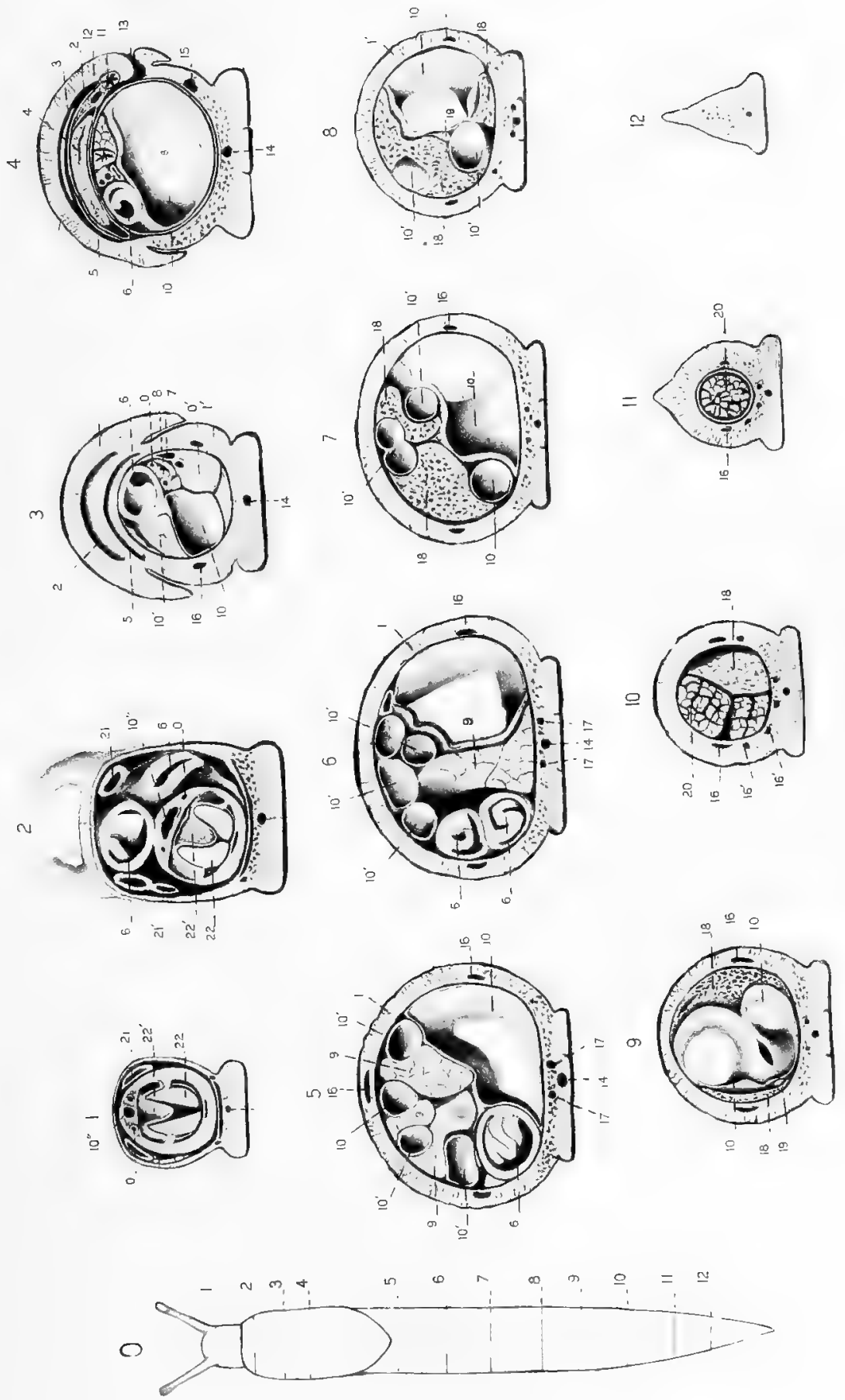

Plate 22

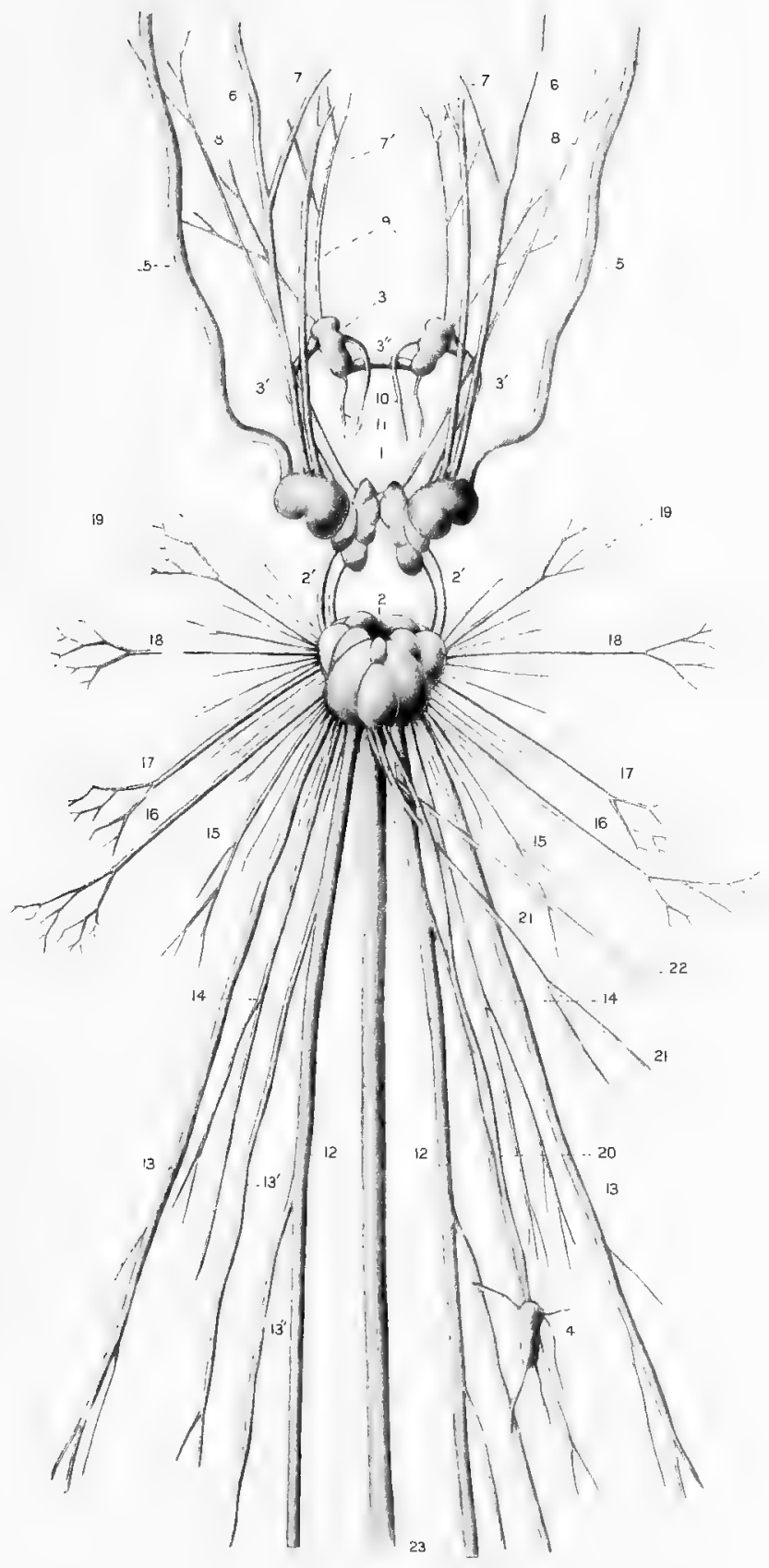



Plate 23

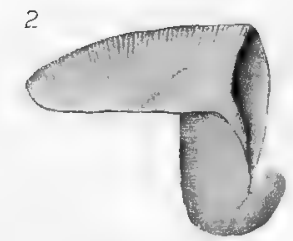

5
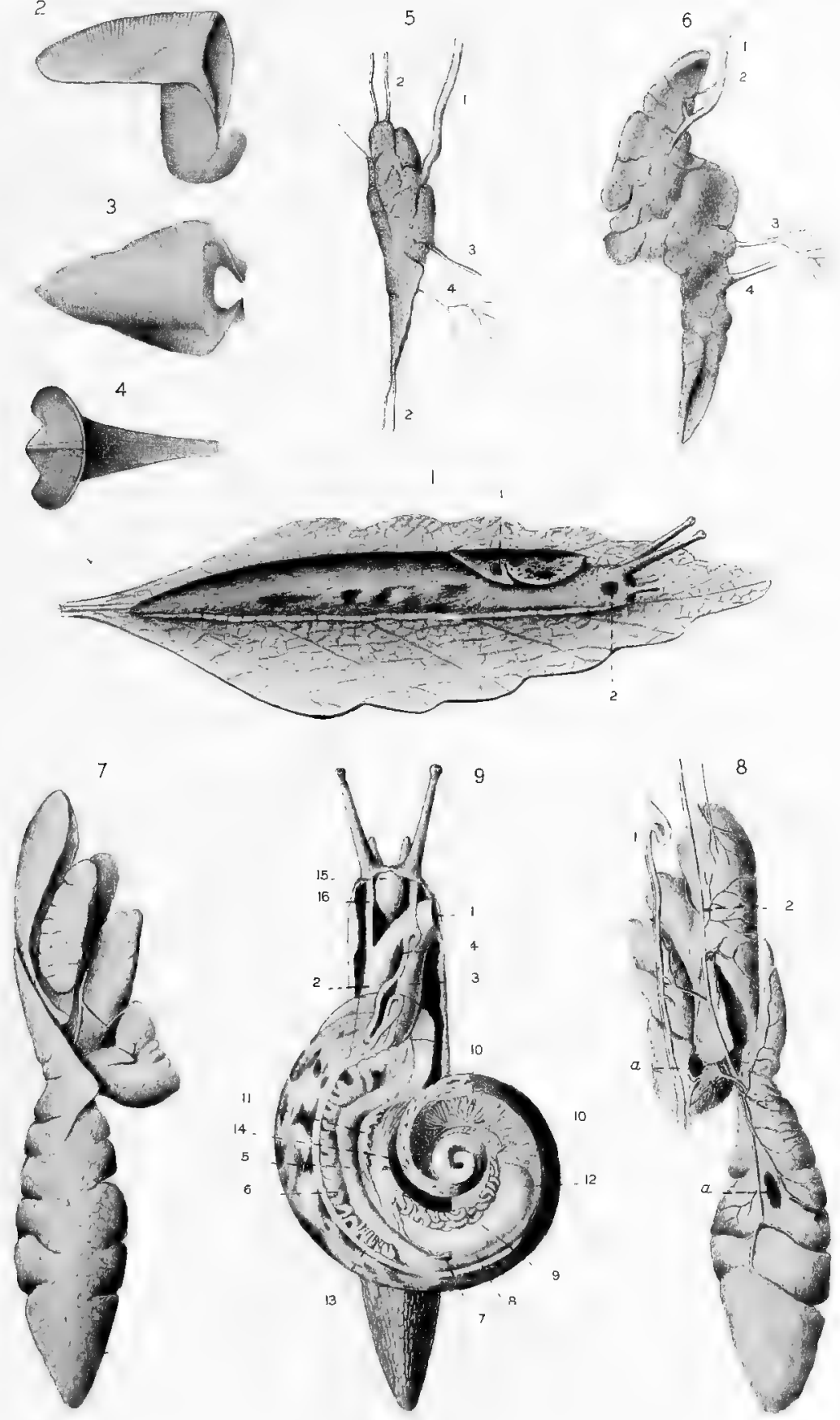



\section{Plate 24}

2

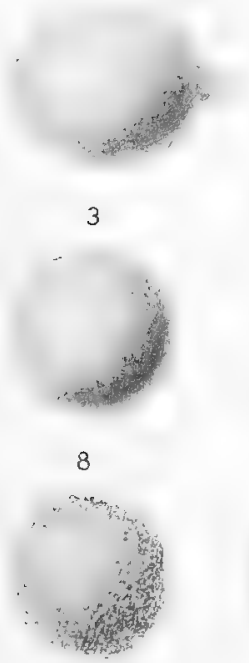

10

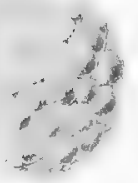

15
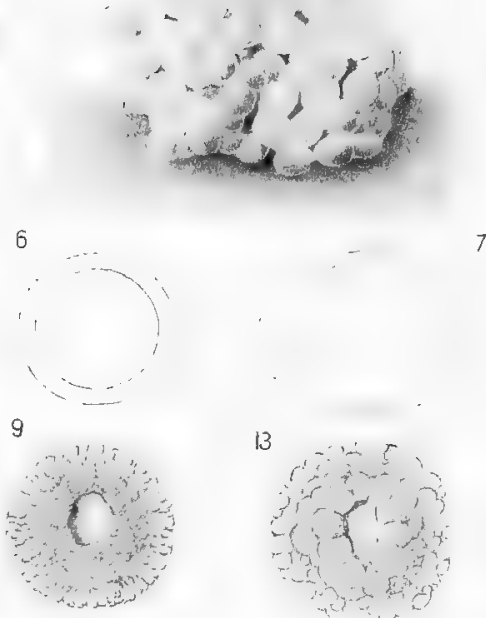

11

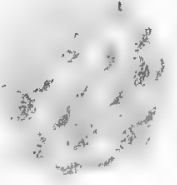

16
4

(4)

5

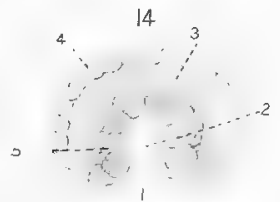

12

17

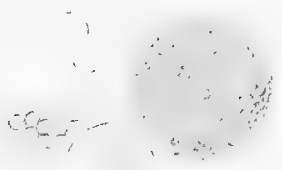

19

20

18 

Plate 25
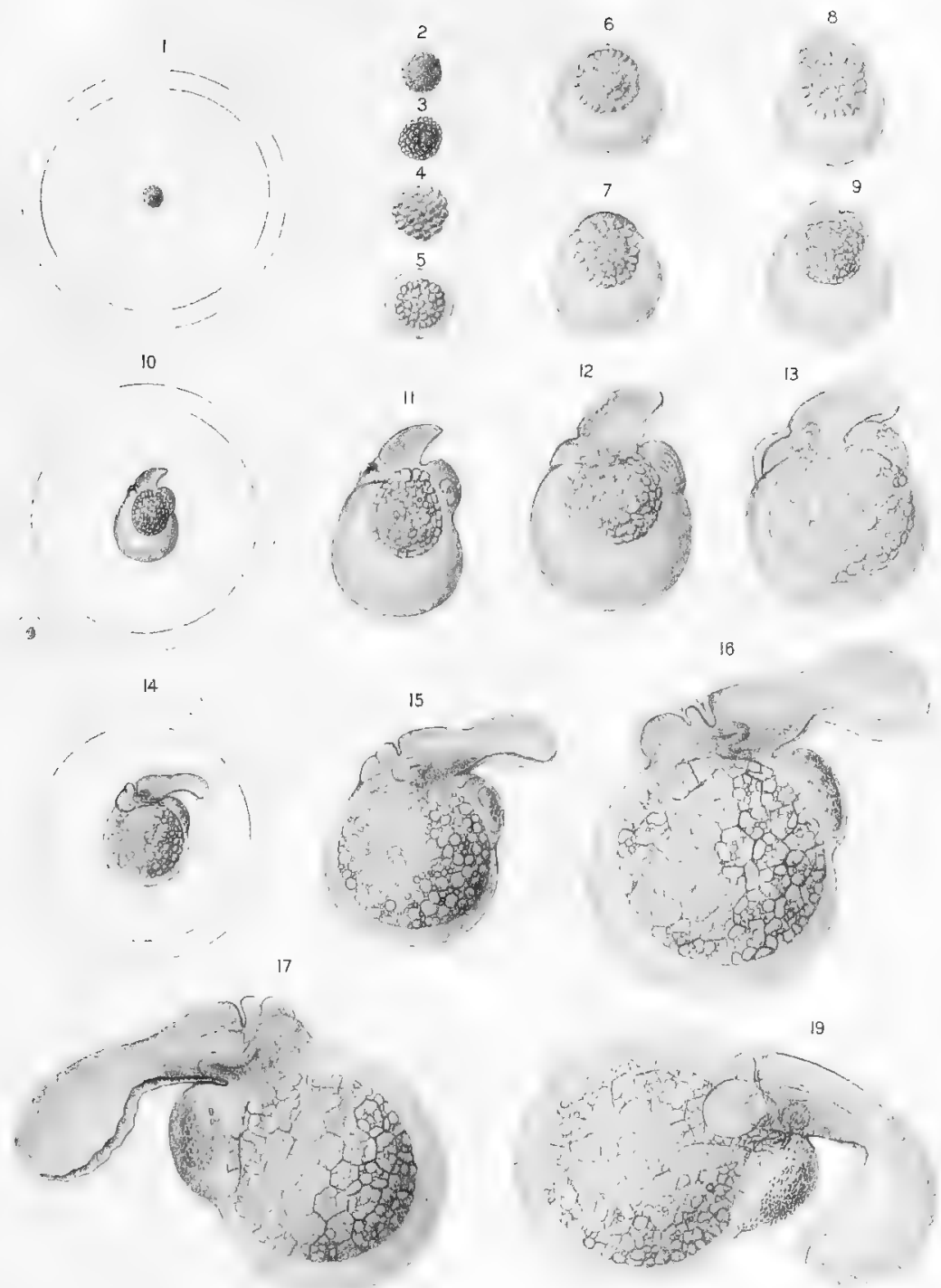

18

21

20
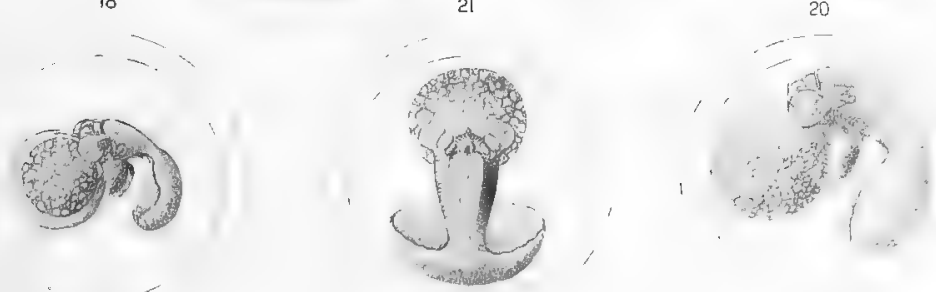

Plate 26
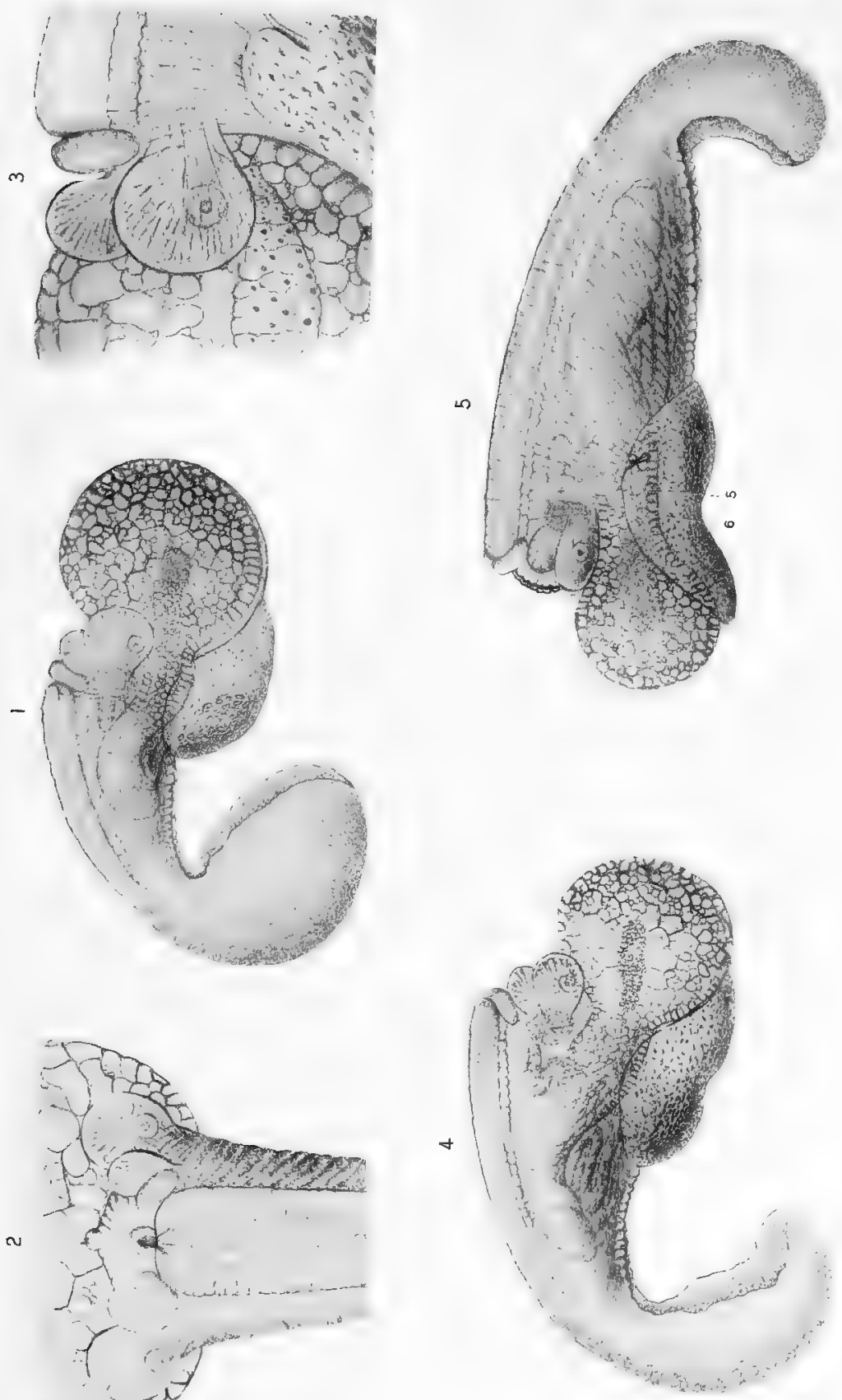



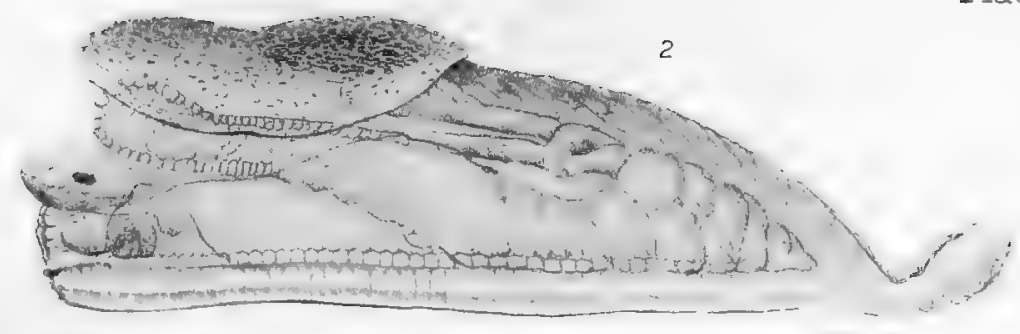

3

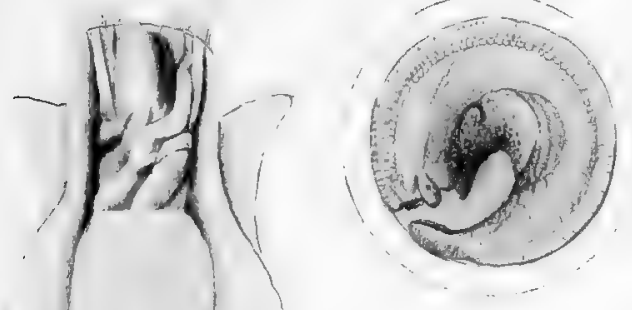

4

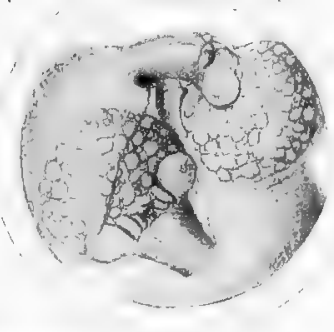

5
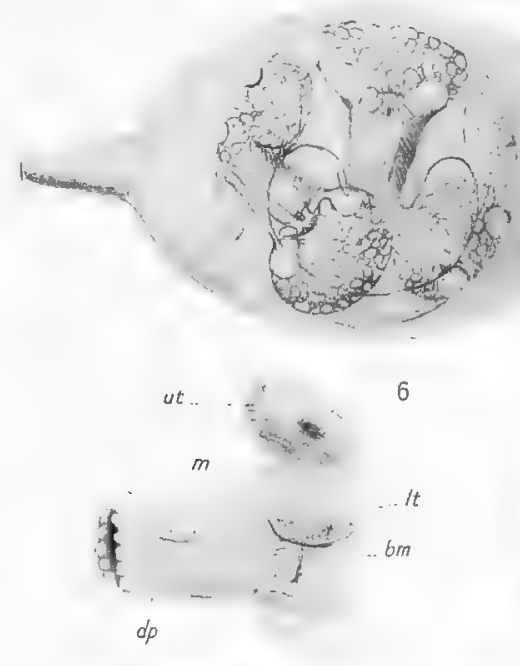

7
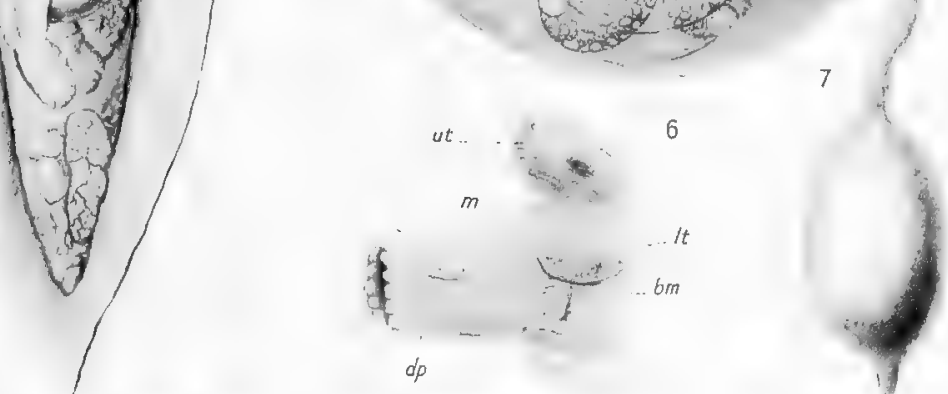

8
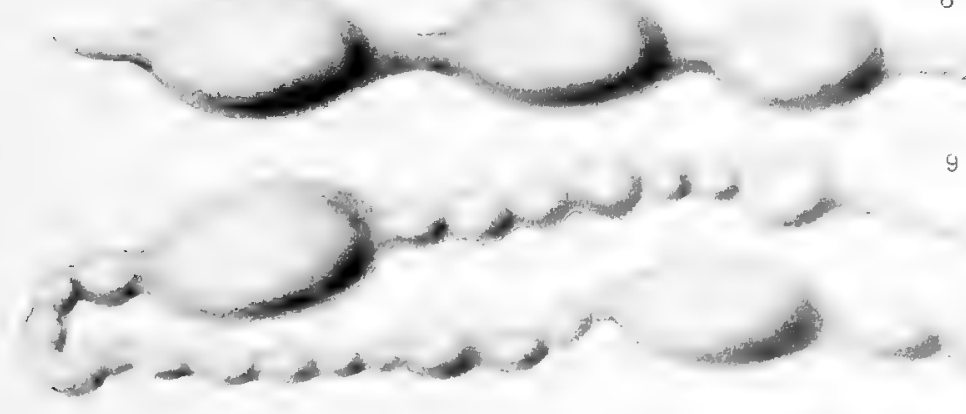

9 

Plate 28
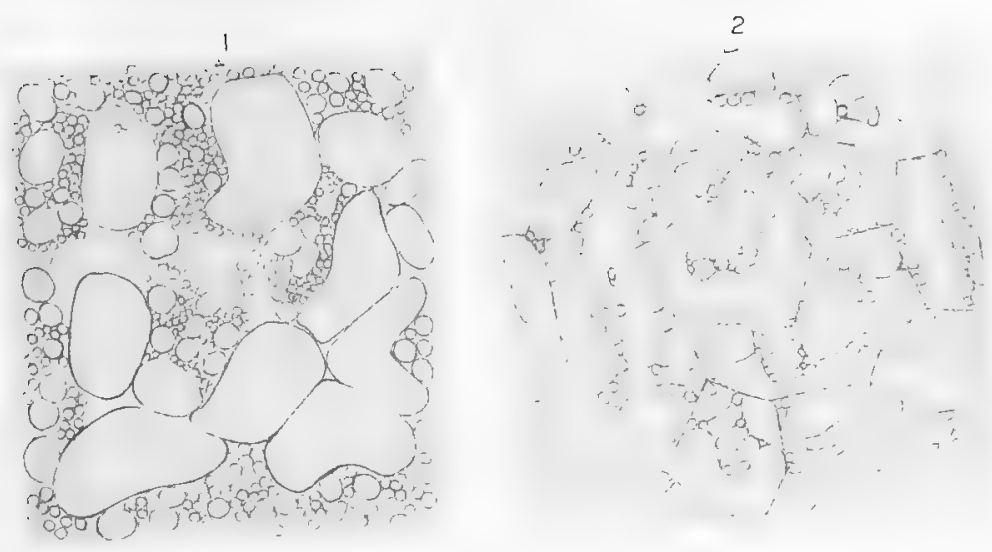

3

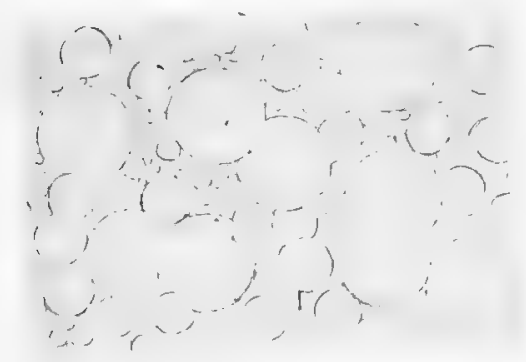

5

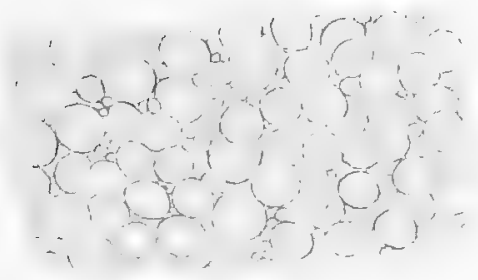

6

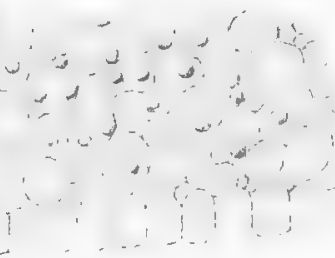

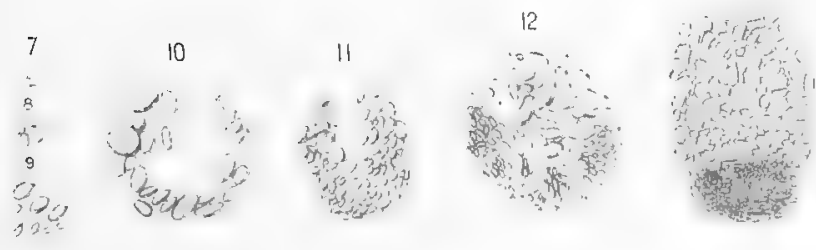





\section{N D EX}

The superior figures tell the exact place on the page in ninths; e. g. $262^{3}$ means page 262, beginning in the third ninth of the page, i. e. about one third of the way down.

Albumen gland of Polygyra albolabris, $257^{8}-58^{8}$; of Limax maximus, $280^{2}$.

Apparatus necessary for study, $241^{2}$.

Arteries of Polygyra albolabris, $264^{9}-66^{\mathrm{z}}$; of Limax maximus, $280^{\mathrm{B}}$ $82^{8}$.

Auditory organs, $275^{9}-76^{4}$.

Blood of Polygyra albolabris, $267^{5}$. $68^{\circ}$.

Carnivorous habits of Polygyra albolabris, $247^{7}-49^{7}$.

Circulatory system, of Polygyra albolabris, $262^{8}-68^{8}$; of Limax maximus, $280^{4}-83^{7}$.

Cryptoicus, $256^{7}, 261^{7}$.

Digestive system, of Polygyra albolabris, $249^{8}-54^{1}$; of Limax maximus, $278^{2}-79^{3}$.

Direction, sense of, $276^{5}-77^{1}$.

Dissection, methods, $242^{7}-43^{5}$.

Eggs of Limax maximus, time of

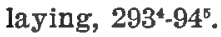

Embryology of Limax maximus, $290^{1}-93^{8}$.

Entozoa, description of a new species, $261^{4}-62^{2}$.

External features of Polygyra albolabris, $245^{8}-46^{8}$.
Food of Polygyra albolabris, $247^{7}$ $49^{7}$.

Generative system, of Polygyra albolabris, $255^{1}-61^{4}$; of Limax maximus, $279^{4}-80^{4}$.

Growth of Limax maximus, rate of, $294^{\circ}$.

Habits, of Polygyra albolabris, $243^{6}$; of Limax maximus, $244^{2}$.

Hancock, Albany, quoted, $275^{\circ}$.

Hearing, sense of, 275'-76".

Heart, of Polygyra albolabris, $264^{3}$; of Limax maximus, $280^{5}$.

Ridney of Limax maximus, $283^{\circ}$.

Killing and manipulating, methods, $241^{8}-43^{5}$.

Leidy, Joseph, description of a new Species of Entozoa, 2614-62: opinion on olfactory organs, $2 \pi 4^{1}$.

Limax maximus, $277^{2}-94^{9}$; circulatory system, 280 $-83^{7}$; digestive system, $278^{2}-79^{3}$ : time of laying

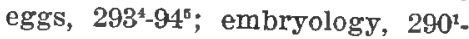
$93^{3}$; generative system, $279^{4}-80^{4}$; rate of growth, $294^{\circ}$; babits, $244^{6}$; muscular system, 287 $87^{\circ}$; nervous system, $283^{8}-87^{7}$; explanation of plates, 309-22.

Manipulating, methods, $241^{8}-43^{5}$.

Methods and apparatus, 2412; of killing and manipulating, $241^{8}-43^{s}$. Microscope, laboratory dissecting, $241^{4}$. 
Movement of Polygyra albolabris, $247^{2}$.

Muscular system of Limax maximus, $287^{7}-89^{\circ}$.

Nervous system, of Polygyra albolabris, $268^{8}-72^{3}$; of Limax maximus, $283^{8}-87^{7}$.

Olfactory organs, $273^{3}-75^{9}$.

Oviduct of Polygyra albolabris, $258^{8}-61^{4}$.

Orotestis, of Polygyra albolabris, $256^{8}-57^{7}$; of Limax maximus, $279^{\circ}, 280^{3}$.

Pedal gland of Polygyra albolabris, $254^{2}$.

Polygyra albolabris, $244^{2}-77^{1}$; carnivorous habits, $247^{7}-49^{7}$; circulatory system, $262^{3}-68^{8}$; digestive system, $249^{8}-54^{1}$; external features, $245^{8}-46^{8} ;$ food, $247^{7}-49^{7}$; generative system, $255^{1}-61^{4}$; habits, $243^{\circ}$; movement, $247^{2}$; nerv- ous system, $268^{\natural}-72^{8}$; pedal gland, $254^{2}$; explanation of plates, 295308; shell, $244^{2}-45^{7}$.

Pulmonary cavity of Limax maximus, $282^{3}$.

Salivary glands of Limax maximus, $279^{1}$.

Sense, special organs, $272^{4}-77^{1}$.

Shell of Polygyra albolabris, 2442$45^{7}$.

Sight, sense of, $272^{7}-73^{3}$.

Smell, , sense of, $273^{3}-75^{8}$.

Sochaczewer, - opinion on olfactory organs, $274^{2}$.

Taste, sense of, $272^{\circ}$.

Touch, sense of, $272^{4}$.

Uterine canal, of Polygyia albolabris, $258^{7}$; of Limax maximus, $280^{2}$.

Veins, of Polygyra albolabris, $266^{3}$; of Limax maximus, $282^{\circ}-83^{\circ}$. 


\section{New York State Museum}

\section{PUBLICATIONS}

Museum reports. New York state museum. Annual report, I847date. O. Albany 1848-date.

Prices for all in print to 1892 , 50 cents a volume; 75 cents in cloth; r802-date, 75 cents, cloth.

Museum bulletins. New York state museum. Bulletins. O. Albany $188_{\boldsymbol{\eta}}$-date. Price to advance subscribers, 75 cents a year.

Volume 1. 6 nos. Price \$r.50 in cloth

I Marshall, W: B. Preliminary list of New York unionidae. 2op. Mar. I892. Price 5 cents.

2 Peck, C: H. Contributions to the botany of the state of New York. 66 p. 2 pl. May 1887 . Price [35] cents.

3 Smock, J: C. Building stone in the state of New York. 152p. Mar. I888. Out of print.

4 Nason, F. L. Some New York minerals and their localities. 2op. I pl. Aug. I888. Price 5 cents.

5 Lintner, J. A. White grub of the May .beetle. 32p. il. Nov. 1888. Price ro cents.

6 Cut-worms. 36p. il. Nov. 1888. Price ro cents.

7 Smock, J: C. First report on the iron mines and iron ore districts in N. Y. $6+7$ op. map $58 \times 60 \mathrm{~cm}$. June 1889 . Out of print.

8 Peck, C: H. Boleti of the U.S. 96p. Sep. 1889. Price[50] cents.

9 Marshall, W: B. Beaks of unionidae inhabiting the vicinity of Albany, N. Y. 24p. I pl. Aug. 189o. Price 10 cents.

ro Smock, J: C. Building stone in New York. 2 rop. map $5^{8} \times 60$ $\mathrm{cm}, \mathrm{tab}$. Sep. $\mathbf{1} 8 \mathrm{go}^{\circ}$. Price 40 cents.

Volume 3. 5 nos.

I Merrill, F: J. H. Salt and gypsum industries in New York. 92p. I2 pl. 2 maps $38 \times 58,6 \mathrm{r} \times 66 \mathrm{~cm}$, i tab. Ap. 1893. Price 40 cents.

$12-\&$ Ries, Heinrich. Clay industries of New York. $174 \mathrm{p}$. 2 pl. map $59 \times 67 \mathrm{~cm}$. Mar. 1895 . Price 30 cents.

13 Lintner, J. A. Some destructive insects of New York state; San José scale. $54 \mathrm{p} .7 \mathrm{pl}$. Ap. 1895 . Price 15 cents.

I4 Kemp, J. F. Geology of Moriah and Westport townships, Essex co. $\mathrm{N}$. Y., with notes on the iron mines. $38 \mathrm{p} .7 \mathrm{pl} .2$ maps $30 \times 33$, $38 \times 44 \mathrm{~cm}$. Sep. 1895 . Price ro cents.

15 Merrill, F: J. H. Mineral resources of New York. 224p. 2 maps $23 \times 36,58 \times 66 \mathrm{~cm}$. Feb. 1896 . Price 40 cents.

I6 Beauchamp, W: M. Aboriginal chipped stone implements of New York. 86p. 23 pl. Oct. 1897 . Price 25 cents.

I7 Merrill, F: J. H. Road materials and road building in New York. $52 p$. I4 pl. 2 maps $34 \times 44,68 \times 92 \mathrm{~cm}$. Oct. 1897 . Price 15 cents.

I8 Beauchamp, W: M. Polished stone articles used by the New York aborigines. I04p. $35 \mathrm{pl}$. Nov. 1897 . Price 25 cents.

I9 Merrill, $\mathrm{F}: \mathrm{J} . \mathrm{H}$. Guide to the study of the geological collections of the New York state museum. r62p. II pl. map $33 \times 43 \mathrm{~cm}$. Nov. 1898 . Price 40 cents.

20 Felt, E. P. Elm-leaf beetle in New York state. $46 \mathrm{p}$. il. 5 pl. June 1898. Price 5 cents. 
2 I Kemp, J. F. Geology of the Lake Placid region. 24p. I pl. map $33 \times 34 \mathrm{~cm}$. Sep. 1898 . Price 5 cents.

22 Beauchamp, W: M. Earthenware of the New York aborigines. 78 p. 33 pl. Oct. 1898 . Price 25 cents.

23 Felt, E. P. 14th report of the state entomologist 1898. I50p. il. 9 pl. Dec. 1898 . Price 20 cents.

24 Memorial of the life and entomologic work of J.A. Lintner Ph. D. State entomologist 1874-98. 316p. I pl. Oct. 1899. Price 35 cents.

25 Peck, C: H. Report of the state botanist $1898 . \quad 76 \mathrm{p} .5 \mathrm{pl}$. Oct. 1899. Out of print.

26 Felt, E. P. Collection, preservation and distribution of New York insects. $36 \mathrm{p}$. il. Ap. 1899 . Price 5 cents.

27 Shade-tree pests in New York. 26 p. il. 5 pl. May 1899. Arice $5 \mathrm{c}$.

28 "Peck, C: H. Plants of" North Elba. 206p. map $2 \times 16 \mathrm{~cm}$. June r899. Price 20 cents.

29 Miller, G. S. jr. Preliminary list of New York mammals. I24p. Oct. 1899 . Price 15 cents.

$3^{\circ}$ Orton, Edward. Petroleum and natural gas in New York. $13^{6} \mathrm{p}$. il. 3 maps $13 \times 23,7 \times 22,9 \times 14 \mathrm{~cm}$. Nov. 1899 . Price ${ }_{5} 5$ cents.

3 Felt, E. P. I $5^{\text {th report }}$ of the state entomologist I899. I28p. June I goo. Price I 5 cents.

32 Beauchamp, W: M. Aboriginal occupation of New York. Igop. I6 pl. 2 maps $44 \times 35,93.5 \times 69.5 \mathrm{~cm}$. Mar. 1900. Price 30 cents.

33 Farr, M. S. Check list of N. Y. birds. 224p. Ap. 1900. Price $25 \mathrm{C}$.

34 Cumings, E. R. Lower Silurian system of eastern Montgomery county: Prosser, C: S. Notes on the stratigraphy of the Mohawk valley and Saratoga county, N. Y. $74 \dot{p}$. ro pl. map $32.5 \times 44 \mathrm{~cm}$. May rgoo. Price 15 cents.

35 'Ries, Heinrich. Clays in New York: their properties and uses. $456 \mathrm{p}$. I40 pl. map $93.5 \times 69.5 \mathrm{~cm}$. June 1900 . Price $\$ \mathrm{I}$, cloth.

$3^{6}$ Felt, F. P. 16th report of the state entomologist 1900. $118 \mathrm{p} .16 \mathrm{pl}$. Ap. Igoi. Price 25 cents.

37 Catalogue of injurious and beneficial insects of New York state. 54p. il. Sep. I900. Price ro cents.

$3^{8}$ Miller, G. S. jr. Key to the land mammals of northeast North America. I o6p. Oct. 1900. Price I 5 cents.

39 Clarke, J: M., Simpson, G: B. \& Loomis, F: B. Paleontologic papers. 72p. il. 16 pl. Qct. I900. Price.r 5 cents.

40 Simpson, G: B. Anatomy and physiology of Polygyra albolabris and Limax maximus and embryology of Limax maximus. 82p. 28 pl. Oct. Igor. Price 25 cents.

4r Beauchamp, W: M. Wampum and shell articles used by New York Indians. 166p. $7 \mathrm{pl}$. Mar. 190r. Price 30 cents.

42 Ruedemann; Rudolf. Hudson river beds near Albany and their taxonomic equivalents. I I4p. 2 pl. map $24.5 \times 51.5 \mathrm{~cm}$. Ap. r9or. Price 25 cents.

43 Kellogg, J. L. Clam and scallop industries of New York. 36p. 2 pl. map $25.5 \times 11.5 \mathrm{~cm}$. Ap. 1901. Price 10 cents.

44 Ries, Heinrich. Lime and cement industries of New York. In pressin

45 Grabau, A. W. Geology and paleontology of Niagara falls and vicinity. " $286 \mathrm{p}$. il. I 8 pl. map $3^{8} \times 84.5 \mathrm{~cm}$. Ap. 1901. Price 65 cents; cloth, 90 cents.

46 Felt, E. P. Scale insects of importance and a list of the species in New York. 94p. I 5 pl. June I901. Price 25 cents. 

